\title{
ANÁLISE DAS VARIAÇÕES DOS PREÇOS E QUANTIDADES DAS PRINCIPAIS CULTURAS ANDINAS DO PERU VISANDO ORIENTAR POLÍTICAS AGRÍCOLAS
}

\author{
JOSÉ ALEJANDRO ROMERO ROJAS \\ Engenheiro Agrônomo
}

Orientadora: Prof. Dra. ANA LÚCIA KASSOUF

Dissertação apresentada à Escola Superior de Agricultura "Luiz de Queiroz", da Universidade de São Paulo, para obtenção do título de Mestre em Ciências, Área de Concentração: Economia Aplicada.

PIRACICABA

Estado de São Paulo - Brasil

Maio - 1996 
Dados Internacionais de Catalogação na Publicação (CIP)

DIVISĀO DE BIBLIOTECA E DOCUMENTAÇĀO - Campus "Luiz de Queiroz"/USP

Romero Rojas, José Alejandro

Análise das variaçōes dos preços e quantidades das principais culturas

Andinas do Peru visando orientar politicas agricolas / José Alejandro Romero

Rojas. - - Piracicaba, 1996.

$88 \mathrm{p}$. : il.

Dissertação (mestrado) - - Escola Superior de Agricultura Luiz de Queiroz, 1996.

Bibliografia.

1. Cultura agrícola - Aspecto econômico - Peru 2. Política agrícola - Peru

3. Preço agrícola - Preço - Peru I. Título

CDD 338.13 


\section{ANÁLISE DAS VARIAÇÕES DOS PREÇOS E QUANTIDADES DAS PRINCIPAIS CULTURAS ANDINAS DO PERU VISANDO ORIENTAR POLÍTICAS AGRÍCOLAS}

JOSÉ ALEJANDRO ROMERO ROJAS

Aprovado em: 04.07.96

Comissão Julgadora:

Prof. Dr. Antonio Francisco Iemma

ESALQ/USP

Prof ${ }^{\mathrm{a}}$. Dr ${ }^{\mathrm{a}}$. Ana Lúcia Kassouf

ESALQ/USP

Prof ${ }^{\mathrm{a}}$. Dr ${ }^{\mathrm{a}}$. Miriam Rumenos Piedade Bacchi

ESALQ/USP

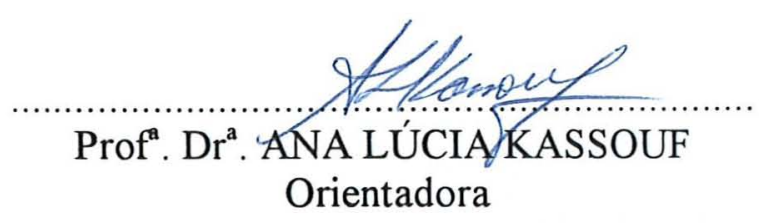


Ao minha mãe

\section{Ofereço}

A Rosa minha esposa e companheira de vida Dedico 


\section{AGRADECIMENTOS}

Meu agradecimento à W.K KELLOGG FOUNDATION, pelo apoio econômico para a realização de meus estudos.

Ao povo do Brasil por sua generosidade e fraternidade.

À Escola Superior de Agricultura "Luiz de Queiroz" e ao Departamento de Economia e Sociologia Rural, pela oportunidade.

Meu agradecimento e gratidão muito especial à Prof. Ana Lúcia Kassouf por sua fina personalidade e brilhante orientação que contribuíram para a superação de minhas dificuldades.

Agradeço também, aos senhores membros da banca Prof. Antonio Francisco Iemma e Mirian Rumenos Piedade Bacchi por sua colaboração no melhoramento da presente pesquisa.

A todos os professores e funcionários do Departamento que direta ou indiretamente colaboraram para a realização desta pesquisa.

Ao Ministério da Agricultura do Peru, por ter proporcionado os dados para a presente pesquisa.

A todos os meus colegas de turma que me apoiaram nos momentos mais dificeis. 


\section{SUMÁRIO}

Página

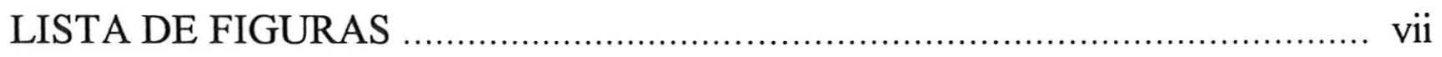

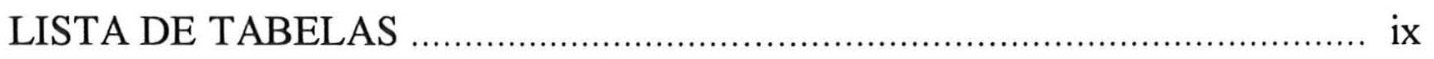

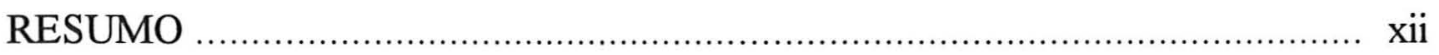

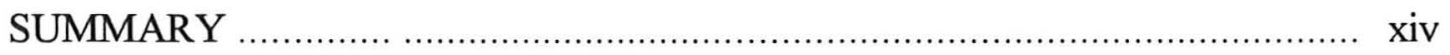

1. INTRODUÇÃO

1.1. Identificação do problema e sua importância ……………………............. 2

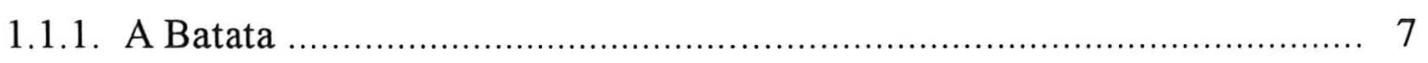

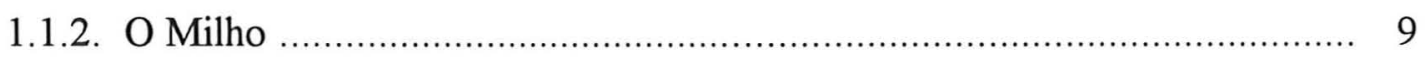

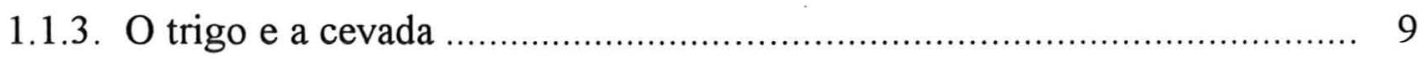

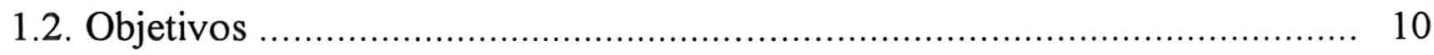

2. REVISÃO DE LITERATURA …........................................................ 11

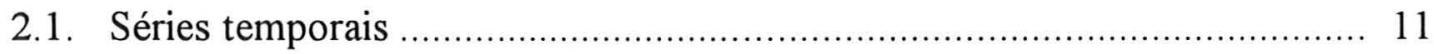

2.2. Aspectos gerais sobre o estudo das séries temporais ................................ 11

2.3. Diferentes métodos utilizados para analisar as séries temporais .................. 14

2.4. Política econômica agrícola nos últimos anos no Peru ................................. 19

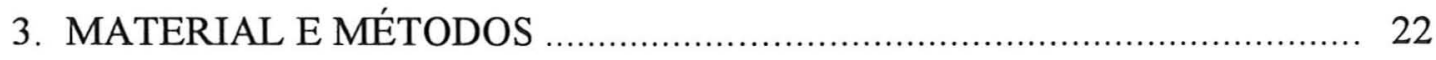

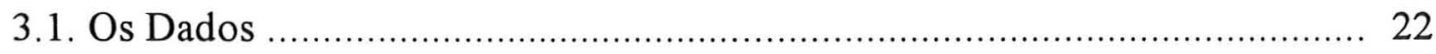

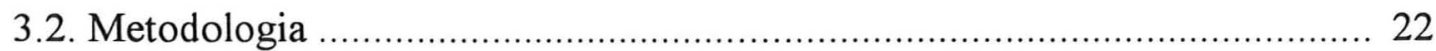

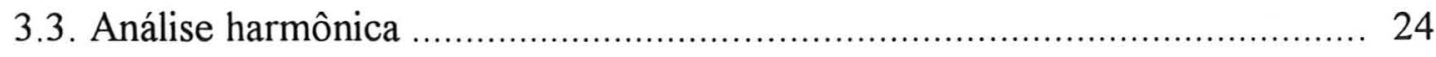

3.4. Análise utilizando-se variáveis binárias ................................................... 30

3.5. Método da média aritmética móvel centralizada ........................................ 31 


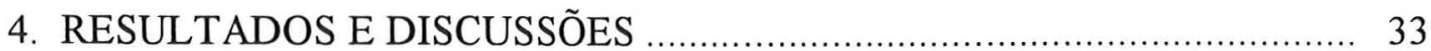

4.1. Análise das variações da cultura de batata ............................................... 33

4.1.1. Análise harmônica ....................................................................... 33

4.1.2. Análise utilizando-se variáveis binárias ................................................ 38

4.1.3. Análise utilizando-se média artmética móvel centralizada ...................... 38

4.2. Análise das variações da cultura de milho ................................................. 41

4.2.1. Análise harmônica ........................................................................... 41

4.2.2. Análise utilizando-se variáveis binárias ................................................ 45

4.2.3. Análise utilizando-se média artmética móvel centralizada ....................... 45

4.3. Análise das variações da cultura de trigo ................................................. 48

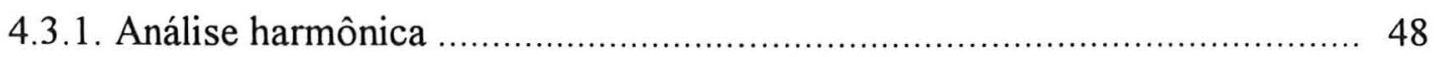

4.3.2. Análise utilizando-se variáveis binárias .............................................. 52

4.3.3. Análise utilizando-se média artmética móvel centralizada ........................ 52

4.4. Análise das variações da cultura de cevada ............................................... 55

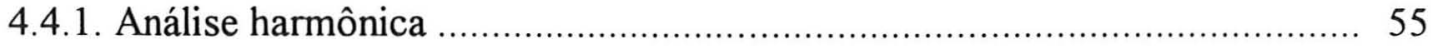

4.4.2. Análise utilizando-se variáveis binárias .............................................. 59

4.4.3. Análise utilizando-se média artmética móvel centralizada ........................ 59

4.5. Estimatiavas da amplitude e fase nos modelos de análise harmônica .............. 62

4.6. Fatores que influem na variação dos preços e quantidades ……………....... 62

4.7. Políticas econômicas agrícolas recomendadas para a produção e preços ....... 65

4.8. Previsões dos preços e quantidades dos principais produtos andinos ............ 66

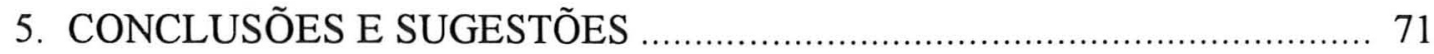

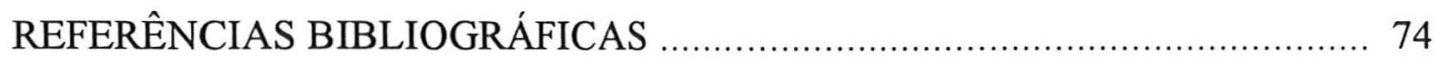

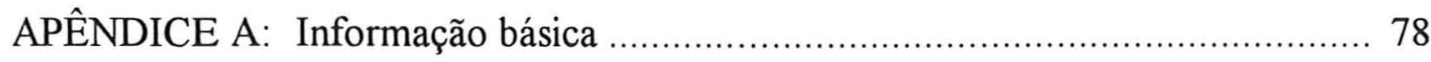

APÊNDICE B: Estimativas dos modelos estatísticos ……............................. 84 


\section{LISTA DE FIGURAS}

Página

Figura 1 Elementos da série periódica de Fourier .......................... 24

Figura 2 Comparação entre preços deflacionado da batata e preços estimados pelo modelo harmônico no período 1975 - 1994.37

Figura 3 Comparação entre quantidades produzidas de batata e quantidades estimadas pelo modelo harmônico no período 1975 - 1994

Figura 4 Variação estacional do preço da batata obtidas pelo método da média aritmética móvel centralizada, no Departamento de Cajamarca, período 1975 - 1994 .

Figura 5 Variação estacional da quantidade da batata obtidas pelo método da média aritmética móvel centralizada, no Departamento de Cajamarca período 1975 - 1994 ............. 40

Figura 6 Comparação entre preço deflacionado de milho e preços estimados pelo modelo harmônico no período 1975 - 1994 .

Figura 7 Comparação entre quantidades produzidas de milho e quantidades estimadas pelo modelo harmônico no período $1975-1994$

Figura 8 Variação estacional do preço de milho obtidas pelo método da média aritmética móvel centralizada, no Departamento de Cajamarca, período 1975 - 1994

Figura 9 Variação estacional da quantidade de milho obtidas pelo método da média aritmética móvel centralizada, no Departamento de Cajamarca período 1975 - 1994

Figura 10 Comparação entre preços deflacionados de trigo de preços estimados pelo modelo harmônico no período 1975 - 1994 .

Figura 11 Comparação entre quantidades produzidas de trigo e 
quantidades estimadas pelo modelo harmônico no período 1975 - 1994

Figura 12 Variação estacional do preço de trigo obtidas pelo método da média aritmética móvel centralizada, no Departamento de Cajamarca, período 1975 - 1994

Figura 13 Variação estacional da quantidade de trigo obtidas pelo método da média aritmética móvel centralizada, no Departamento de Cajamarca período 1975 - 1994

Figura 14 Comparação entre preços deflacionados da cevada e preços estimados pelo modelo harmônico no período 1975 - 1994 . 58

Figura 15 Comparação entre quantidades produzidas da cevada e quantidades estimadas pelo modelo harmônico no período 1975 - 1994

Figura 16 Variação estacional do preço da cevada obtidas pelo método da média aritmética móvel centralizada, no Departamento de Cajamarca, período 1975 - 1994

Figura 17 Variação estacional da quantidade da cevada obtidas pelo método da média aritmética móvel centralizada, no Departamento de Cajamarca período 1975 - 1994 


\section{LISTA DE TABELAS}

Página

Tabela 1 Principais produtos agrícolas, e suas respectivas zonas ecológicas de produção nos Andes do Peru ...................... 5

Tabela 2 Produção e preços das principais culturas nos Andes do Peru. $1991-1993$................................................... 6

Tabela 3 Produto Interno Bruto e participação relativa por setores de produção no Departamento de Cajamarca. 1981 -1987 ..... 6

Tabela 4 Caraterística climáticas por distrito no Departamento de Cajamarca ...................................................... 8

Tabela 5 Estimativas da amplitude e fase dos modelos de análise harmônica das séries de preços e quantidades de batata. milho, trigo e cevada ............................................ 62

Tabela 6 Preços $(\mathrm{P})$ e previsões de preços reais do $\mathrm{kg}$. de batata utilizando-se análise harmônica, período 1991 a 1995 ....... 67

Tabela 7 Quantidade (Q) e previsões das quantidades em TM. de batata utilizando-se análise harmônica, período 1991 a 1995

Tabela 8 Preços (P) e previsões de preços reais de $\mathrm{kg}$. de milho utilizando-se análise harmônica, período 1991 a 1995 ........ 68

Tabela 9 Quantidade (Q) e previsões das quantidades em TM. de milho utilizando-se análise harmônica, período 1991 a $1995 \quad 68$

Tabela 10 Preços $(\mathrm{P})$ e previsões de preços reais de $\mathrm{kg}$. de trigo utilizando-se análise harmônica, período 1991 a 1995 ........ $\quad 69$

Tabela 11 Quantidade (Q) e previsões das quantidades em TM. de trigo utilizando-se análise harmônica, período 1991 a 1995.69

Tabela 12 Preços (P) e previsões de preços reais de kg. de cevada utilizando-se análise harmônica, período 1991 a 1995 ........ 70

Tabela 13 Quantidade (Q) e previsões das quantidades em TM. de 
cevada utilizando-se análise harmônica, período 1991 a 1995

LISTA DE TABELAS DO APÊNDICE A

Tabela A1. Preços em novos soles $/ \mathrm{kg}$. da cultura de batata,

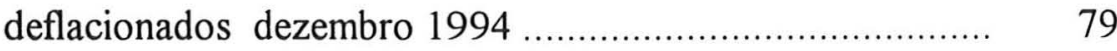

Tabela A2. Preços em novos soles $/ \mathrm{kg}$. da cultura de milho,

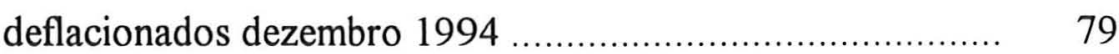

Tabela A3. Preços em novos soles $/ \mathrm{kg}$. da cultura de trigo,

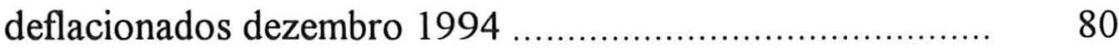

Tabela A4. Preços em novos soles/kg. da cultura de cevada,

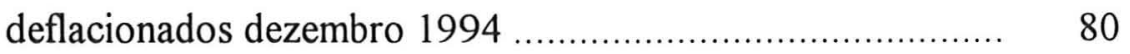

Tabela A5. Quantidade produzida da cultura de batata (TM) .............. 81

Tabela A6. Quantidade produzida da cultura de milho (TM) .............. 81

Tabela A7. Quantidade produzida da cultura de trigo (TM) ................ 82

Tabela A8. Quantidade produzida da cultura de cevada (TM) ............. 82

Tabela A9. Precipitações medias mensais históricas para o vale de Cajamarca no período 1973 - 1988

\section{LISTA DE TABELAS DO APÊNDICE B}

Tabela B.1. Estimativas dos parâmetros utilizando-se análise harmônica para as séries de preços (P) e quantidades (Q) de batata, milho, trigo e cevada, período 1975 - 1994

Tabela B.2. Estimativas dos parâmetros utilizando-se análise binárias das séries de preços $(\mathrm{P})$ e quantidades $(\mathrm{Q})$ de batata, milho, trigo e cevada, período 1975 - 1994.

Tabela B.3. Estimativas do componente estacional $\left(\hat{\mathrm{e}}_{\mathrm{j}}\right)$ e índices de irregularidade $\left(\mathrm{S}_{\mathrm{j}}\right)$ dos preços e quantidades da batata obtidas pelo método da média aritmética móvel, no Departamento de Cajamarca, período 1975-1994

Tabela B.4. Estimativas do componente estacional $\left(\hat{\mathrm{e}}_{\mathrm{j}}\right)$ e índices de 
irregularidade $\left(\mathrm{S}_{\mathrm{j}}\right)$ dos preços e quantidades do milho obtidas pelo método da média aritmética móvel, no Departamento de Cajamarca, período 1975-1994 …….......

Tabela B.5. Estimativas do componente estacional $\left(\hat{\mathrm{e}}_{\mathrm{j}}\right)$ e índices de irregularidade $\left(\mathrm{S}_{\mathrm{j}}\right)$ dos preços e quantidades de trigo obtidas pelo método da média aritmética móvel, no Departamento de Cajamarca, período 1975-1994 .......................................

Tabela B.6. Estimativas do componente estacional $\left(\hat{\mathrm{e}}_{\mathrm{j}}\right)$ e índices de irregularidade $\left(\mathrm{S}_{\mathrm{j}}\right)$ dos preços e quantidades da cevada obtidas pelo método da média aritmética móvel, no Departamento de Cajamarca, período 1975-1994 ............... 


\title{
ANÁLISE DAS VARIAÇÕES DOS PREÇOS E QUANTIDADES DAS PRINCIPAIS CULTURAS ANDINAS DO PERU VISANDO ORIENTAR POLÍTICAS AGRÍCOLAS
}

\author{
Autor: JOSÉ ALEJANDRO ROMERO ROJAS \\ Orientadora: Prof. Dra. ANA LÚCIA KASSOUF
}

\section{RESUMO}

As freqüentes variações nos preços e nas quantidades dos produtos agrícolas causam desequilíbrio da produção e comercialização desses produtos, assim como afetam a renda do setor agrícola e sobretudo dos pequenos produtores. É de grande importância analisar as causas dessas flutuações com a finalidade de definir algumas políticas que permitam regularizar as amplitudes das variações.

Nesse sentido, este estudo analisa as variações ciclo tendências e, principalmente, as variações sazonais das culturas andinas mais importantes do Peru: batata, milho, trigo e cevada. Para isso, foram utilizados dados mensais de preços pagos aos produtores e quantidades produzidas no Departamento de Cajamarca no período de 1975 a 1994. As equações foram ajustadas utilizando-se métodos de regressão com função harmônica e variáveis binárias, através do Proc Reg do Statistical Analysis System (SAS), assim como o método da média aritmética móvel centralizada.

Os resultados obtidos mostram tendências decrescentes significativas dos preços reais nas quatro culturas estudadas, indicando perdas reais do poder aquisitivo dos produtores no período abordado. As perdas reais no caso da batata são de $56 \%$ da média do período 1975 a 1980 comparado com o período 1989 a 1994, 65\% para o cado do milho, $68 \%$ para o trigo e $72 \%$ para a cevada nos mesmos períodos. As 
quantidades produzidas de batata mostram uma ligeira tendência crescente não significativa estatisticamente, enquanto o milho mostra tendência decrescente não significativa $(\mathrm{P}>0,10)$. Entretanto, as quantidades produzidas de trigo e cevada mostram tendências decrescentes significativas. Esse declínio na produção é motivado por desestímulos aos produtores causados por congelamento de preços e supervalorização da taxa de câmbio, que incentivaram as importações.

As estimativas obtidas através da análise harmônica e variáveis binárias mostram-se eficientes na determinação de sazonalidade determinística, caso das quantidades produzidas, mas para os preços, o método da média aritmética móvel centralizada mostrou ser mais eficiente.

Os resultados sugerem que os principais fatores que afetam a sazonalidade dos preços e quantidades produzidas das culturas andinas do Peru são a sazonalidade das precipitações pluviométricas e alguns hábitos de consumo da população.

Dentro das políticas econômicas agrícolas visando a redução das variações dos preços e quantidades produzidas consideram-se: (a) Formação de estoques na época de safra, assim como a instalação de pequenas agroindústrias nas regiões mais produtivas com a finalidade de aumentar o valor agregado dos produtos, (b) Implementação de programas de assistência técnica para produtores e comunidades rurais, com a finalidade de melhorar o acesso aos avanços tecnológicos, informações de mercado e capacidade técnica de gestão, (c) Fomentação da integração regional com os países do grupo andino com a finalidade de incrementar as exportações dos produtos andinos do Peru, principalmente de batata e milho. 


\title{
ANALYSIS OF PRICE AND QUANTITY VARIATIONS OF THE MAIN AGRICULTURAL ANDINIAN CROPS OF PERU SUGGESTING AGRICULTURAL POLICIES
}

\author{
Author: JOSE ALEJANDRO ROMERO ROJAS \\ Adviser: Prof. Dra. ANA LÚCIA KASSOUF
}

\section{SUMMARY}

Frequent variations in prices and quantities of agricultural products give rise to unbalanced trade and production of these products, and affect the income of the agricultural sector, specially for small producers. It is very important to analyze the causes of these fluctuations as a way to sugget policies to decrease the variations.

In this sense, this study analyze cyclical variations and trends, and especially seasonal variations, which are more relevant to the main Andinian cultures of Peru: potato, corn, wheat and barley. We used monthly prices paid to the producers and quantity produced at the Department of Cajamarca during the period 1975 - 1994. Equations were adjusted by regression methods: harmonic analysis and the use of binary variables using the Proc Reg of the Statistical Analysis System (SAS) and centralized arithmetic moving average.

The results show a significant decreasing trend of real prices in the four studied crops, indicating losses in the purchasing power of the producers during the studied period. The losses for potato were $56 \%$ of the mean during the period $1975-1980$ compared with the period 1989 - 1994, $65 \%$ for corn, $68 \%$ for wheat and $72 \%$ for barley during the same period. The amount of potato produced showed slight, statistically non-significant increasing trend, corn shows a non significant decreasing trend $(\mathrm{P}>0,10)$, but quantity produced of wheat and barley showed decreasing 
significant trend due basically to the discouragment of the producers caused by the fixed price policy and an over-valued exchange rate that increase imports.

Estimates using harmonic analysis and binary variables models were good in determining deterministic seasonality, like the quantities produced but for prices, the best method was centralized aritmethic moving average.

The results suggest that the main factor that affects seasonality in prices and quantities produced in the Andinian crop of Peru are the seasonality of the rain fall and the consumption habits of the population.

Among the measures of agricultural economic policy that can allow for reductions in the variations of price and quantity we consider: (a) Stocks formation during harvest season, and the development of small agro-industries in the more productive regions with the goal of increasing the value added of these products, (b) Implementation of programs of technical assistance for producers and rural communities, with the goal of facilitating access to technical progress, market information and management capability, (c) Integration with the countries of the Andinian group with the objective of increasing exports of the Andinian products of Perú, mainly potato and corn. 


\section{INTRODUÇÃO}

A agricultura constitui uma das atividades mais importantes do Peru. Na região andina a principal atividade econômica, a agricultura, é praticada por mais de $80 \%$ da população (Monge 1994), apesar dos riscos serem altos, especialmente devido às flutuações das quantidades produzidas e dos preços. Acredita-se que as flutuações das quantidades produzidas sejam de características sazonais, e devem-se, principalmente, às condições climáticas (pluviosidade), avanços tecnológicos e intervenções governamentais.

A batata, assim como o milho, trigo e cevada são de grande importância na produção e na alimentação do consumidor e do trabalhador andino. Dadas as variações climáticas e topográficas da região, ausência total de cronogramas de plantios, falta de sistemas adequados de comercialização e carência de políticas governamentais (preços mínimos, subsídios, etc.), o estudo do comportamento dos preços e das quantidades produzidas destas culturas tornam-se de grande importância. Este estudo se refere a zona norte dos Andes do Peru, Departamento (Estado) de Cajamarca.

Serão utilizados dados históricos mensais de preços e quantidades para o período 1975-1994, das culturas acima mencionadas. Os mesmos servirão para analisar o comportamento das variações (tendências, e principalmente as variações sazonais), assim como as possíveis causas dessas variações. Pretende-se, para isso, fazer uso da análise de regressão (com função harmônica e utilizando-se variáveis binárias), devido à sua eficiência para captar estas variações. Alem disso, será utilizado o método a média aritmética móvel centralizada.

Hoffmann (1969) menciona que o conhecimento da variação estacional de preços e quantidades é de grande importância para a orientação de produtores agrícolas e para 
os comerciantes, no auxílio da previsão dos preços de um determinado produto em uma dada época do ano.

Devido a falta de estudos sobre variações de preços e quantidades dos produtos agrícolas na região Andina do Peru, espera-se que este trabalho sirva de subsídio para o delineamento de políticas que permitam auxiliar agricultores, empresas agrícolas, intermediários, autoridades governamentais, comunidades camponesas e cooperativas agrárias, visando diminuir as irregularidades que ocorrem no mercado desses produtos, acarretando uma renda mais estável para o produtor andino.

\subsection{Identificação do problema e sua importância}

O Peru é um país que tem sua atividade econômica baseada no setor agrário. Devido às suas características topográficas muito heterogêneas, o país divide-se em 3 grandes regiões (ver mapa p. 4): litoral (costa), serra e floresta (selva). No litoral cultivase arroz, milho (consumo animal), feijão, soja, como culturas tradicionais; e hortaliças, algodão e cana-de-açúcar, para exportação, as quais desfrutam de melhores solos, irrigação e clima estável. Na região da floresta cultiva-se chá, café, cacau, banana, mandioca e pecuária. Na região andina, produz-se culturas típicas da região, como batata, milho (consumo humano), trigo, cevada, cañihua, kiwicha, quinua, oca, olluco, mahua, etc. É interessante ressaltar que as culturas de cañihua, kiwicha, quinua, oca, olluco e mashua constituíram a dieta alimentícia da civilização Inca.

Nos Andes do Peru encontra-se mais de $60 \%$ da população do país, em sua maioria dedicada à agricultura, principalmente às culturas típicas dos Andes. A tabela 1 mostra as principais culturas da região, as quais são produzidas em solos muito pobres, sem uso de irrigação. A área cultivada com culturas anuais não é maior do que 1.300 .000 hectares (Oficina Nacional de evaluaioón de Recursos Naturales. 1985), onde mais de $50 \%$ está localizada em terrenos com muita declividade e sujeitos a fortes erosões, tornando-se, em muitos casos, inadequados à agricultura.

A agricultura andina é principalmente de subsistência e atende ao mercado interno, sobretudo com produtos como batata, milho, trigo e cevada. As quantidades 
ofertadas e demandadas no mercado andino são muito instáveis e a comercialização concentra-se nos meses de safra (maio e junho), causando redução dos preços na época de maior oferta do produto e aumento dos mesmos na entressafra. Este problema agrava-se com a ausência de agroindústrias com capacidade de transformar o produto primário. A tabela 2 mostra as produções e variações anuais dos preços das principais culturas nos andes do Peru, observando-se grandes variações nas culturas em estudo.

O Peru encontra-se situado no hemisfério sul. O território localiza-se entre os meridianos $68^{\circ} 39^{\prime} 27,0^{\prime \prime}$ leste e $81^{\circ} 19^{\prime} 34,5^{\prime \prime}$ Oeste, enquanto que os pontos extremos Norte e Sul são, respectivamente, os paralelos $0^{\circ} 01$ ' $48,0^{\prime \prime}$ no extremo setentrional e $18^{\circ} 20^{\prime} 50,8^{\prime \prime}$ no extremo meridional (Instituto Nacional de Estatística, 1986). A região andina, encontra-se distribuída ao longo do território peruano de sul a norte, o que origina muitos climas e microclimas com altitudes e temperaturas muito variadas.

O Departamento de Cajamarca encontra-se localizado na parte norte dos Andes peruanos entre os paralelos $4^{\circ} 36^{\prime}$ e $7045^{\prime}$ de latitude sul e entre os meridianos $77^{\circ} 44^{\prime} \mathrm{e}$ $79^{\circ} 27^{\prime}$ de longitude oeste, com altitudes que variam entre $800 \mathrm{~m}$ e mais de $4.500 \mathrm{~m}$ acima do nível do mar. As atividades econômicas importantes são: extração mineral, construção civil e, principalmente, a agricultura, caracterizando-se pela ausência de agroindústria. Na tabela 3 está apresentado o Produto Interno Bruto (PIB) para diferentes atividades do Departamento de Cajamarca, observando-se que o setor agricultura contribue com mais do $40 \%$ do PIB. 


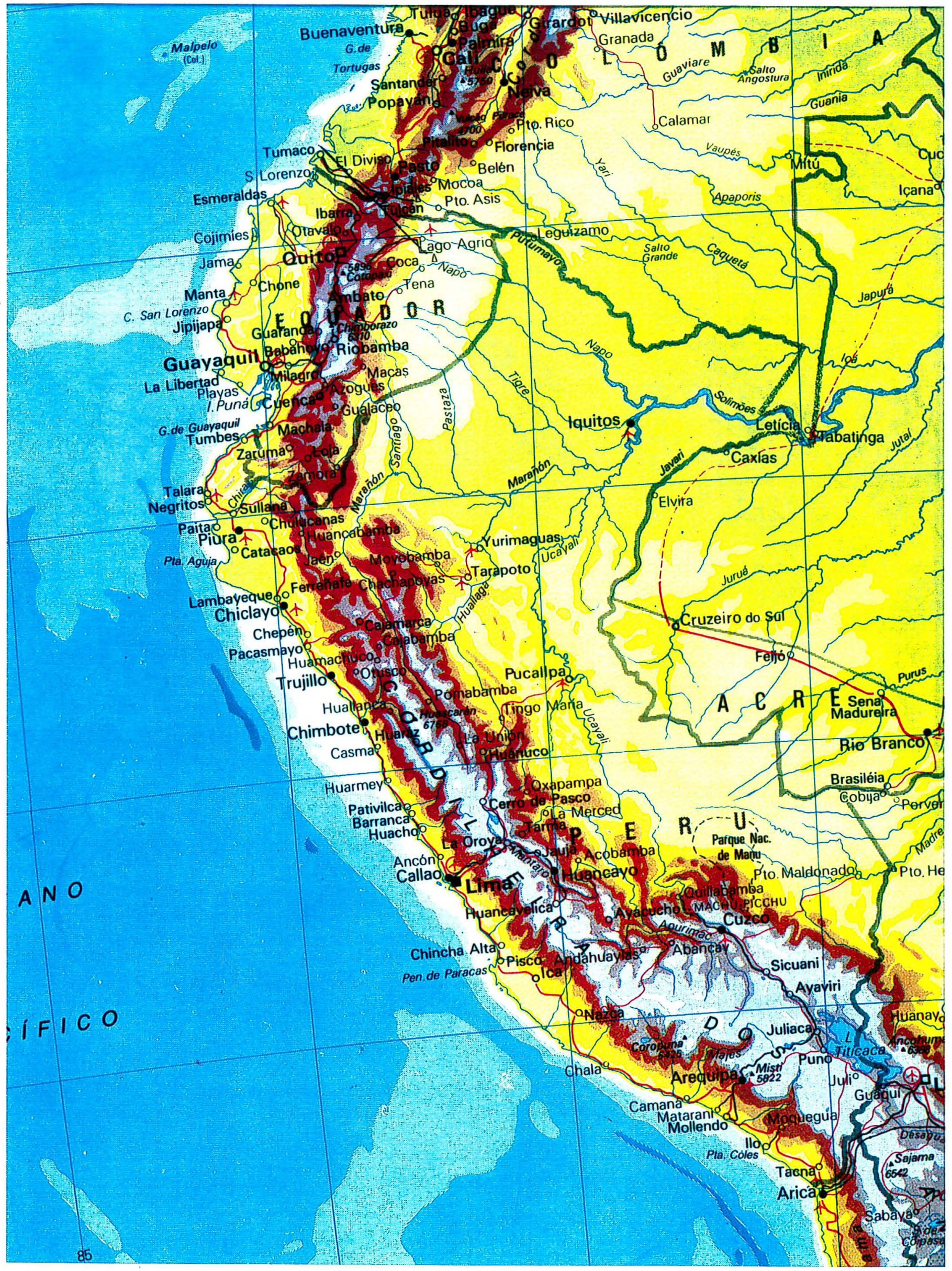


Tabela 1 - Principais produtos agrícolas, e suas respectivas zonas ecológicas de produção nos Andes do Peru.

\begin{tabular}{|c|c|c|c|}
\hline Cultura & Nome latino & Altura & Zona ecológica \\
\hline \multicolumn{4}{|l|}{ Tubérculos } \\
\hline \#* Batata & Solanum andigena & $1.000-3.900$ & Yunga, quechua, suni \\
\hline \#* Batata amarga & Solanum jucsepczukii & $3.900-4.200$ & Suni, puna \\
\hline \#* Oca & Oxalis tuberoso & $2.300-4.000$ & Quechua alta, suni \\
\hline \#* Olluco, Batata lisa & Ullucus tuberosus & $2.800-4.000$ & Quechua alta, suni \\
\hline \#* Mashwa, isaño, añu & Topealum tuberosum & $3.500-4.100$ & Suni, puna \\
\hline \multicolumn{4}{|l|}{ Raízes } \\
\hline \#* Arracacha, raqacha & Arracacia xanthoriza & $1.000-2.800$ & Yunga, quechua baja \\
\hline \#* Yacón, aricoma & Polymnia sanchifolia & $1.000-3.000$ & Yunga, quechua baja. \\
\hline$\#^{*}$ Achira & Canna edulis & $1.000-2.500$ & Yunga, quechua baja. \\
\hline \#* Chagos,mauka,miso & Mirabilis expansa & $1.000-2.500$ & Yunga, quechua húm. \\
\hline \#* Maca & Lepidium meyeni & $3.900-4.100$ & Puna \\
\hline \multicolumn{4}{|l|}{ Grãos } \\
\hline * Milho & Zea mays & $0-3.500$ & Chala, yunga, quec. \\
\hline \#* Quinua & Chenopodium quinoa & $2.300-3.900$ & Quechua, suni \\
\hline \#* Kañiwa & Ch. pallidicaule & $2,500-4.100$ & Suni, puna \\
\hline \#* Kiwicha, amaranto & Amaranthus caudatus & $2.000-3.000$ & Quechua \\
\hline \multicolumn{4}{|l|}{ Leguminosas } \\
\hline \#* Tarwi, chocho & Lupinun mutabilis & $500-3.800$ & Yunga, quechua, suni. \\
\hline \#* Ñuña & Phaseolus vulvaris & $1.500-3.500$ & Yunga, quechua \\
\hline \multicolumn{4}{|l|}{ Frutos } \\
\hline \#* Pepino & Solanum muricatum & $500-2.300$ & Yunga \\
\hline \#* Sachatomate & Cyphomandra betecea & $500-2.700$ & Yunga, quechua alta \\
\hline \#* Lúcuma & Lucuma abovata & $0-2,700$ & Yunga, quechua baja. \\
\hline \#* Tuna & Opuntia ficus indica & $1.500-2.800$ & Quechua \\
\hline \#* Tumbo & Passiflora mollisima & $2.000-3.200$ & Quechua \\
\hline \#* Aguaymanto & Physalis peruviana & $500-2.800$ & Yunga, quechua \\
\hline
\end{tabular}

Fonte: Oficina Nacional de Evaluación de Recursos Naturales do Perú (1985) .

\# Originário dos Andes.

* Domesticado e/ou cultivado em época pré-inca. 
Tabela 2 - Produção e preços das principais culturas nos andes do Peru. 1991-1993.

\begin{tabular}{lrrrrrr}
\hline & \multicolumn{3}{c}{$\begin{array}{c}\text { Produção } \\
\text { Cultura }\end{array}$} & \multicolumn{1}{c}{ (TM) } & & \multicolumn{3}{c}{$\begin{array}{c}\text { Preços } \\
\text { (Novos soles) }\end{array}$} \\
\cline { 2 - 7 } & \multicolumn{1}{c}{1991} & 1992 & 1993 & 1991 & 1992 & 1993 \\
\hline Cañihua & 2.827 & 1,001 & 3.062 & 0,02 & 0,04 & 0,05 \\
Cevada & 117.074 & 68.916 & 112.499 & 0,18 & 0,24 & 0,40 \\
Kiwicha & 455 & 329 & 550 & 0,49 & 0,72 & 1,26 \\
Milho Amiláceo & 225.896 & 127.936 & 186.273 & 0,26 & 0,38 & 0,68 \\
Mashau & 17.826 & 9.786 & 17.353 & 0,13 & 0,22 & 0,26 \\
Oca & 61.790 & 35.350 & 51.474 & 0,15 & 0,23 & 0,34 \\
Olluco & 69.763 & 49.691 & 76.956 & 0,15 & 0,26 & 0,37 \\
Batata & 453.559 & 1.003 .082 & 1.492 .705 & 0,14 & 0,26 & 0,35 \\
Quínua & 15.439 & 3.960 & 14.095 & 0,25 & 0,45 & 0,58 \\
Tarhui & 3.498 & 2.181 & 3.547 & 0,30 & 0,42 & 0,43 \\
Trigo & 127.046 & 73.061 & 108.126 & 0,23 & 0,30 & 0,50 \\
\hline
\end{tabular}

Fonte: Ministério de Agricultura. Oficina de Información Agrária. Lima-Perú.

Tabela 3 - Produto Interno Bruto e participação relativa por setores de produção no Departamento de Cajamarca. 1981 - 1987.

\begin{tabular}{lrrrr}
\hline \multirow{2}{*}{ Atividade Econômica } & \multicolumn{3}{c}{ Mil Intis $^{\left({ }^{*}\right)}$} & \multicolumn{2}{c}{ Porcentagem } \\
\cline { 2 - 5 } & 1981 & 1987 & 1981 & 1987 \\
\hline Agricultura & 41.310 & 34.667 & 47,7 & 39,6 \\
Mineração & 3.157 & 3.754 & 3,6 & 4,3 \\
Indústrias Manufacturarias & 6.923 & 9.822 & 8,0 & 11,2 \\
Construção & 6.243 & 7.727 & 7,2 & 8,8 \\
Comércio (rest. hot) & 6.224 & 6.168 & 7,2 & 7,0 \\
Serviços & 18.098 & 20.543 & 20,9 & 23,4 \\
Outros (aluguel, vivenda) & 4,587 & 4,967 & 5,3 & 5,7 \\
\hline TOTAL & 87.542 & 87.651 & 100,0 & 100,0 \\
\hline
\end{tabular}

1 dólar = 16,84 Intis (media anual 1987).

(*) Moeda corrente do Peru no período 1985 a 1990

Fonte: Instituto Nacional de Estatística 1986. Lima - Perú 
É importante reconhecer que as condições climáticas e de solos das montanhas alto-andinas apresentam micro-climas variados, com uma distribuição geográfica muito heterogênea, composta por áreas agrícolas muito diferenciadas. Na tabela 4 visualizamse as características geográficas e climáticas dos principais distritos do Departamento de Cajamarca. Essas variações de altitude e temperatura são os fatores que têm maior influência na agricultura andina, gerando, como consequência, produção e preços sujeitos a fortes oscilações.

Tapia (1994) menciona que, em certas partes da serra, acima de 2.500 m., é comum observar-se, em um período de 10 anos, dois anos muito chuvosos, três secos e 5 intermediários e, em pleno período agrícola, presença de geadas pelo menos três vezes em cinco anos.

As intervenções governamentais influenciam os preços dos produtos e as quantidades produzidas pelos agricultores. O sistema de posse da terra consiste quase que totalmente na presença de pequenas propriedades rurais. A falta de capital e a presença de intermediários, também influenciam nas variações de preços e quantidades.

Em seguida analisam-se as características das culturas de batata, milho, trigo e cevada, as quais constituem a base da alimentação popular no Peru.

\subsubsection{A Batata}

A cultura da batata é originária dos Andes do Peru, e cultivada desde a época pré-inca, existindo múltiplas variedades e representando uma das principais fontes calóricas. A cultura é plantada desde o nível do mar até $4.200 \mathrm{~m}$. de altitude e cultivada na região costeira como produto de exportação. Na serra andina a produção de batata é basicamente de subsistência. 
Tabela 4 - Características climáticas por distrito no Departamento de Cajamarca.

\begin{tabular}{|c|c|c|c|}
\hline \multirow[t]{2}{*}{ Distrito } & Altitude & Temperatura & Precipitação \\
\hline & (m.) & $\left({ }^{\circ} \mathrm{C}\right)$ & $(\mathrm{mm})$ \\
\hline \multicolumn{4}{|c|}{ Zona Ecológica Yunga Marítima } \\
\hline Contumaza & 2.300 & 14,3 & 893 \\
\hline LLama & 2.090 & 16,9 & 734 \\
\hline Santa Cruz & 2.000 & 17,3 & 695 \\
\hline San Benito & 1.200 & 20,1 & 307 \\
\hline Cascas & 1.330 & 20,4 & 258 \\
\hline Chilete & 900 & 22,1 & 293 \\
\hline \multicolumn{4}{|c|}{ Zona Ecológica Quechua } \\
\hline Encañada & 3.450 & 9,8 & 1.047 \\
\hline Bambamarca & 2.800 & 12,1 & 1.104 \\
\hline Cajamarca & 2.700 & 13,9 & 650 \\
\hline Celendin & 2.620 & 13,7 & 915 \\
\hline Ichocan & 2.600 & 14,7 & 575 \\
\hline Cutervo & 2.450 & 13,4 & 939 \\
\hline Chota & 2.410 & 15,6 & 855 \\
\hline \multicolumn{4}{|l|}{ Zona Ecológica Jalca } \\
\hline Cajamarca (Porcón) & 3.850 & 7,8 & 1.101 \\
\hline Cajamarca (Huanico) & 3.520 & 7,8 & 827 \\
\hline Cajamarca (Negritos) & 3.560 & 8,6 & 1.041 \\
\hline Hualgayoc & 3.502 & 8,9 & 1.324 \\
\hline \multicolumn{4}{|c|}{ Zona Ecológica Yunga Fluvial } \\
\hline San Marcos & 2.254 & 18,1 & 672 \\
\hline Huanbos & 2.200 & 18,1 & 754 \\
\hline Condebamba & 2.010 & 19,0 & 503 \\
\hline Cochabamba & 1.700 & 18,9 & 773 \\
\hline Chontali & 1.500 & 19,2 & 1.108 \\
\hline San Ignacio & 1.324 & 19,5 & 1.203 \\
\hline
\end{tabular}

Departamento $=$ Estado; $\quad$ Distrito $=$ Vila.

Fonte: Servicio Nacional de Meteorología e Hidrología (1988). 
No Departamento de Cajamarca esta cultura representa $14,6 \%$ da área agrícola total cultivada. As práticas agrícolas não são mecanizadas, realizando-se o cultivo sem uso de irrigação.

A produção é também muito variada, alcançando rendimentos médios de 7.000 $\mathrm{Kg}$ por hectare, os quais são muito inferiores comparados com a produção de outros países como é o caso da Rússia, cuja produtividade é de $25.000 \mathrm{Kg} / \mathrm{ha}$, e Holanda com $40.000 \mathrm{Kg} / \mathrm{ha}$.

Esta cultura é a mais importante para o país porque constitui a base da alimentação popular devido as suas diversas formas de utilização. O consumo per capita é de mais de $100 \mathrm{Kg} /$ pessoa/ano (Tapia 1994). A batata representa, para os agricultores, a principal fonte de renda, apesar de ser muito susceptível a baixas temperaturas e exigente em água, gerando um risco muito grande para os agricultores locais.

\subsubsection{O Milho}

O milho é outra das culturas originárias do Peru. Segundo Montoya (1990) é a cultura que ocupa a maior área plantada no Peru $(28,4 \%$ da área cultivada na região andina), com consumo per capita acima de $40 \mathrm{~kg} /$ pessoa/ano. Sua utilização na alimentação é bastante grande, principalmente pela existência de diferentes variedades com cor e sabor diferenciados. A plantação é feita desde o nível do mar até $2.800 \mathrm{~m}$ de altitude.

A produtividade das variedades de milho nativas do Peru é muito baixa (1.500 $\mathrm{Kg} / \mathrm{ha}$ ), comparadas com as cultivadas nos Estados Unidos e Itália que têm rendimentos de 5.000 e $10.000 \mathrm{Kg} / \mathrm{ha}$, respectivamente.

Na região andina o milho é cultivado sem irrigação, acarretando altos riscos, e grandes variações nos preços e quantidades.

\subsubsection{O Trigo e a Cevada}

Essas culturas não são originárias do Peru, tendo sido trazidas da Europa, mas estando muito bem adaptadas às condições da região andina, principalmente por serem resistentes às baixas temperaturas e pouco exigentes a solo fértil e adubação. São 
cultivadas especialmente quando as condições de risco são altas, não sendo possível cultivar batata ou milho.

A produtividades do trigo e cevada são muito baixas (inferior a $1.000 \mathrm{Kg} / \mathrm{ha}$ ), o que faz com que sua rentabilidade também seja muito baixa. Entretanto, constituem alimento de grande importância na complementação da dieta da população, e também para a alimentação animal.

\subsection{Objetivos}

Este estudo, de modo geral, pretende analisar as variações de preços e quantidades produzidas, no período de 1975 a 1994, de quatro produtos agrícolas que constituem os alimentos básicos da população andina do Peru, utilizando técnicas estatísticas.

Especificamente, pretende-se:

a) Analisar as variações sazonais, as variações tendênciais de preços e quantidades de batata, milho, trigo e cevada, na região andina do norte do Peru.

b) Determinar possíveis causas das variações dos preços e quantidades das culturas andinas na região.

c) Aplicar técnicas estatísticas de análise harmônica, médias móveis e variáveis binárias às séries de preços e quantidades, para estudar as variações.

d) Analisar algumas políticas econômicas de produção e de preços das culturas andinas do Peru.

e) Fazer previsões para as quantidades produzidas e preços das culturas. 


\section{REVISÃO DE LITERATURA}

\subsection{Séries temporais}

Uma série temporal, segundo Otárala (1993), é qualquer conjunto de observações, ordenados no tempo, por exemplo: valores mensais de vendas de um produto, quantidade anual de chuva numa localidade, índices diários da Bolsa de Valores, valores diários de temperatura de uma cidade, exportações mensais dos produtos agrícolas, quantidades produzidas anuais de um produto, preços diários ou mensais dos produtos, etc.

Os principais objetivos da análise de séries temporais são: (a) investigar como as séries foram geradas, através da análise da variabilidade. (b) fazer previsões de valores futuros da série no curto prazo, como para séries de vendas, produção ou estoque, ou no longo prazo, como para séries populacionais e de produtividade. (c) descrever o comportamento da série. Neste caso, a construção de gráficos, a verificação da existência de tendências, variações sazonais e, a construção de figuras são de muita utilidade. (d) procurar periodicidades relevantes nos dados.

\subsection{Aspectos gerais sobre o estudo das séries temporais}

O conhecimento das variações estacionárias, flutuações cíclicas dos preços e quantidades produzidas dos produtos agrícolas, segundo Thomsen e Foote ${ }^{1}$, citado por Cavalcanti (1978), é de suma importância para os agricultores individuais, empresas agrícolas e instituições do governo em situações como:

a) Seleção e administração das atividades agrícolas;

b) Determinação da época e do lugar da compra das matérias primas e suprimentos;

c) Seleção dos mercados e melhor época de venda dos produtos;

d) Na decisão de participar dos programas agrícolas do governo;

${ }^{1}$ THOMSEN, F.L. \& FOOTE, R. JAY Agricultural prices 2a Edição, New York, MC Graw-Hill, 509 pag. 1952. 
e) No planejamento governamental dos programas agrícolas a nível local, regional, nacional e internacional.

As variações muito acentuadas no nível de preços pagos aos produtores afetam negativamente o desenvolvimento do setor agrícola, pois a renda dos agricultores tornase muito instável. Uma razão para isso é a relativa rigidez da produção agrícola ao estímulo dos preços. Quando os preços baixam, os agricultores não podem reduzir a produção imediatamente, como acontece no sector industrial.

Outras razões que tornam instável a renda do agricultor são: as atividades dos intermediários, as limitações financeiras dos agricultores, a carência de vias adequadas de transporte, disponibilidade de armazenagem, capacidade tecnológica limitada, além das variações estacionais de preços e quantidades, resultantes das variações climáticas, e condições de safra e entressafra. A situação se agrava ainda mais devido a falta de infraestrutura e condições financeiras para armazenar os produtos, visando melhores preços em época de baixa produção (época de escassez de chuva sem utilização de irrigação).

Hoffmann (1969) menciona que os movimentos cíclicos seguem o seguinte comportamento: quando os preços estão altos, novos produtores entram no mercado, aumentando a oferta. Como a oferta aumenta, os preços declinam até o ponto em que alguns produtores saem do mercado. A produção torna a cair e os preços tendem a aumentar até induzir nova expansão da oferta, iniciando-se novo ciclo. O tempo requerido para a expansão da produção depende das características de cada produto. Assim, os preços de mercado flutuam em torno do preço de equilíbrio em maior ou menor escala.

Uma explicação econômica das características cíclicas inerentes do sistema de produção de alguns produtos agrícolas é dada pelo chamado teorema da teia de aranha. Este teorema explica como, no caso de alguns produtos agrícolas, o preço não se fixa em um ponto de equilíbrio, mas flutua em torno dele (Salvatore 1984). O teorema é utilizado para conceituar o comportamento dos preços agrícolas e não para determinar os preços e quantidades atuais. Se o modelo se apresenta numa curva de oferta mais elástica do que a demanda, os ciclos são divergentes e, em caso contrário, convergentes. Hoffmann (1969) menciona que o fenômeno cíclico também está associado ao fato de que os 
produtores agrícolas são influenciados mais fortemente pelo preço vigente do que pelas expetativas de preço. Além disso, a produção isolada de cada produtor é pequena em relação ao total produzido devido ao fato de ele ser um tomador de preços e não influenciar o preço de mercado.

$\mathrm{O}$ mesmo autor indica que quando os preços dos produtos agrícolas se tornam extremamente variáveis, geram uma diminuição dos investimentos em bens de capital na empresa agrícola, podendo inclusive, essas variações, perturbar o funcionamento global da economia. Ainda mais, as variações dos preços causam desequilíbrio na procura, no processo de comercialização, na produção e nas rendas agro-pecuárias, sendo praticamente impossível conseguir que um sistema de mercado para produtos agropecuários tenha funcionamento adequado.

Segundo Brandt ${ }^{2}$, citado por Cavalcanti (1978), os preços dos produtos agrícolas tendem a ser afetados pelos ciclos econômicos. Existem problemas de instabilidade na procura em regiões onde a elasticidade renda dos produtos agrícolas é relativamente alta e a economia não agrícola está sujeita a grandes variações cíclicas. Além da oscilação cíclica no lado da procura, pode existir o movimento cíclico que afeta a produção, devido a fenômenos biológicos. Observa-se que quando a produção é baixa, a demanda supera a oferta, gerando um aumento nos preços dos produtos, o que estimula os agricultores a plantarem mais no próximo ciclo de produção, e isso, por sua vez, faz com que nesse novo ciclo de produção a oferta seja maior que a demanda, provocando uma queda dos preços.

Segundo Pereira ${ }^{3}$, citado por Moreira (1991), os índices de variação estacional dependem, principalmente, da viabilidade técnica e econômica do armazenamento, caso muito comum nas culturas andinas. $\mathrm{O}$ autor menciona, que variações estacionais na procura podem variar muito em função dos fatores climáticos, os quais afetam, também, as quantidades produzidas, e que os fatores culturais e sociais tendem a afetar a demanda pelo produto.

\footnotetext{
2 BRANDT, S.A. \& DUARTE, F.R. Avaliação do impacto do ICM sobre a comercialização de cerais en São Paulo. Agricultura em São Paulo, 16 (9/10); 55-66, set/out., 1969.

${ }^{3}$ PEREIRA . I.F. Variação estacional de preços agrícolas no Estado de São Paulo. Agricultura no Estado de São Paulo, (10); 3-63, 1963.
} 
Obviamente, a estabilidade do padrão de variação estacional depende do comportamento dos fatores que causam estas flutuações.

\subsection{Diferentes métodos utilizados para analisar as séries temporais}

Morettin \& Toloi (1985) mencionam que existem muitos procedimentos para estimar sazonalidade, sendo os mais usuais: modelos de regressão e método de médias móveis.

Os modelos de regressão são mais adequados para séries temporais que apresentam sazonalidade determinística, ou seja, o componente estacional pode ser estimado a partir dos dados dos meses anteriores. Nesse modelo, o componente sazonal pode ser dado por uma variável periódica (seno, co-seno ou variável binária); o componente aleatório por uma variável de média zero e variância constante e a partir da matriz de regressão é possível obter os estimadores de mínimos quadrados ordinários.

$\mathrm{O}$ método de médias móveis é apropriado quando se tem séries temporais cujo componente sazonal varia com o tempo. Este método consiste, basicamente, em determinar uma tendência, dada pela média móvel e determinar os desvios em relação a esta média. $\mathrm{O}$ método é bastante utilizado devido a sua concepção simples e relativa precisão dos resultados.

Conforme mostrado por Lange (1967), se existem flutuações periódicas de "n" meses numa série, elas são eliminadas com uma média móvel de " $n$ " meses. Entretanto, movimentos irregulares, normalmente, não têm estas flutuações periódicas e o método da média móvel irá apenas eliminar parcialmente estes efeitos. Quando os três componentes, cíclico, sazonal e aleatório $\left(\mathbf{C}_{\mathbf{t}}, \mathbf{S}_{\mathbf{t}} \mathbf{e} \mathbf{u}_{\mathbf{t}}\right)$ estão combinados e são tratados como divergentes, provavelmente, não existe período comum para os três elementos, de modo que a eliminação das divergências será apenas parcial.

O autor recomenda cuidados ao utilizar a média móvel para projetar tendências. Deve-se admitir, por exemplo, que os fatores que provocam a tendência não sofrem modificações.

Thomsen \& Foote, citado por Cavalcanti (1978), apontam que a média móvel tem a desvantagem de perder alguns dados no começo e no final da série. O outro 
Paniago $^{4}$, citado por Hoffmann (1969), analisou a variação estacional do preço de milho no Estado de São Paulo no período 1951/63, e verificou que os índices correspondentes aos meses de abril a setembro apresentaram tendência decrescente, ao passo que os índices correspondentes aos meses de outubro a março apresentaram-se tendência crescente no período analisado.

Hoffmann (1969) estudou a variação estacional dos preços recebidos pelos produtores de cebola no Estado de São Paulo no período de 1954/67, verificando que os índices estacionários são mais altos de maio a agosto e apresentam os valores mais baixos em novembro e dezembro. O autor constatou que entre 1956 e 1965 houve uma alternância, de ano para ano, no padrão de variação estacional de preço da cebola no estado. Verificou que nos anos pares desse período a amplitude da variação estacional era maior que nos anos ímpares, sugerindo a existência de um mecanismo tipo "Teia de aranha" influindo sobre a produção, e esta, por sua vez, influindo sobre o padrão de variação estacional do preço.

O mesmo autor, determinou as variações estacionárias dos preços, e as causas do fenômeno de alguns produtos agro-pecuários no Estado de São Paulo. As culturas agrícolas estudadas foram: limão, cenoura, pepino, repolho, tomate, berinjela, abobrinha, caju, couve-flor, alface, pimentão, vagem, ervilha, quiabo, batata-doce, mandioquinha, laranja, abacate, abacaxi e mamão. Ele utilizou os métodos das médias aritméticas móveis e das médias geométricas móveis para captar o índice de flutuação estacional dos preços. Comparando os resultados obtidos para os produtos analisados, concluiu que os dois métodos levam a índices de variação estacional semelhantes. Mencionou, também, que as flutuações estacionárias da produção e, conseqüentemente, dos preços dos produtos estudados, principalmente dos hortícolas, dependem, basicamente, da variação da temperatura, e que a pluviosidade não é tão importante porque normalmente essas culturas são irrigadas.

\footnotetext{
${ }^{4}$ PANIAGO, E. An evoluation of agricultural prices policies for selected food products: Brazil. Lafayete, Indiana, Purdue University, 1969. 147 p. (Tese Ph. D).
} 
$\mathrm{O}$ autor considera, finalmente, que todo o aperfeiçoamento no processo de produção que tenha como consequência o aumento da quantidade ofertada na época de maior escassez, diminuindo assim a amplitude da variação estacional da produção, e também do preço do produto, vem a beneficiar o consumidor. A industrialização do produto, aperfeiçoamento no processo de armazenamento e a existência de uma política efetiva de preços mínimos e de crédito para os produtores são outros fatores, além dos já mencionados, que podem determinar diminuição na amplitude da variação estacional dos preços dos produtos agro-pecuários.

Pereira (1963), citado por Moreira (1991), realizou análises dos padrões de variação estacional dos preços de 21 produtos agro-pecuários no Estado de São Paulo, no período de 1954 a 1962. O trabalho apresenta índices de variação estacional dos referidos produtos.

O centro de estudos agrícolas (1971) do Instituto Brasileiro de Economia (IBRE), da Fundação Getulio Vargas (FGV), calculou o índice da variação estacional para 13 culturas de diferentes estados do Brasil: algodão, amendoim, arroz, banana, batata inglesa, cacau, café, cana de açúcar, feijão, fumo de folha, laranja, mandioca, e milho, utilizando o método das médias móveis centradas, partindo dos preços mensais deflacionados. Os resultados indicaram que as culturas apresentam índices de variação estacional.

A utilização do método de média móvel em séries temporais é relativamente fácil devido ao fato deste método não demandar qualquer especificação sobre a natureza da tendência sendo, portanto, bem flexível.

Outro método utilizado para o estudo das séries temporais é o da análise harmônica, pois possui uma série de vantagens sobre o método da média móvel. Segundo Cavalcanti (1978) as vantagens do método de análise harmônica são:

1) Permite que se trabalhe com os dados originais. Isto é importante porque o uso de sucessivas médias móveis pode, em alguns casos, introduzir variações sazonais fictícias, além de eliminar as irregularidades que existem nos dados originais;

2) $O$ uso da análise harmônica permite testar mudanças nos padrões de variação sazonal, isto é, mudanças na fase e amplitude, bem como na taxa dessa variação e; 
3) O padrão sazonal e a tendência podem ser estimados concomitantemente.

Thiebaut (1976) aplicou um modelo de análise harmônica para estudar as variações estacionárias das precipitações pluviométricas no município de Viçosa. Para tanto, utilizou dados mensais e como resultado encontrou períodos de 6 a 12 meses. Concluiu que Viçosa apresenta um período chuvoso (outubro a março) e um período seco (abril a setembro) bem definidos.

Cavalcanti (1978) estudou as variações cíclicas de preços e quantidades de feijão, milho, arroz e batata inglesa no mercado de São Paulo, através de um modelo de análise harmônica, estimando os padrões cíclicos, utilizando dados anuais de preços pagos aos produtores no Estado de São Paulo e as quantidades ofertadas no período de 1949 a 1976.

O autor determina ciclos de 3,4 e 5 anos como os mais representativos para milho, arroz e batata, respectivamente. $\mathrm{O}$ autor atribue condições climáticas adversas e comportamento irregular das séries para explicar os ciclos. O feijão, dado seu comportamento irregular no mercado, não apresentou um padrão cíclico definido.

Araujo \& Khan (1987) fazendo uso da análise harmônica, estudaram as variações de preços e quantidades de laranja e banana (período 1972 a 1980) nos mercados nordestinos. Observaram a existência de ciclos estacionais de 12 meses na séries de preços e quantidades comercializadas, e que as amplitudes estimadas das séries de preços foram superiores às das séries de quantidades.

Araujo et alii (1985), utilizando a análise harmônica, estudaram o padrão cíclico de séries de preços e quantidades de arroz, farinha de mandioca e feijão nos mercados do nordeste no período de 1971 a 1982, observando que as amplitudes das séries de preços e quantidades de arroz foram maiores do que as amplitudes das séries de preços e quantidades de farinha e feijão. Baseado nos padrões cíclicos, sugerem que sejam implementadas políticas de formação de estoques dos produtos na época da safra, que seriam posteriormente comercializados nas épocas de pico de preços, que correspondem ao período de entressafra.

Kassouf (1988) estudou as séries de preços mensais do bezerro, boi magro boi gordo no Estado de São Paulo, para o período de janeiro de 1970 a dezembro de 1986 a 
fim de obter previsões de preços. A autora mostrou que as séries temporais eram compostas por uma tendência linear de crescimento de preços, variações cíclicas estacionárias, caracterizados por períodos de safra e entressafra dentro do ano e, plurianuais, com período em torno de 6 anos, resultante do abate de matrizes em época de preços baixos, além de variações irregulares.

O melhor modelo encontrado continha componentes harmônicos mais ARIMA (modelo autoregressivo integrado de médias móveis) e variáveis binárias, captando os ciclos anuais, plurianuais e variações aleatórias.

\subsection{Política econômica agrícola nos últimos anos no Peru}

Segundo Figueroa (1992) a política econômica peruana nos últimos 20 anos, favoreceram o desenvolvimento da indústria, e deram um impulso ao processo de substituicão das importações. Decisiões como a supervalorização da moeda nacional, necessária para estimular as indústrias dada a maior facilidade de obtenção de materias primas importadas, perjudicaram aos produtores agrícolas.

Um efeito dessa crise agrícola é deterioração dos térmos de troca da agricultura com relação aos demais setores da economia, desde 1960. Em adição a essa tendência, a partir de 1970, os preços do produtor registraram amplias flutuações em torno da média, perjudicando ao produtor. A intervenção do estado durante a década de setenta seguia a estratégia de fornecer alimentos baratos aos consumidores urbanos. Para isso, realizaram rígidos controles de preços, criando-se várias empresas públicas, como a Empresa Pública de Serviços Agropecuários (EPSA) e a Empresa Comercializadora de Insumos (ENCI).

No período de 1975 a 1980, a política agrícola visou proteger a agricultura através da garantia de preços (preços mínimos), mas excluiu a região andina, já que nesta área a maioria dos produtos é de consumo local. Os produtores andinos, entretanto, foram favorecidos por créditos agrícolas baratos e por insumos subsidiados.

Dancourt (1994) menciona que período de 1980 a 1985, o governo reduziu a intervenção direta do estado em conseqüência de desequilíbrios fiscais e da balança de pagamentos. Durante os primeiros dois anos desse governo logrou-se altas taxas de crescimento que permitiram uma política de gasto expansiva, incrementando-se os 
investimentos na agricultura. A lei de promoção e desenvolvimento agrário liberalizou os preços ao produtor e suprimiu os controles à comercialização.

Os crescentes desequilíbrios fiscais e da balança de pagamentos obrigaram o governo a fazer um ajuste no final de 1982. Esse ajuste foi na política monetaria, taxa de câmbio, crédito restrito e nos preços dos principais bems públicos (eletricidade, água, gás, telefone, etc.). Dentro deste contexto, ocorre uma aceleração inflacionária, exigindo modificações nas políticas adotadas. A preocupação do governo com a inflação, leva a uma redução do rítmo de ajustes da taxa de câmbio, e como conseqüência as importações, em especial as de alimentos, aumentam-se substancialmente.

No período de 1985 a 1990 (governo de García), o governo retorna a uma política expansiva de gasto, aumentando os salários em termos reais, mantendo os preços dos produtos agropecuários abaixo da inflação, dando créditos agrícolas com taxas reais negativas e fornecendo insumos a preços subsidiados 5 .

Cavassa (1994) menciona que, para financiar a expansão dessa demanda o governo reduziu unilateralmente o pagamento da dívida externa, utilizando as reservas internacionais. Entretanto, esse programa durou apenas dois anos. Ao final de 1987, foram observadas as incoerências do programa econômico, mas não se corrigiram as distorções no sistema de preços relativos, resolvendo-se fazer emissão monetária para o financiamento dos gastos. Os desequilíbrios se fizeram sentir no final de 1988, ocasionando uma inflação alta, que chegou a 63\% mensal em 1990, como conseqüência do excesso de demanda agregada.

Em 1990, o governo de Fujimori aplicou um programa de estabilização para acabar com a inflação elevada, e um programa de reformas estruturais orientadas para modificar a organização e o funcionamento do setor público.

5 CAVASSA, A (1994) analisou os créditos agrícolas, os quais tiveram taxa de juros zero quando a inflação do país era mais de $35 \%$ ao ano. Esses empréstimos incrementaram-se na década do 80 , e foram suprimidos en 1990. Em relação aos subsídios, o autor estima que nos anos 1985-1988, os adubos eram vendidos somente a $5 \%$ de seu custo de produção. Fonte: Estratégias productivas y financiamiento rural. 
O governo suprimiu o controle de preços dos alimentos, insumos agropecuários e seu monopólio na comercialização, reduziu drasticamente o número de funcionários da administração pública, além de desativar o banco agrário e o financiamento agrícola. Esse governo também mantém reduzida a taxa de câmbio para permitir importações de produtos. Essas políticas agrícolas adotadas ocasionaram desestímulo aos produtores e prejuízos ao setor agrário em geral. 


\section{MATERIAL E MÉTODOS}

\subsection{Os dados}

Para analisar as variações dos preços e quantidades de batata, milho, trigo e cevada, bem como atender aos objetivos específicos a que se propõe o presente estudo, foram coletadas informações sobre os preços recebidos pelos produtores e as quantidades produzidas.

As informações referentes aos preços e as quantidades foram fornecidas pelo Ministério de Agricultura dos Departamentos de Cajamarca e Lima. Os preços são médias mensais recebidas pelos produtores de cada cultura, e as quantidades correspondem ao total produzido na região (tabelas A.5 a A8 do apêndice A). Essas informações abrangeram o período de janeiro de 1975 a dezembro de 1994.

Os preços foram deflacionados para valores reais em "Novos soles" ( $\mathrm{S} /$.) de dezembro de 1994 utilizando-se o índice de preços ao consumidor, extraídos dos registros do 'International Financial, Statistic International Monetary Fund", e do Instituto Nacional de Estatística de Lima-Peru ( tabelas A1 a A4 do apêndice A).

\subsection{Metodologia}

Basicamente, as séries temporais são caracterizadas por quatro componentes que determinam sua variação:

a) Tendência. Mostra o comportamento da série em um longo período de tempo, podendo ser: crescente, decrescente ou constante. O primeiro tipo de tendência é o da média. A média tem uma tendência ascendente se a série está oscilando em torno de um valor crescente; um segundo tipo de tendência, também facilmente visível, principalmente numa série de preços ou de quantidades, é a tendência da variância. A amplitude das 
oscilações em torno da média pode aumentar com o tempo. Otárala (1993) menciona que a tendência na média é a parte que descreve um movimento suave, de longo prazo, dos dados, e que ocorre, em geral, de mudanças tecnológicas e de alterações nas preferências do consumidor pelo produto. São de longo prazo pois a tecnologia requer certo tempo para a assimilação por todos os produtores, como também a mudança de hábitos de consumo da população não ocorre de forma brusca.

b) Variação Sazonal. Mostra as flutuações ocorridas regularmente dentro de um ano. Morettin \& Toloi (1985) mencionam que dentre todos os componentes, a sazonalidade é o de mais fácil entendimento, resultando de variações dos dados dentro de um ano. Reflete diferentes estações do ano e mudanças no fotoperíodo e pluviosidade, o que caracteriza as chamadas safras e entressafras da produção agro-pecuária. Trata-se de variações em torno da tendência.

c) Variações cíclicas ou plurianuais. Embora as variações sazonais e as tendências sejam as mais evidentes, pode-se também observar flutuações que se repetem a intervalos de dois ou mais anos. Essas flutuações são as variações cíclicas.

d) Variações Aleatórias. São causadas por fatores irregulares e não obedecem a nenhum padrão de ocorrência. Podem ser causadas por fenômenos climáticos, intervenções governamentais, eventos esporádicos (guerras, secas ou inundações generalizadas) e outros de caráter social.

Segundo Morettin \& Toloi (1985) e considerando que os componentes são aditivos, pode-se escrever:

$$
\mathbf{Z}_{\mathbf{t}}=\mathbf{T}_{\mathbf{t}}+\mathbf{S}_{\mathbf{t}}+\mathbf{u}_{\mathbf{t}},
$$

Onde $\mathbf{Z}_{\mathbf{t}}$ é a variável em análise (Preço ou quantidade de um produto), $\mathbf{T}_{\mathbf{t}}$ é o componente ciclo tendencial, $\mathbf{S}_{\mathbf{t}}$ é a sazonalidade, enquanto $\mathbf{u}_{\mathbf{t}}$ é o componente aleatório.

Neste trabalho, o estudo das variações dos preços e quantidades será feito por meio de modelos de regressão através do Proc Reg do Statistical Analysis System (SAS), utilizando-se o modelo de análise harmônica para determinar a amplitude e os ângulos fase dos preços e quantidades. Regressões com variáveis binárias serão usadas 
para determinar as médias mensais ou constantes sazonais. Para comparar essas médias mensais será utilizado, também, o método da média aritmética móvel centralizada.

\subsection{Análise harmônica}

\section{a) Séries estacionárias e séries de Fourier}

Diz-se que uma série estacionária é periódica, quando suas flutuações se repetem a dado intervalo de tempo. Dentre os componentes que caracterizam as séries temporais, as variações sazonais e cíclicas geralmente apresentam padrões de comportamento regular. Quando isto ocorre, as séries temporais podem ser expressas em forma de uma função periódica.

Uma série periódica estacionária segundo Cavalcanti (1978), pode ser decomposta nos elementos mostrados na Figura 1.

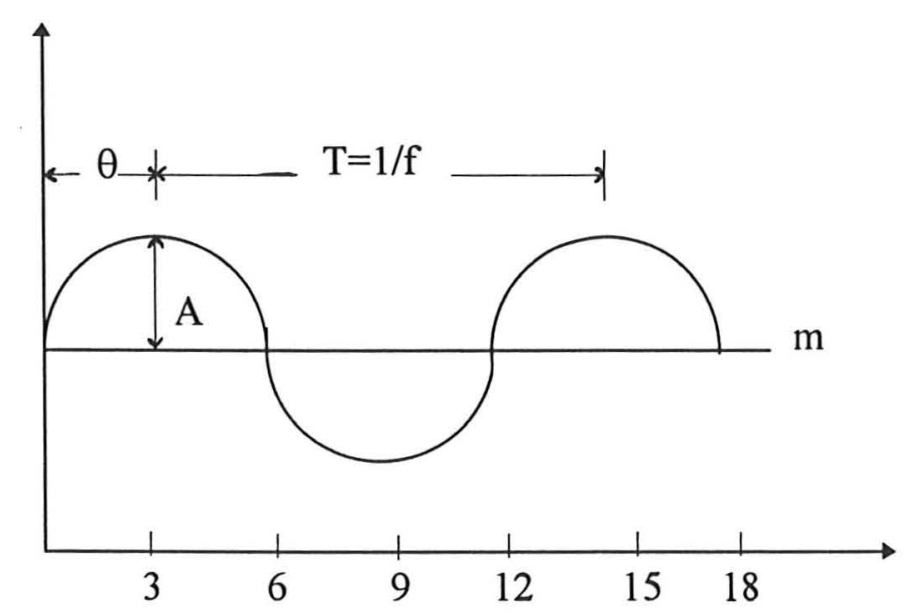

Figura 1 - Elementos da série periódica de Fourier.

Onde:

$\mathrm{m}=$ Valor médio, em torno do qual flutuam os valores observados da série periódica.

$\mathrm{T}=$ Período, é a distância entre 2 picos ou cavas e é medido em termos de unidade de tempo por ciclo. (tempo necessário para que um ciclo se repita). 
$\mathrm{f}=$ Frequência é o inverso do período e é medida em termos de ciclo por unidade de tempo $(1 / \mathrm{T})$.

$\mathrm{A}=$ Amplitude, é a distância do valor médio da série até um pico ou uma cava.

$\theta=$ Fase, é a distância entre a origem e o pico mais próximo.

Fourier mostrou que uma série periódica é composta por o somatorio de infinitas séries temporais periódicas, así:

$$
f(t)=f(t+T)=f(t+2 T)=\ldots . .=f(t+n T)
$$

onde;

$\mathrm{t}=$ Tempo

$\mathrm{T}$ = Período considerado sendo igual a $\mathrm{N} / \mathrm{i}$, com $\mathrm{i}$ sendo o número de repetições de periodo $\mathrm{T}$.

$\mathrm{N}=$ Número de observações

$\mathrm{n}$ = Número máximo de repetições do período $\mathrm{T}, \mathrm{n} \leq \mathrm{N} / 2$

Uma série periódica pode ser expressa através de uma função trigonométrica, como mostrado na equação (3.2).

$$
f(t)=m+\sum_{i=1}^{\infty}\left[\alpha_{i} \cos \frac{2 \pi i t}{T}+\beta_{i} \operatorname{sen} \frac{2 \pi i t}{T}\right]
$$

onde;

$\mathrm{m}=$ é o valor médio

$\pi=$ constante 3,1415927

$\alpha$ e $\beta=$ coeficientes a serem estimados.

Esta função trigonométrica se caracteriza pela soma de elementos harmônicos que são representados pelo seno e co-seno de cada período. 


\section{b) O modelo de análise harmônica}

Com base nos conceitos definidos para as séries de Fourier, pode-se representar uma série de tempo periódica estacionária através da expressão:

$$
Y_{t}=m+A \cos \left(\frac{2 \pi}{T} t-\theta\right)
$$

Por facilidade, expressa-se as funções periódicas em termos de frequência angular (W), a qual pode ser medida em radianos (ou graus) por unidade de tempo, da seguinte maneira:

$$
\mathrm{W}=2 \pi / \mathrm{T}
$$

Substituindo a equação (3.4) na equação (3.3), obtém-se a expressão:

$$
Y_{t}=m+A \cos (W t-\theta)
$$

A função periódica é composta então pelos elementos: $m$ que é a média de $\mathrm{Y}_{\mathrm{t}}$; $\mathrm{T}=$ é o período (1/f), W é a frequência angular.

A expressão $A \cos (\mathrm{Wt}-\theta)$, pode ser representada pelas funções seno e co-seno na forma,

$$
\mathrm{A}(\cos \mathrm{Wt} \cos \theta+\operatorname{sen} \mathrm{Wt} \operatorname{sen} \theta)
$$

Ou, na forma mais sintética,

$$
A \cos (W t-\theta)=\alpha \cos W t+\beta \operatorname{sen} W t
$$


onde;

$$
\alpha=A \cos \theta
$$

$\mathrm{e}$

$$
\beta=A \operatorname{sen} \theta
$$

Na qual $\alpha$ e $\beta$ são parâmetros a serem estimados.

Substituindo (3.7) na expressão (3.5), chega-se à expressão:

$$
\mathrm{Y}_{\mathrm{t}}=\mathrm{m}+\alpha \cos \mathrm{Wt}+\beta \operatorname{sen} \mathrm{Wt}
$$

Elevando ao quadrado ambos os membros das equações (3.8) e (3.9) e somando os resultados, membro a membro, obtém-se:

$$
\alpha^{2}+\beta^{2}=A^{2}\left(\cos ^{2} \theta+\operatorname{sen}^{2} \theta\right)
$$

Sabendo que $\cos ^{2} \theta+\operatorname{sen}^{2} \theta=1$, chega-se à equação:

$$
\mathrm{A}^{2}=\alpha^{2}+\beta^{2}
$$

Por outro lado, dividindo a equação (3.9) pela equação (3.8), obtém-se:

$$
\frac{\beta}{\alpha}=\frac{\operatorname{sen} \theta}{\cos \theta}=\operatorname{tg} \theta
$$

Esta também é uma relação trigonométrica conhecida, e pode ser calculada:

$$
\operatorname{arctg} \beta / \alpha=\theta
$$


Os parâmetros $\mathrm{A}$ e $\theta$ são, respectivamente, a amplitude e a fase da série temporal. Estas expressões são válidas para cada uma das séries temporais periódicas.

Um modelo de série temporal estacionária é constituído pelo somatório de infinitas séries temporais periódicas mais a média. Assim, é possível obter a seguinte equação:

$$
\mathrm{Y}_{\mathrm{t}}=\mathrm{m}+\sum_{\mathrm{i}=1}^{\infty} \mathrm{A}_{\mathrm{i}} \cos \left(\mathrm{W}_{\mathrm{i}} \mathrm{t}-\theta_{\mathrm{i}}\right)
$$

onde, $0<\mathrm{W}_{\mathrm{i}} \leq 2 \pi$; ou $\left(0<\mathrm{W}_{\mathrm{i}} \leq 360^{\circ}\right)$, e o índice $\mathrm{i}$ se refere à i-ésima série temporal periódica.

De modo alternativo, pode-se expressar a equação (3.14) da seguinte forma:

$$
\mathrm{Y}_{\mathrm{t}}=\mathrm{m}+\sum_{\mathrm{i}=1}^{\mathrm{h}} \alpha_{\mathrm{i}} \cos \mathrm{W}_{\mathrm{i}} \mathrm{t}+\sum_{\mathrm{i}=1}^{\mathrm{k}} \beta_{\mathrm{i}} \operatorname{sen} \mathrm{W}_{\mathrm{i}} \mathrm{t}
$$

onde;

$\mathrm{h}=\mathrm{k}=(\mathrm{T}-1) / 2$ quando $\mathrm{T}$ for impar, e

$\mathrm{h}=\mathrm{T} / 2$ e $\mathrm{k}=(\mathrm{T} / 2)-1$ quando $\mathrm{T}$ for par

Nos dois casos o número de parâmetros $\left(\mathrm{m}, \alpha_{\mathrm{i}}\right.$ e $\left.\beta_{\mathrm{i}}\right)$ no modelo (3.15) é igual a $\mathrm{T}$.

Cada um dos coeficientes $A_{i}$ 's da equação (3.14) relaciona-se com os $\alpha_{i}$ 's e $\beta_{i}$ 's da equação (3.15) da seguinte forma:

$$
\begin{array}{ll}
\mathrm{A}_{\mathrm{i}}{ }^{2}=\alpha_{\mathrm{i}}{ }^{2}+\beta_{\mathrm{i}}{ }^{2} & \mathrm{i}=1,2, \ldots \\
\theta_{\mathrm{i}}=\operatorname{arctg} \beta_{\mathrm{i}} / \alpha_{\mathrm{i}} & \mathrm{i}=1,2, \ldots
\end{array}
$$




\section{c) Modelo estatístico utilizando-se análise harmônica}

Para se estimar a tendência e as variações estacionais dos preços e quantidades de batata, milho, trigo e cevada, será utilizado uma função harmônica que é a representação de uma série periódica.

O modelo a ser utilizado será o seguinte:

$$
\mathrm{Y}_{\mathrm{t}}=\mathrm{m}+\gamma \mathrm{t}+\sum_{\mathrm{i}=1}^{\mathrm{h}} \alpha_{\mathrm{i}} \cos \mathrm{W}_{\mathrm{i}} \mathrm{t}+\sum_{\mathrm{i}=1}^{\mathrm{k}} \beta_{\mathrm{i}} \operatorname{sen} \mathrm{W}_{\mathrm{i}} \mathrm{t}+\mathrm{u}_{\mathrm{t}}
$$

onde:

$\mathrm{m}=$ valor esperado médio (termo constante)

$\mathrm{t}=$ tempo

$\gamma, \alpha_{i}, \beta_{i},=$ parâmetros, ( $\gamma$ é parâmetro do componente tendência, $\alpha_{i}, \beta_{i}$, são parâmetros do componente sazonal)

$$
\mathrm{u}_{\mathrm{t}}=\text { termo aleatório com média zero e variância constante } \sigma^{2} \text {. }
$$

Para determinar a tendência da série inclui-se na regressão um termo linear em $t$, com $\mathrm{t}=1$ em janeiro de 1975 .

A $\mathrm{O}$ modelo (3.18) também pode ser escrito de acordo com a metodologia detalhada anteriormente como:

$$
\mathrm{Y}_{\mathrm{t}}=\mathrm{m}+\gamma \mathrm{t}+\sum_{\mathrm{i}=1}^{\mathrm{h}} \mathrm{A}_{\mathrm{i}} \cos \left(\mathrm{W}_{\mathrm{i}} \mathrm{t}-\theta_{\mathrm{i}}\right)+\mathrm{u}_{\mathrm{t}}
$$

Os parâmetros do modelo (3.18), podem ser estimados pelo método de mínimos quadrados ordinários (MQO). 


\subsection{Análise utilizando-se variáveis binárias}

Quando a sazonalidade é determinística, ou seja, pode ser prevista perfeitamente a partir dos meses anteriores, outro método a ser aplicado é a análise de regressão com variáveis binárias (Morettin \& Toloi 1985). O modelo (3.18) pode ser escrito na forma,

$$
Y_{t}=m+\gamma t+\sum_{j=1}^{11} \alpha_{j} Z_{j t}+u_{t}
$$

onde $Z_{\mathrm{jt}}$ são variáveis binárias, $\alpha_{\mathrm{j}}$ são as constantes sazonales e $u_{\mathrm{t}}$ é o termo aleatório com média zero e variância constante $\sigma^{2}$.

Com a restrição adicional,

$$
\sum_{j=1}^{12} \alpha_{j}=0
$$

Como se esta supondo sazonalidade constante, $\alpha_{\mathrm{j}}$ não depende da tendência e

$$
Z_{\mathrm{jt}}=\left\{\begin{array}{c}
1, \text { se o período } \mathrm{t} \text { corresponde ao mês } \mathrm{j}, \\
-1 \text { se o período } \mathrm{t} \text { corresponde ao mês } 12 \\
0, \text { caso contrário, para todo } \mathrm{j}=1, \ldots, 11
\end{array}\right.
$$

Assim como no modelo harmônico, podemos utilizar a teoria de mínimos quadrados ordinários (MQO) para obter as estimativas dos parâmetros.

A vantagem deste método é que os valores estimados $\hat{\alpha}_{j}$ proporcionam informações diretas das características mensais da série temporal, por isso essas estimativas são chamadas de médias mensais ou constantes sazonais. Outra vantagem que oferece o modelo de regressão (3.20), é a simplicidade dos métodos estatísticos de estimação dos parâmetros. 


\subsection{Método da média aritmética móvel centralizada}

A seguir apresenta-se o método da média aritmética móvel centralizada para o modelo aditivo. Para maiores detalhes ver Lange (1967), Morettin \& Toloi (1985) e Hoffmann (1987).

Considerando o modelo

$$
P_{t}=P_{i j}=a+b t+e_{j}+u_{t}
$$

Onde,

$\mathrm{P}_{\mathrm{t}}$ representa preços, por exemplo

$a+b$ é a tendência linear, sendo a e b, parâmetros,

$e_{j}$ é o componente estacional, com

$$
\sum_{j=1}^{12} e_{j}=0
$$

$\mathrm{u}_{\mathrm{t}}$ é o componente aleatório, com

$$
\mathrm{E}\left(\mathrm{u}_{\mathrm{t}}\right)=0
$$

i representa o número de anos

j representa o número de meses

$t$ observações (meses $x$ anos)

A média aritmética móvel centralizada para uma série de preços é dada por:

$$
M_{i j}=M_{t}=\frac{1}{12}\left(0,5 P_{t-6}+P_{t-5}+\ldots+P_{t}+\ldots+P_{t+5}+0,5 P_{t+6}\right)
$$

O estimador do componente estacional $\mathrm{e}_{\mathrm{j}}$ será denominado $\mathrm{d}_{\mathrm{ij}}$, 


$$
\mathrm{d}_{\mathrm{ij}}=\mathrm{d}_{\mathrm{t}}=\mathrm{P}_{\mathrm{ij}}-\mathrm{M}_{\mathrm{ij}}
$$

Estimadores mais eficientes são obtidos calculando-se a média aritmética dos $d_{i j}$ para cada mês. Estes estimadores serão denominados $\overline{\mathrm{d}}_{\mathrm{j}}$.

Para satisfazer a condição (3.23), deve-se calcular uma correção c, onde:

$$
c=\frac{1}{12} \sum_{j=1}^{12} \bar{d}_{j}
$$

a qual deverá ser subtraída de cada estimativa do componente estacional $\overline{\mathrm{d}}_{\mathrm{j}}$, isto é,

$$
\hat{\mathrm{e}}_{\mathrm{j}}=\overline{\mathrm{d}}_{\mathrm{j}}-\mathrm{c}
$$

$\mathrm{O}$ índice de irregularidade $\left(\mathrm{S}_{\mathrm{j}}\right)$ é uma medida de dispersão dos $\mathrm{d}_{\mathrm{ij}}$ relativos a um mês e pode ser medido por meio da estimativa do desvio padrão, dada por

$$
S_{j}=\sqrt{\frac{1}{n-2} \sum_{i=1}^{n-1}\left(d_{i j}-\bar{d}_{j}\right)^{2}}
$$

se $7 \leq \mathrm{j} \leq 12$ e por

$$
S_{j}=\sqrt{\frac{1}{n-2} \sum_{i-2}^{n}\left(d_{i j}-\bar{d}_{j}\right)^{2}}
$$

se $1 \leq \mathrm{j} \leq 6$. 


\section{RESULTADOS E DISCUSSÕES}

Os resultados encontrados, de modo geral, estiveram de acordo com as expectativas com relação à evolução dos preços e quantidades dos produtos analisados. Esses produtos apresentaram padrões estacionais bem definidos e tendências decrescentes para os preços. No caso das quantidades de batata e milho, a tendência foi constante, enquanto o trigo e a cevada apresentaram tendência decrescente, refletindo o desestímulo por parte dos produtores devido a baixa rentabilidade dessas culturas.

\subsection{Análise das variações da cultura de batata}

\subsubsection{Análise harmônica}

As estimativas dos parâmetros das séries de preços e quantidades utilizando-se a análise harmônica para as culturas de batata encontram-se na tabela B1 do apêndice B.

\section{a) Preços}

A análise harmônica aplicada aos preços reais mensais da batata, durante o período de estudo fornece os seguintes resultados:

$$
\begin{aligned}
& \hat{\mathrm{P}}(\mathrm{t})=1,9988-0,0057 \mathrm{t}-0,1518 \cos \frac{2 \pi \mathrm{t}}{12}-0,1594 \operatorname{sen} \frac{2 \pi \mathrm{t}}{12}-0,0424 \cos \frac{4 \pi \mathrm{t}}{12}- \\
& \left(-10,737^{* *}\right)\left(-2,914^{* *}\right) \quad\left(-3,057^{* *}\right) \\
& 0,0268 \operatorname{sen} \frac{4 \pi \mathrm{t}}{12}-0,0076 \cos \frac{6 \pi \mathrm{t}}{12}+0,0234 \operatorname{sen} \frac{6 \pi \mathrm{t}}{12}-0,0022 \cos \frac{8 \pi \mathrm{t}}{12}+0,0182 \operatorname{sen} \frac{8 \pi \mathrm{t}}{12}+ \\
& (-0,514) \quad(-0,450)
\end{aligned}
$$


$0,0121 \cos \frac{10 \pi \mathrm{t}}{12}+0,0007 \operatorname{sen} \frac{10 \pi \mathrm{t}}{12}+0,0039 \cos \frac{12 \pi \mathrm{t}}{12}$

$(0,233) \quad(0,013) \quad(0,107)$

$\mathrm{R}^{2}=0,37 \quad \mathrm{~F}=11,105^{* *}$

** Significativamente diferente de zero ao nível de 0,05 de probabilidade

* Significativamente diferente de zero ao nivel de 0,10 de probabilidade

Os valores entre parênteses abaixo dos coeficientes são os valores obtidos no teste " $t$ "

Expressando a equação (4.1) em termos de co-seno e ângulo fase, obtém-se a seguinte equação, para os coeficientes significativos ate 0,10 de probabilidade

$$
\hat{\mathrm{P}}(\mathrm{t})=1,9988-0,0057 \mathrm{t}+0,2201 \cos \left(\frac{2 \pi \mathrm{t}}{12}-3,9514\right)
$$

\section{b) Quantidade}

A análise harmônica aplicada às quantidades da batata, durante o período de estudo fornece os seguintes resultados:

$$
\begin{aligned}
& \hat{Q}(t)=8586,2124+0,7939 t+2266,0269 \cos \frac{2 \pi t}{12}+1596,4406 \operatorname{sen} \frac{2 \pi t}{12}+41,7769 \cos \frac{4 \pi t}{12}- \\
& (0,445) \quad(12,973 * *) \quad(9,134 * *) \quad(0,239) \\
& 113,1962 \operatorname{sen} \frac{4 \pi \mathrm{t}}{12}-292,7189 \cos \frac{6 \pi \mathrm{t}}{12}-216,0478 \operatorname{sen} \frac{6 \pi \mathrm{t}}{12}-232,9564 \cos \frac{8 \pi \mathrm{t}}{12}-190,9172 \operatorname{sen} \frac{8 \pi \mathrm{t}}{12}+ \\
& \begin{array}{lllll}
(-0,648) & \left(-1,676^{*}\right) \quad(-1,237) \quad(-1,334) \quad(-1,093)
\end{array} \\
& 289,4103 \cos \frac{10 \pi \mathrm{t}}{12}-226,5318 \operatorname{sen} \frac{10 \pi \mathrm{t}}{12}+199,1197 \cos \frac{12 \pi \mathrm{t}}{12} \\
& \left(1,657^{*}\right) \quad(-1,297) \quad(1,612) \\
& \mathrm{R}^{2}=0,54 \quad \mathrm{~F}=22,228^{* *}
\end{aligned}
$$


** Significativamente diferente de zero ao nível de 0,05 de probabilidade

* Significativamente diferente de zero ao nivel de 0,10 probabilidade

Os valores entre parênteses abaixo dos coeficientes são os valores obtidos no teste " $t$ "

Escrevendo a equação (4.3) em termos de co-seno e ângulo fase, para o componente anual, obtém-se a seguinte equação:

$$
\hat{Q}(t)=8586,2124+0,7939 t+2771,9128 \cos \left(\frac{2 \pi t}{12}-0,6137\right)
$$

Os coeficientes significativos estão associados ao par de variáveis Cos $2 \pi \mathrm{t} / 12+$ Sen $2 \pi \mathrm{t} / 12$, indicando que os ciclos nessas variáveis repetem-se anualmente, não havendo, portanto, a ocorrência de mais de um ciclo de preços e de quantidades de batata durante o ano. Isso pode ser justificado pelo ciclo biológico da cultura na região andina e particularmente no Departamento de Cajamarca, que produz, normalmente, uma safra do tubérculo por ano. Resultados similares são observados nas culturas de arroz, farinha de mandioca e feijão estudados por Araújo et alii (1985), nos mercados do nordeste do Brasil, onde esses produtos apresentam uma safra por ano.

Em relação ao coeficiente estimado da variável tendência, observa-se que a série de preços apresenta tendência negativa (decrescente), indicando diminuição da renda dos produtores em valores reais, o que contribuiu para a maior descapitalização do setor rural. Os incrementos que se observam em alguns períodos, não conseguiram reverter a tendência decrescente.

As perdas reais para a batata são de $56 \%$ da média do período $75-80$ comparado com o período 89-94 (tabela A1), esses resultados corroboram os encontrados por Dancourt \& Mendoza (1994), que observam perdas pelos agricultores de $22 \%$ para a cultura de batata comparando o período 1990-1992 com o período 1988-1990.

A tendência da quantidade de batata é positiva, assim existe ligeiro incremento da quantidade produzida de batata, mas não é considerada significativa pelo modelo $(\mathrm{P}>0,10)$, flutuando sempre ao redor da média que é de 104.183 toneladas (tabela A.5). 
As quantidades produzidas no período 1990 a 1994 foram ligeiramente inferiores a média, devido às restrições econômicas adotadas nesse período, como as restrições ao crédito, diminuição de subsídios aos adubos, liberalização de impostos às importações de produtos com a finalidade de eliminar a inflação.

As magnitudes dos coeficientes de determinação associadas às duas séries foram, respectivamente, $37 \%$ para as séries de preços e $54 \%$ para a série de quantidades. Os valores das séries originais e estimados pelo modelo harmônico podem ser visualizados nas figuras 2 e 3 , observando-se melhor ajuste no caso das quantidades produzidas. 


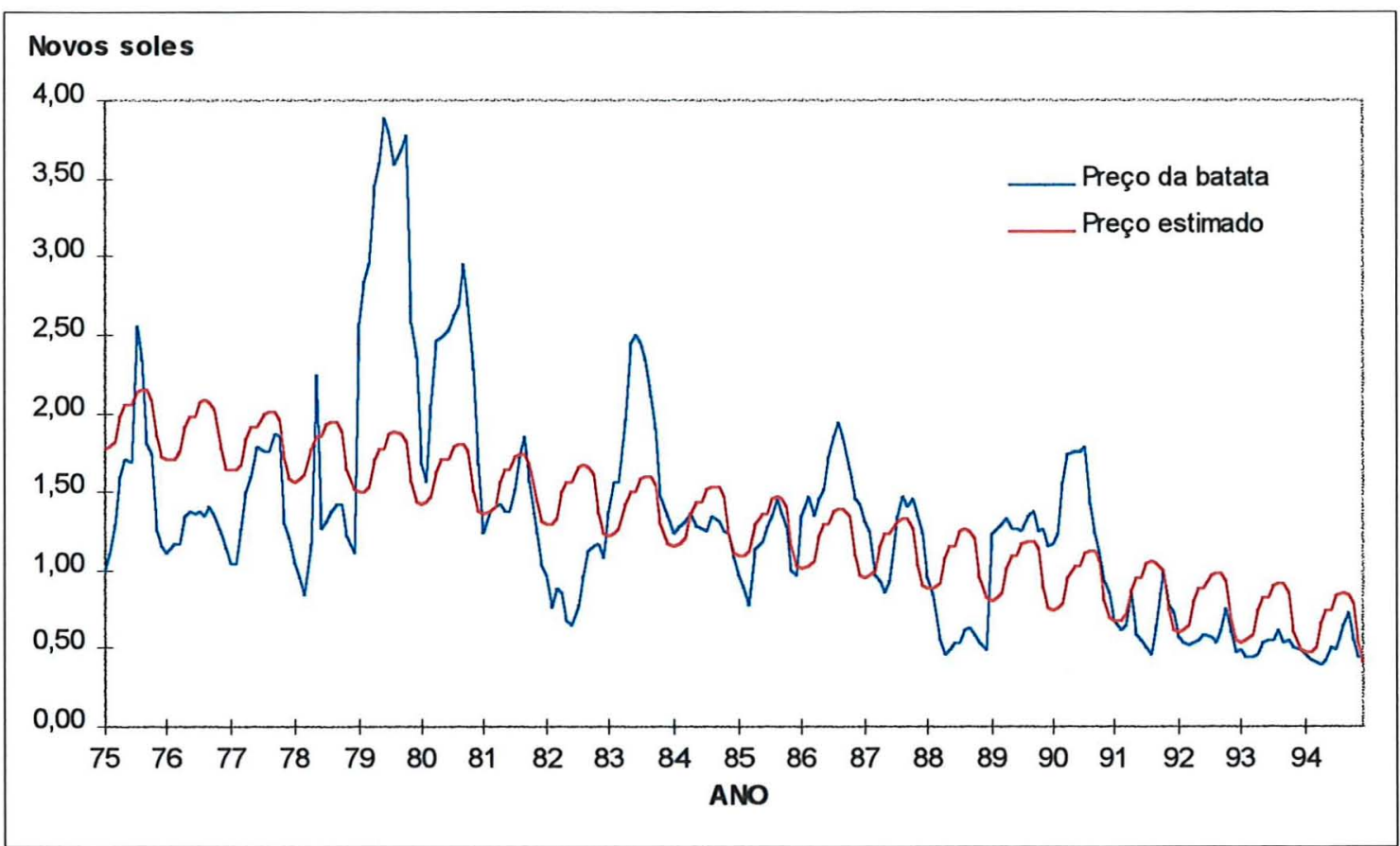

Figura 2 - Comparação entre preços deflacionados da batata e preços estimados pelo modelo harmônico no período 1975 - 1994.

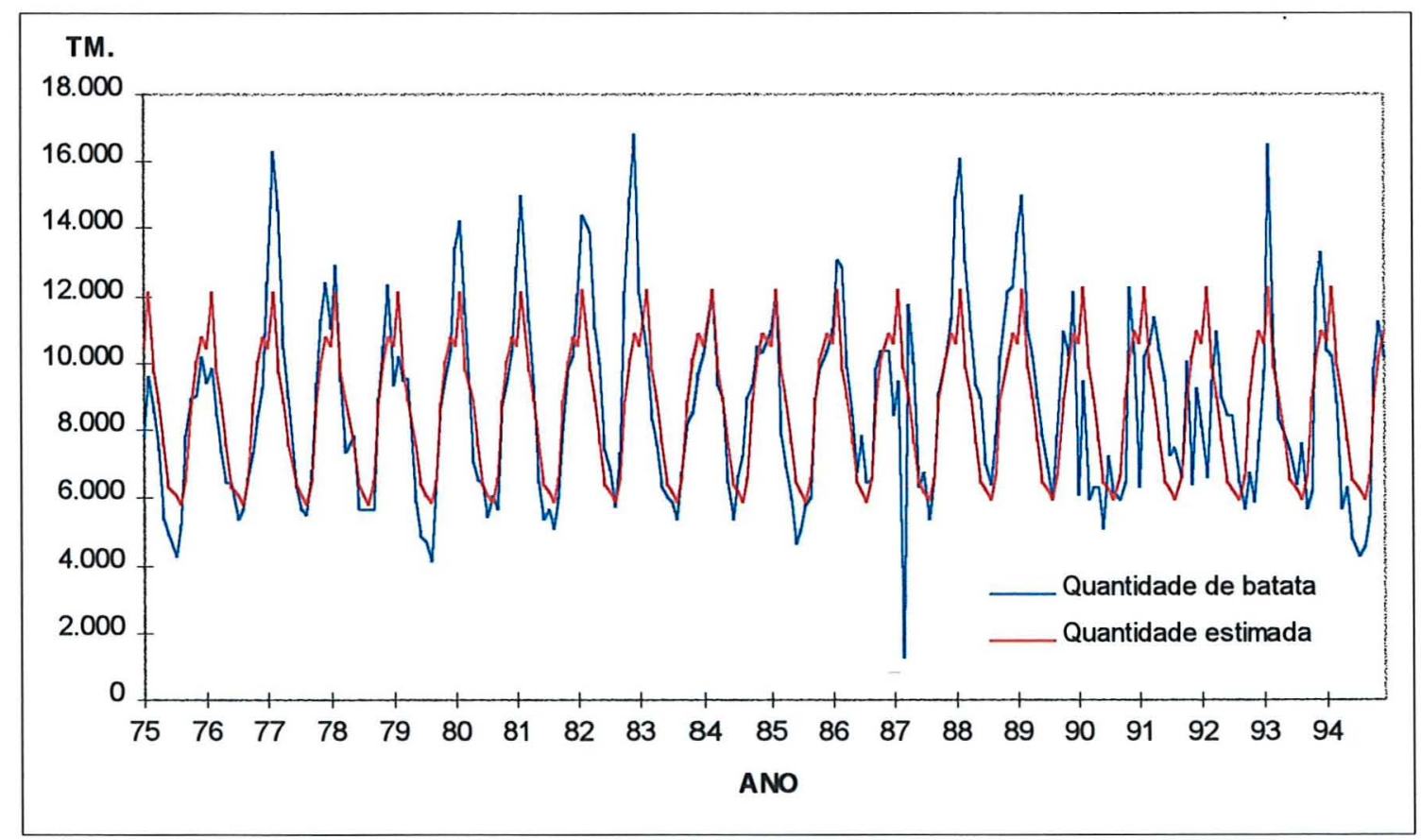

Figura 3 - Comparação entre quantidades produzidas de batata e quantidades estimadas pelo modelo harmônico no período 1975 - 1994. 


\subsubsection{Análise utilizando-se variáveis binárias}

Na tabela B.2 do apêndice B, estão apresentadas as estimativas dos preços e quantidades da cultura de batata utilizando-se variáveis binárias. Na realidade, a análise harmônica e binária são iguais para captar a tendência e a sazonalidade.

Resultados com relação à tendência são iguais à análise já feita no modelo harmônico. Esse modelo é muito importante porque permite conhecer as médias mensais, que são conhecidas como constantes sazonais $\left(\alpha_{j}\right)$ da equação (3.20), que têm uma interpretação complementar a do modelo harmônico. Observa-se que o coeficiente do preço para o mês de dezembro é -0,2104 (obtido da equação 3.21 da metodologia). De novembro a abril, os preços foram inferiores à média $(1,31)$, como se observa nos sinais desses meses. Por sua vez, os meses com sinais positivos (maio a outubro) são meses em que os preços estão acima do preço médio.

Em relação às quantidades produzidas, observa-se que os meses de outubro a abril, com sinal positivo, são significativamente superiores à média (8681,875 TM), indicando que as quantidades produzidas são sazonais. Os meses de maio a setembro têm sinal negativo, indicando que a produção é inferior à média. Essa análise permite observar claramente que os preços baixos estão coincidindo com os meses de maior produção de batata.

\subsubsection{Análise utilizando-se média aritmética móvel centralizada}

Na tabela B.3 do apêndice B, estão-se as estimativas do componente estacional e, os índices de irregularidade dos preços e quantidade calculados pelo método da média aritmética móvel centralizada. As estimativas do componente estacional encontram-se em valores referentes a zero ( 0 ) e não em valores percentuais devido ao modelo aplicado de ajustamento para componentes aditivos da série temporal.

As estimativas do componete estacional para os preços e quantidades mostram a existência de uma razoável instabilidade. Como é conhesido, safras abundantes com preços baixos são sucedidas por safras reduzidas com preços elevados. Essas estimativas do componete estacional são semelhantes às médias mensais ou constantes sazonais $\left(\alpha_{\mathrm{j}}\right)$ obtidas utilizando-se variáveis binárias. 
A cultura da batata na região andina do Peru tem uma caraterística peculiar com relação às outras culturas andinas; ela é plantada em qualquer época do ano, mas é uma cultura muito sensível à geada e por isso em lugares onde se dispõe de irrigação planta-se desde o mês de agosto.

O plantio principal (onde não existe irrigação) é feito em outubro e novembro, acompanhando o período chuvoso da região (outubro a abril), como se observa na tabela A.9 do apêndice). Essa característica da cultura faz com que as estimativas do componente estacional para preços sejam baixas nesse período e com sinal negativo e altos com sinal positivo para o caso das quantidades produzidas. Esses resultados são muito similares aos observados com as médias mensais ou constantes sazonais no modelo binário (tabela B.2 do apêndice B).

Os índices irregulares (tabela B.3 do apêndice) indicam que, para o caso dos preços, o mês de maio é o que apresenta maior variabilidade $(0,325)$, enquanto o mês de março é o de menor variabilidade $(0,217)$. Para as quantidades, observa-se menor variabilidade em setembro (1.024), e maior variabilidade no mês de março (2.588), isto é, maior variabilidade nos meses de safra e menor variabilidade nos meses de entressafra.

Na figura 4 observa-se a variação estacional dos preços no período 1975 a 1994. Nessa figura foi assinalado, também para cada mês, um intervalo indicativo da dispersão das estimativas do componente estacional cujos limites superior e inferior, são obtidos adicionando e susbtraindo os índices de irregularidade das estimativas do componente estacional mensal. As mesmas flutuações para as quantidades produzidas observam-se na figura 5 . 


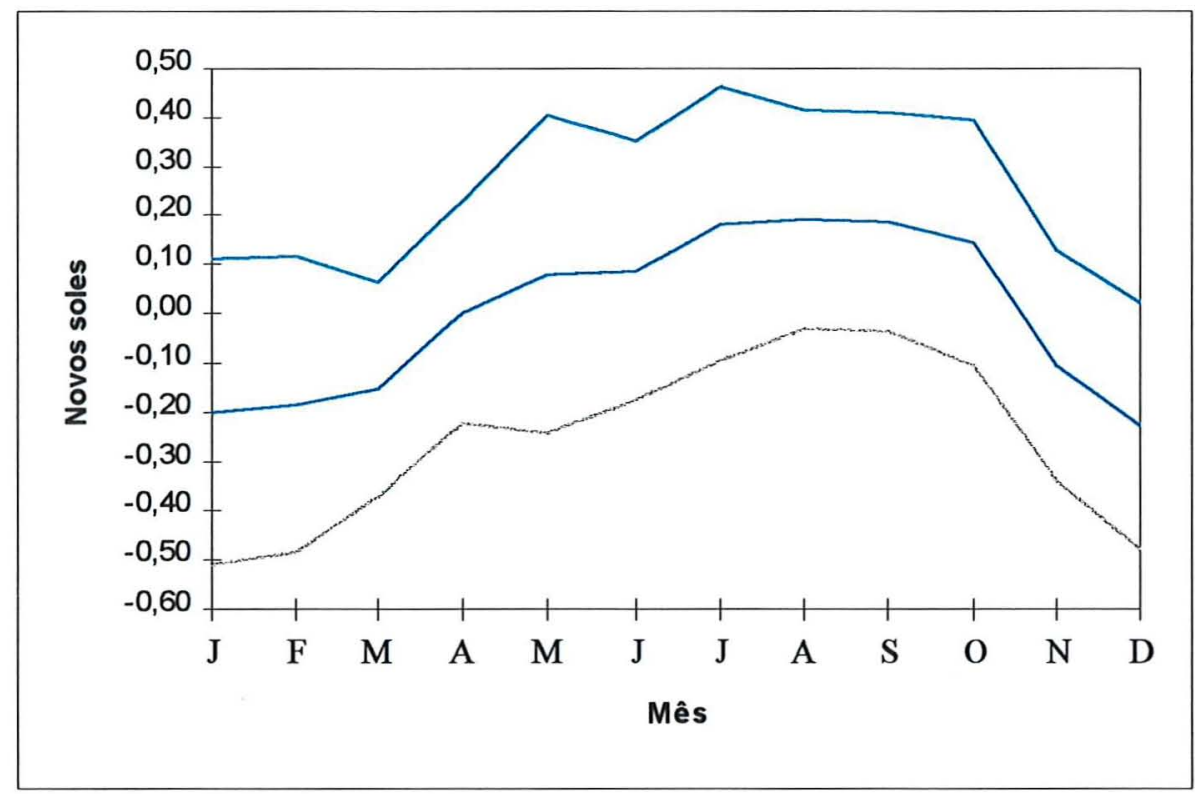

Figura 4 - Variação estacional do preço da batata obtidas pelo método da média aritmética móvel centralizada, no Departamento de Cajamarca, período 1975 - 1994.

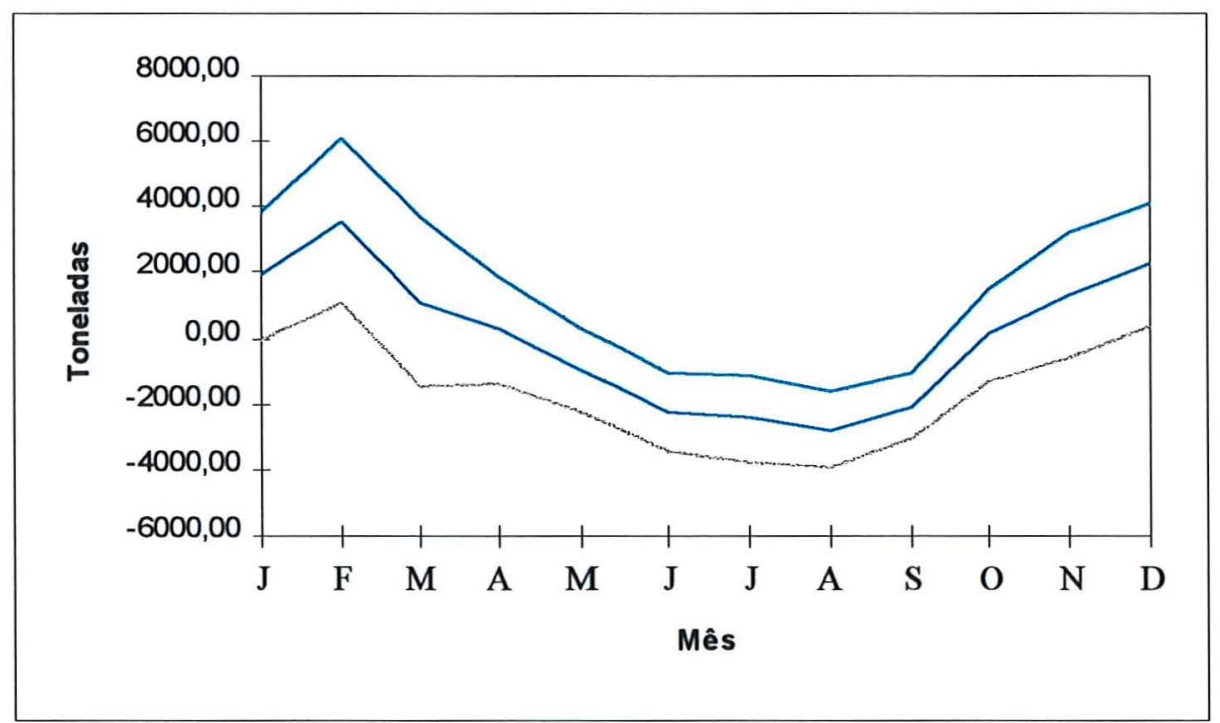

Figura 5 - Variação estacional da quantidade de batata obtidas pelo método da média aritmética móvel centralizada, no Departamento de Cajamarca, período 1975 - 1994. 


\subsection{Análise das variações da cultura de milho}

\subsubsection{Análise harmônica}

As estimativas dos parâmetros da série de preços e quantidades utilizando-se análise harmônica para a cultura de milho encontra-se na tabela B1 do apêndice B.

\section{a) Preços}

A análise harmônica aplicada aos preços reais mensais do milho, durante o período de estudo fornece os seguintes resultados:

$$
\begin{aligned}
& \hat{\mathrm{P}}(\mathrm{t})=2,9353-0,0087 \mathrm{t}+0,1671 \cos \frac{2 \pi \mathrm{t}}{12}+0,0516 \operatorname{sen} \frac{2 \pi \mathrm{t}}{12}-0,0224 \cos \frac{4 \pi \mathrm{t}}{12}- \\
& \left(-17,182^{* *}\right) \quad\left(3,378^{* *}\right) \quad(1,042) \quad(-0,452) \\
& 0,0069 \operatorname{sen} \frac{4 \pi \mathrm{t}}{12}-0,0001 \cos \frac{6 \pi \mathrm{t}}{12}+0,0060 \operatorname{sen} \frac{6 \pi \mathrm{t}}{12}+0,0021 \cos \frac{8 \pi \mathrm{t}}{12}+0,0054 \operatorname{sen} \frac{8 \pi \mathrm{t}}{12}+ \\
& \begin{array}{lllll}
(-0,139) & (-0,001) & (0,121) & (0,042) & (0,110)
\end{array} \\
& 0,0018 \cos \frac{10 \pi \mathrm{t}}{12}+0,0046 \operatorname{sen} \frac{10 \pi \mathrm{t}}{12}-0,0036 \cos \frac{12 \pi \mathrm{t}}{12} \\
& (0,036) \quad(0,093) \quad(-0,103) \\
& \mathrm{R}^{2}=0,58 \quad \mathrm{~F}=25,756^{* *}
\end{aligned}
$$

Escrevendo a equação (4.5) em termos de co-seno e ângulo fase, obtém-se a seguinte equação:

$$
\hat{\mathrm{P}}(\mathrm{t})=2,9353-0,0087 \mathrm{t}+0,1749 \cos \left(\frac{2 \pi \mathrm{t}}{12}-0,2995\right)
$$




\section{b) Quantidade}

A análise harmônica aplicada às quantidades de milho, durante o período de estudo fornece os seguintes resultados:

$$
\begin{aligned}
& \hat{Q}(t)=3523,1865-2,0842 t-5247,6824 \cos \frac{2 \pi t}{12}-453,0937 \operatorname{sen} \frac{2 \pi t}{12}+2928,4883 \cos \frac{4 \pi t}{12}+ \\
& (-1,340) \quad\left(-34,481^{* *}\right) \quad\left(-2,975^{* *}\right) \quad\left(19,243^{* *}\right) \\
& 734,8210 \operatorname{sen} \frac{4 \pi \mathrm{t}}{12}-1070,8408 \cos \frac{6 \pi \mathrm{t}}{12}-760,2259 \operatorname{sen} \frac{6 \pi \mathrm{t}}{12}+85,7800 \cos \frac{8 \pi \mathrm{t}}{12}+462,0256 \operatorname{sen} \frac{8 \pi \mathrm{t}}{12}+ \\
& \begin{array}{lllll}
\left(4,828^{* *}\right) & \left(-7,036^{* *}\right) & \left(-4,975^{* *}\right) & (0,564) & \left(3,036^{* *}\right)
\end{array} \\
& 129,1508 \cos \frac{10 \pi \mathrm{t}}{12}-242,7847 \operatorname{sen} \frac{10 \pi \mathrm{t}}{12}-40,9746 \cos \frac{12 \pi \mathrm{t}}{12} \\
& (0,849) \quad(-1,595) \quad(-0,381) \\
& \mathrm{R}^{2}=0,88 \quad \mathrm{~F}=22,228^{* *}
\end{aligned}
$$

Expressando a equação (4.7) em termos de co-seno e ângulo fase, obtém-se a seguinte equação:

$$
\begin{aligned}
\hat{Q}(t)= & 3523,1865-2,0842 t+5267,2065 \cos \left(\frac{2 \pi t}{12}-3,2277\right)+3019,2724 \cos \left(\frac{4 \pi t}{12}-0,2458\right)+ \\
& 1313,2568 \cos \left(\frac{6 \pi t}{12}-3,7590\right)
\end{aligned}
$$

Para as séries de preços e quantidades, observa-se que os coeficientes harmônicos significativamente diferentes de zero estão associados ao ciclo anual, indicando que os ciclos repetem-se similarmente todos os anos, caracterizando um período de pico nos preços, nas épocas de entressafra, e de pico na produção (com conseqüente queda nos preços) nas épocas de safra. Observa-se também coeficientes significativos nos pares de variáveis: $\cos 4 \pi \mathrm{t} / 12+\operatorname{sen} 4 \pi \mathrm{t} / 12$ (período de 6 meses) e $6 \pi \mathrm{t} / 12+\operatorname{sen} 6 \pi \mathrm{t} / 12$ (período de 3 meses), indicando a existência de ciclos de produção menores do que um ano, podese verificar maior importância relativa para o milho produzido e comercializado pelos 
produtores andinos no período de 12 meses, acompanhando o período chuvoso para a região, como pode ser observado na tabela A.9 do apêndice.

Em relação aos coeficientes da variável tendência, observa-se uma tendência negativa significativa $(\mathrm{P}<0,05)$ para os preços. Para as quantidades, existe ligeira tendência negativa, mas essa diminuição não é estatisticamente significativa. A diminuição nos preços traduz-se numa queda de renda dos produtores. A perda real para a cultura do milho é $65 \%$ da média do período 75-80 comparado com o período 89-94 (tabela A.2), mas para as quantidades produzidas a produção flutua em torno da média 39.265 T.M. (tabela A.6).

Essas condições de queda na renda dos produtores geram desestímulo a produção da cultura, que se agravou ainda mais com a retirada de certos subsídios a fertilizantes e sementes nos últimos anos ${ }^{6}$. As magnitudes dos coeficientes de determinação foram, $58 \%$ para a série de preços e $88 \%$ para a série de quantidades. Os valores das séries originais e estimadas pelo modelo podem se visualizados nas figuras 6 e 7 , observando-se melhor ajuste no caso das quantidades produzidas.

\footnotetext{
${ }^{6}$ Nos primeros 7 anos da década de 80 o Banco Agrário do Peru realizou empréstimos aos produtores com impostos zero em algums casos para incentivar a produção agrária, subsidiou a adubação e sementes, mas a partir de 1990 o governo desativou o Banco Agrário, criando o FONDEAGRO (Fundo de Desenvolvimento Agrario), Fundo Rotatório de Sementes e as Caixas Rurais, mas restringindo o crédito, até quase desaparecer em 1992. DANCOURT, O. (1994). Agricultura e política de estabilização do Perú.
} 


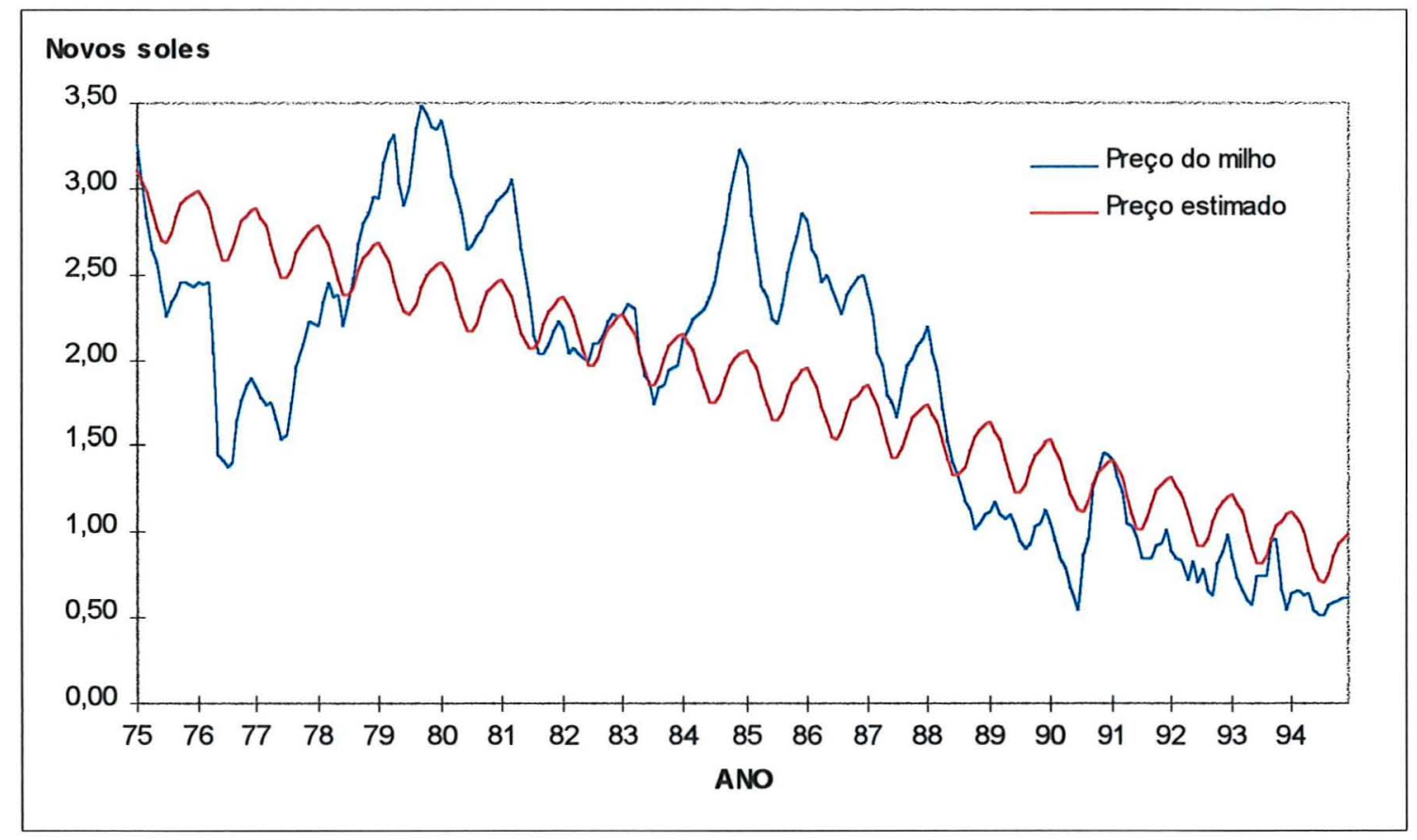

Figura 6 - Comparação entre preços deflacionados de milho e precos estimados pelo modelo harmônico no período 1975 - 1994.

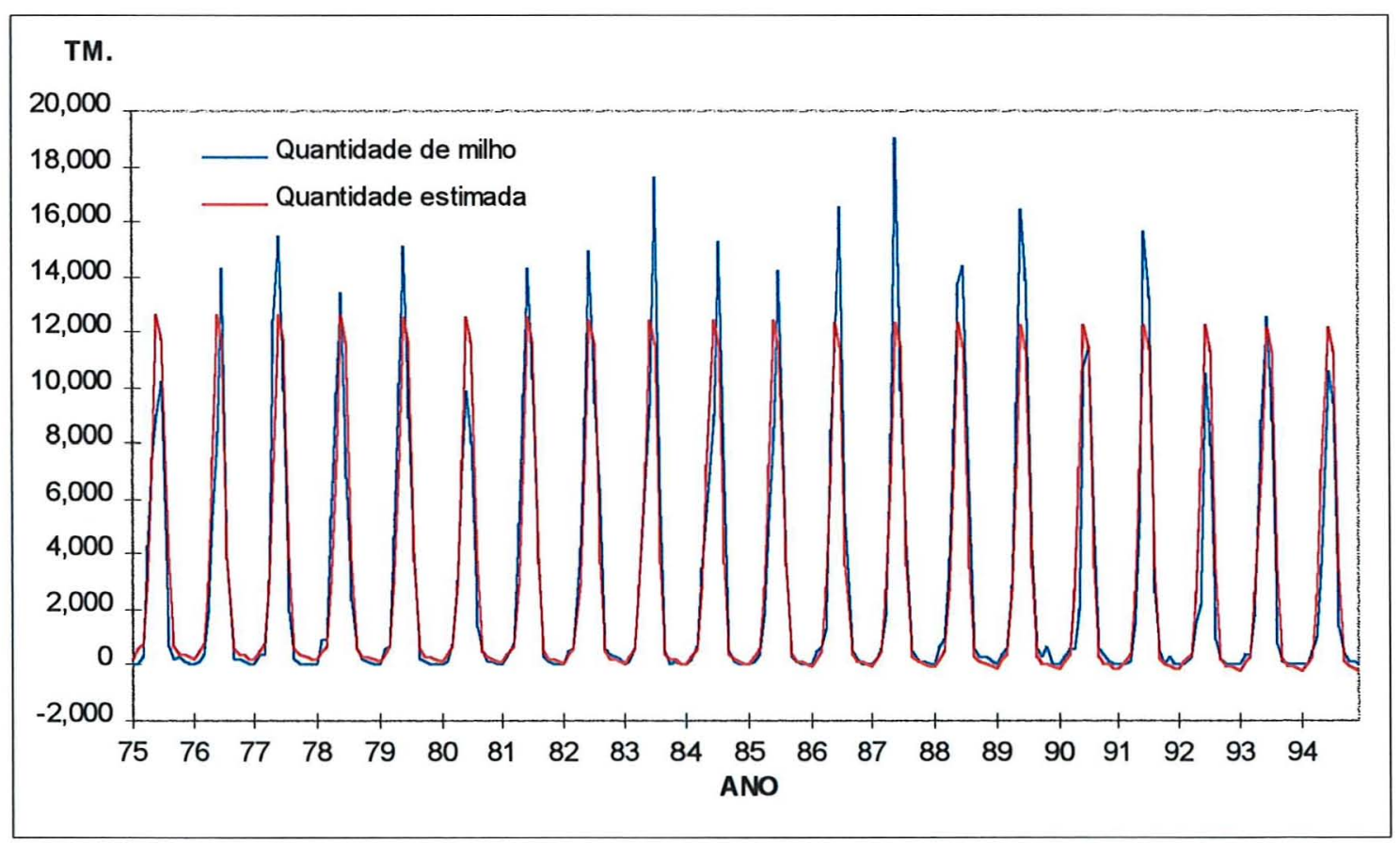

Figura 7 - Comparação entre quantidades produzidas de milho e quantidades estimadas pelo modelo harmônico no período 1975 - 1994. 


\subsubsection{Análise utilizando-se variáveis binárias}

Os resultados indicam que de outubro a março os índices mensais ou constantes sazonais dos preços do milho (tabela B.2), são superiores à média (sinal positivo), e de abril a setembro inferiores à média $(1,889)$, embora essas diferenças não sejam consideradas significativas pelo modelo $(\mathrm{P}>0,10)$, os preços são inferiores à média nos meses de abril a setembro.

No caso das quantidades produzidas dessa cultura, percebe-se duas épocas muito diferenciadas no transcorrer do ano: a época da safra, de maio a agosto (sinal positivo), estatisticamente significativa $(\mathrm{P}<0,05)$ e, superior à média $(3272,042 \mathrm{TM})$, e a época de entressafra de setembro a março, onde as quantidades produzidas são muito inferiores a média.

Esse grão é pouco perecível, podendo ser conservado por algum tempo. Provavelmente, devido a este fato, os produtores não vendem a totalidade de seu produto na época de safra, armazenando uma parcela razoável para o período de entressafra, onde os preços são ligeiramente maiores.

\subsubsection{Análise utilizando-se média aritmética móvel centralizada}

As estimativas do componente estacional para a cultura de milho podem ser observadas na tabela B.4.

A cultura de milho de consumo humano na região andina do Peru tem características muito similares à batata; em alguns lugares é plantada antecedendo a época normal da plantação. A finalidade é obter melhores preços no início da safra, uma vez que parte da produção dessa cultura é consumida como grão verde.

As estimativas do componente estacional para as quantidades produzidas de milho são superiores à média (sinal positivo) nos meses de maio a agosto. O plantio do milho realiza-se a partir dos meses de novembro a fevereiro, acompanhando o período chuvoso da região (que é de novembro a março tabela A.9) para poder ser colhido entre os meses de abril a agosto.

As estimativas do componente estacional para os preços da cultura do milho são inferiores à média nos meses de abril a setembro (sinal negativo), enquanto essas 
estimativas são superiores nos meses de outubro a março, exatamente no período de entressafra. Esses resultados são muito similares aos observados para as médias mensais ou constantes sazonais no modelo binário (tabela B.2 do apêndice B).

$\mathrm{O}$ índice de irregularidade para as quantidades produzidas apresentam alta variabilidade no período de safra e baixa variabilidade no período de entressafra, comportamento contrario observa-se no caso dos preços. (tabela B.4 do apêndice B).

As variações estacionais dos preços de milho, podem ser visualizadas na figura $8 \mathrm{e}$ para as quantidades produzidas observam-se na figura 9. 


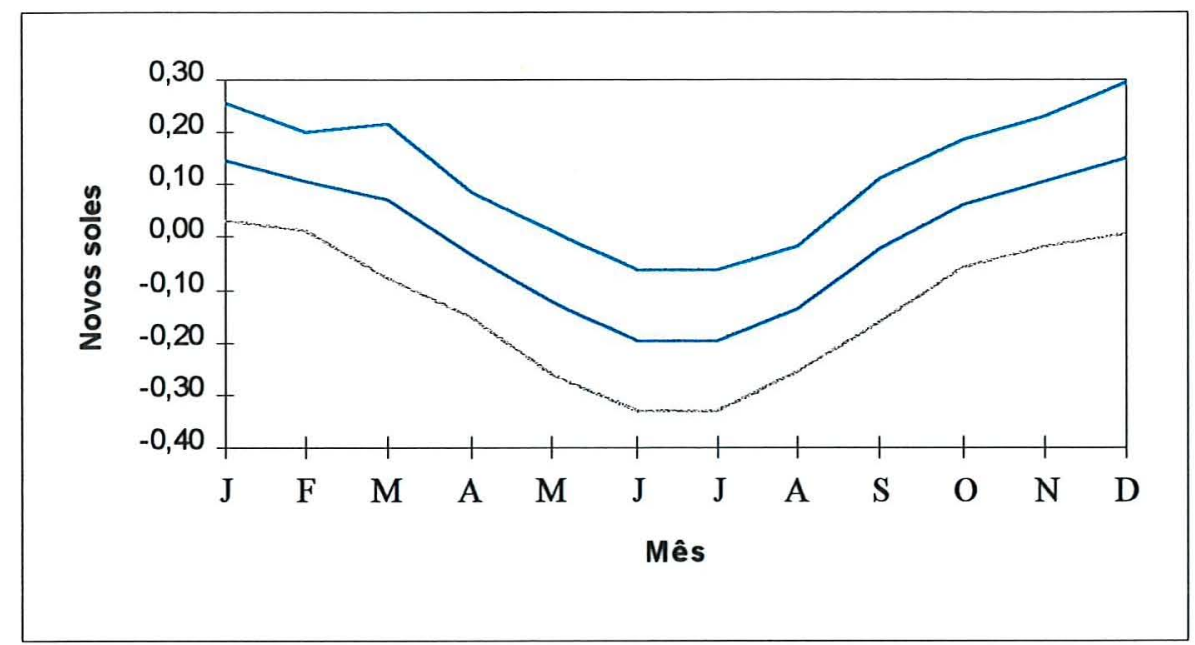

Figura 8 - Variação estacional do preço de milho obtidas pelo método da média aritmética móvel centralizada, no Departamento de Cajamarca, período 1975 - 1994.

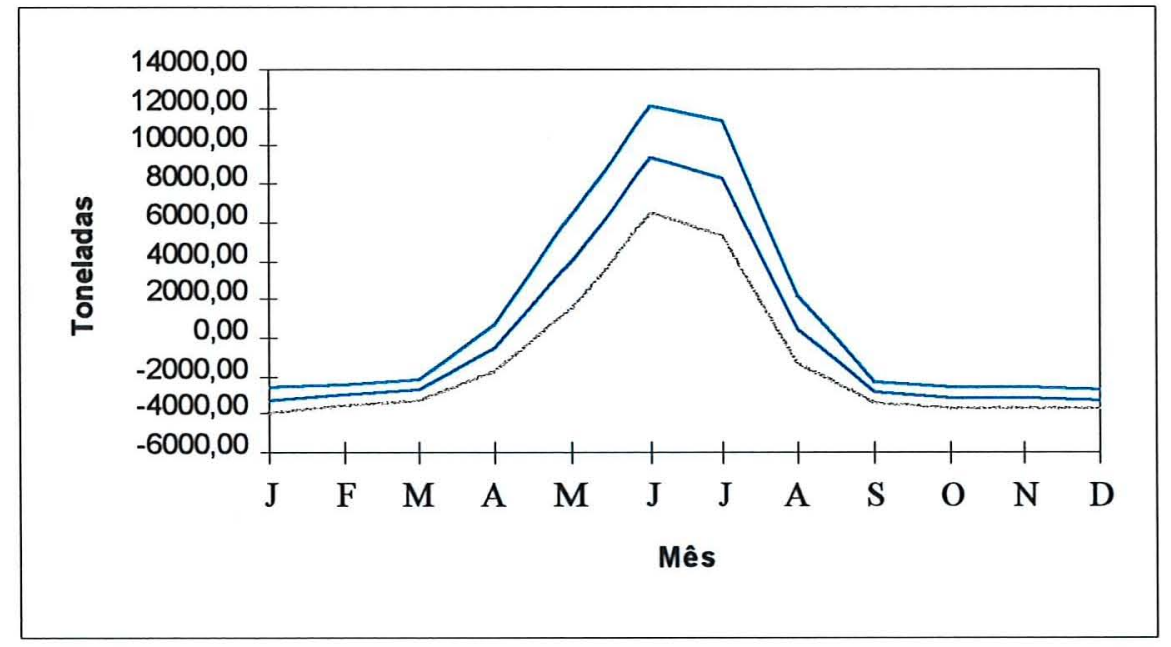

Figura 9 - Variação estacional da quantidade de milho obtidas pelo método da média aritmética móvel centralizada, no Departamento de Cajamarca, período 1975 $-1994$. 


\subsection{Análise das variações da cultura de trigo}

\subsubsection{Análise harmônica}

As estimativas dos parâmetros das séries de preços e quantidades utilizando-se análise harmônica para as culturas de trigo encontram-se na tabela B1 do apêndice B.

\section{a) Preços}

A análise harmônica aplicada aos preços reais mensais do trigo, durante o período de estudo fornece os seguintes resultados:

$$
\begin{aligned}
& \hat{\mathrm{P}}(\mathrm{t})=3,2820-0,0104 \mathrm{t}+0,1524 \cos \frac{2 \pi \mathrm{t}}{12}-0,1414 \operatorname{sen} \frac{2 \pi \mathrm{t}}{12}-0,0168 \cos \frac{2 \pi \mathrm{t}}{12}- \\
& \left(-19,014^{* *}\right)\left(2,837^{* *}\right) \quad(-2,629 * *) \quad(-0,314) \\
& 0,0288 \operatorname{sen} \frac{4 \pi \mathrm{t}}{12}-0,0221 \cos \frac{6 \pi \mathrm{t}}{12}-0,0186 \operatorname{sen} \frac{6 \pi \mathrm{t}}{12}+0,111 \cos \frac{8 \pi \mathrm{t}}{12}-0,0094 \operatorname{sen} \frac{8 \pi \mathrm{t}}{12}+ \\
& (-0,537) \quad(-0,411) \quad(-0,346) \quad(0,207) \quad(-0,175) \\
& 0,0032 \cos \frac{10 \pi \mathrm{t}}{12}+0,0179 \operatorname{sen} \frac{10 \pi \mathrm{t}}{12}+0,0101 \cos \frac{12 \pi \mathrm{t}}{12} \\
& (0,334) \\
& \mathrm{R}^{2}=0,62 \quad \mathrm{~F}=31,085^{* *}
\end{aligned}
$$

** Significativamente diferente de zero ao nivel de 0,05 de probabilidade

* Significativamente diferente de zero ao nivel de 0,10 de probabilidade

Os valores entre parênteses abaixo dos coeficientes são os valores obtidos no teste " $t$ "

Escrevendo a equação (4.9) em termos de co-seno e ângulo fase, obtém-se a seguinte equação:

$$
\hat{\mathrm{P}}(\mathrm{t})=3,2820-0,0104 \mathrm{t}+0,2079 \cos \left(\frac{2 \pi \mathrm{t}}{12}-2,3936\right)
$$




\section{b) Quantidade}

A análise harmônica aplicada às quantidades de trigo, durante o período de estudo fornece os seguintes resultados:

$$
\begin{aligned}
& \hat{Q}(t)=1026,8557-0,7045 t-1222,1074 \cos \frac{2 \pi t}{12}-992,5877 \operatorname{sen} \frac{2 \pi t}{12}+194,3504 \cos \frac{4 \pi t}{12}+ \\
& \left(-1,757^{*}\right) \quad\left(-31,137^{* *}\right) \quad\left(-25,274^{* *}\right) \quad\left(4,972^{* *}\right) \\
& 911,0126 \operatorname{sen} \frac{4 \pi \mathrm{t}}{12}+147,6295 \cos \frac{6 \pi \mathrm{t}}{12}-342,6295 \operatorname{sen} \frac{6 \pi \mathrm{t}}{12}-22,9163 \cos \frac{8 \pi \mathrm{t}}{12}+64,2656 \operatorname{sen} \frac{8 \pi \mathrm{t}}{12}- \\
& \begin{array}{lllll}
(23,209 * *) & \left(3,762^{* *}\right) & (-8,730 * *) & (-0,584)
\end{array} \\
& 23,6085 \cos \frac{10 \pi \mathrm{t}}{12}-52,4305 \operatorname{sen} \frac{10 \pi \mathrm{t}}{12}-5,4311 \cos \frac{12 \pi \mathrm{t}}{12} \\
& (-0,602) \quad(-1,336) \quad(-0,196) \\
& \mathrm{R}^{2}=0,91 \quad \mathrm{~F}=189,171^{* *} \\
& \text { ** Significativamente diferente de zero ao nivel de 0,05 de probabilidade } \\
& \text { * Significativamente diferente de zero ao nivel de 0,10 de probabilidade } \\
& \text { Os valores entre parênteses abaixo dos coeficientes são os valores obtidos no teste " } t \text { " }
\end{aligned}
$$

Escrevendo a equação (4.11) em termos de co-seno e ângulo fase, obtém-se a seguinte equação:

$$
\begin{aligned}
\hat{Q}(t)= & 1026,8557-0,7045 t+1574,4132 \cos \left(\frac{2 \pi t}{12}-3,8237\right)+931,5128 \cos \left(\frac{4 \pi t}{12}-1,3606\right)+ \\
& 373,0810 \cos \left(\frac{6 \pi t}{12}-1,9776\right)
\end{aligned}
$$

Em relação às séries de preços e quantidades da cultura de trigo, observa-se que as variações se concentram na faixa de um ciclo por ano, indicando forte influência do ciclo biológico dessa cultura sobre seus preços e quantidades produzidas.

A análise para a variável tendência para as séries de preços e quantidades produzidas é significativamente decrescente como pode ser observado na tabela B.1 e visualizado nas figuras 10 e 11 . Esse resultado indica que houve perda real por parte dos 
produtores ao longo do período analisado, o que ocasionou redução da área reservada a essa cultura, e substituição por outras culturas com maior rentabilidade como batata, a qual tem uma maior produtividade, ou por pastagens. O desestímulo dos produtores agrava-se ainda mais devido às políticas do governo de importar ${ }^{7}$ esses produtos de países onde os preços são muito inferiores aos custos de produção interna.

As perdas reais dos produtores das cultura do trigo é de $68 \%$ da média no período 1975-1980 comparado com o período 1989-1994 (tabela A.4). Esses resultados corroboram com os encontrados por Dancourt \& Mendoza (1994), que observaram perdas para essa cultura superiores a $20 \%$ comparado o período de 1988 - 1990 com o período $1990-1992$.

Para as quantidades produzidas, a diminuição é suave ao longo dos anos, observando-se uma redução nos últimos anos. Isso se deve, provavelmente, à redução da área plantada devido a sua baixa rentabilidade e ao desestímulo dos produtores devido aos preços baixos (tabela A.7).

Os coeficientes de determinação foram respectivamente de $62 \%$ para as séries de preços e $91 \%$ para as de quantidades, o que é considerado um bom ajustamento.

\footnotetext{
${ }^{7}$ As importações de trigo mantêm-se no Peru na ordem de 380.000 toneladas/ano para satisfazer o mercado interno, mas nos últimos 5 anos as importações estão aumentando acima do $20 \%$ da média histórica das importações. GALLARDO, J. (1994). Efectos del ajuste estructural sobre los determinates de la produtividad en la economía campesina.
} 


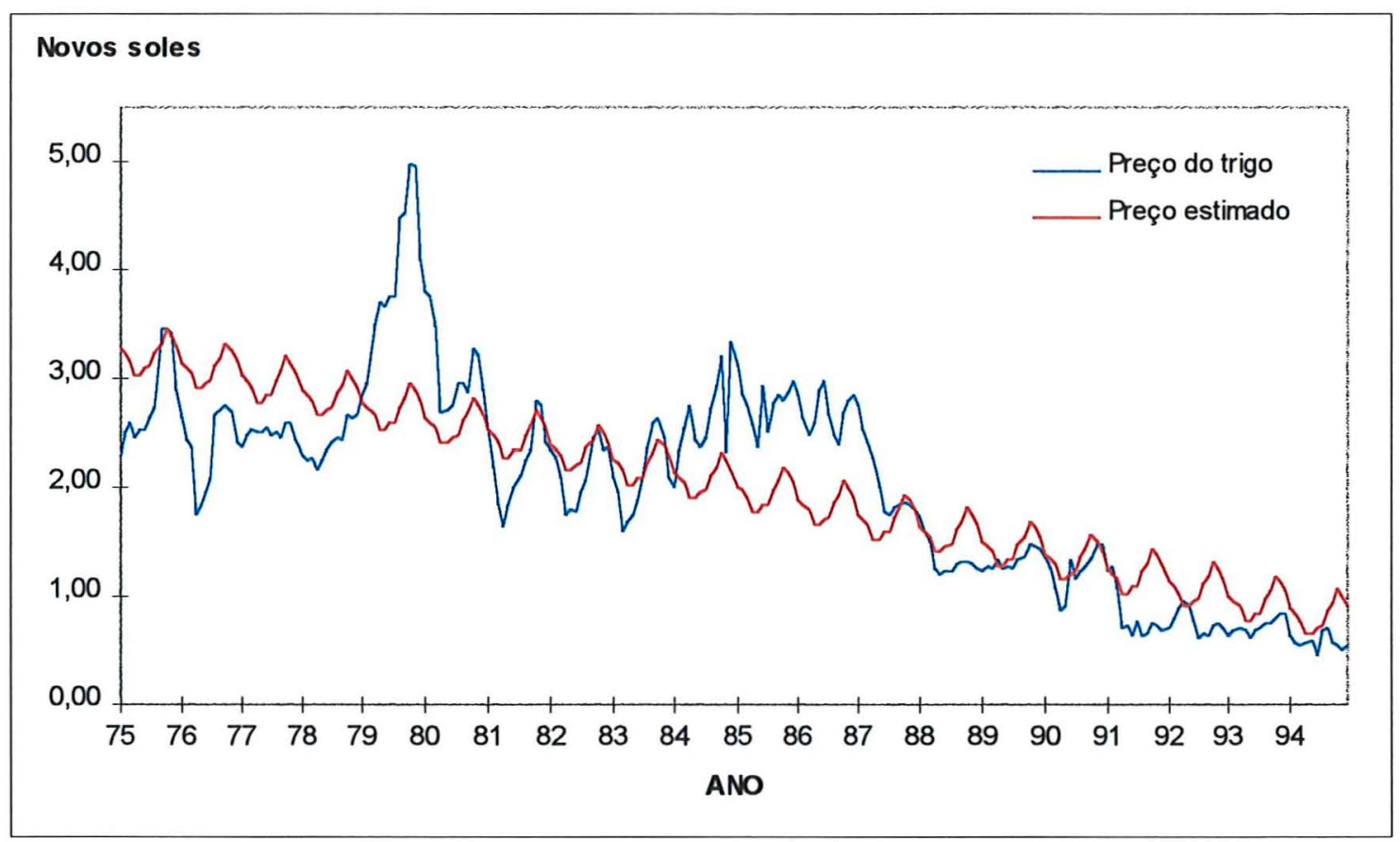

Figura 10 - Comparação entre preços deflacionados do trigo e preços estimados pelo modelo harmônico no período 1975 - 1994.

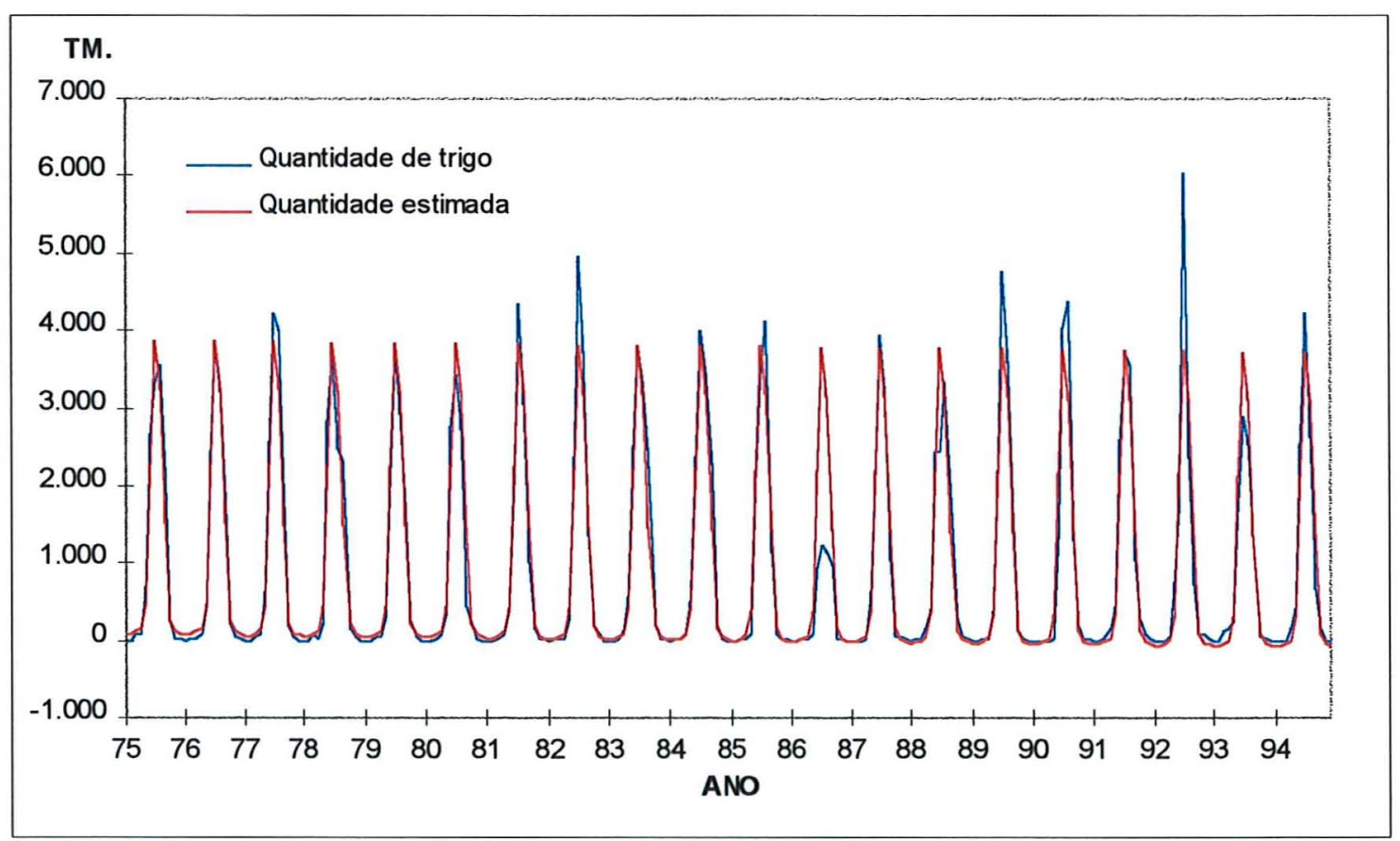

Figura 11 - Comparação entre quantidades produzidas de trigo e quantidades estimadas pelo modelo harmônico no período 1975 - 1994. 


\subsubsection{Análise utilizando-se variáveis binárias}

$\mathrm{Na}$ tabela B.2 do apêndice B estão apresentadas as estimativas dos preços e quantidades da cultura de trigo obtidas através da utilização de variáveis binárias. Para os preços observam-se dois períodos, um período superior à média $(2,024)$ nos meses de agosto a dezembro, e inferior a essa média de janeiro a julho (sinal negativo), mas essas diferenças não são estatisticamente significativas $(\mathrm{P}>0,10)$, indicando uma ligeira estabilidade dos preços no transcorrer do ano.

Em relação às quantidades produzidas de trigo, observa-se que essas são superiores à média $(941,958)$ de julho a setembro, que corresponde ao período de safra, o que acompanha o período sazonal das precipitações da região que se observa na tabela A.9. O período de entressafra para esta cultura corresponde aos meses de outubro a maio (sinal negativo), período no qual as quantidades produzidas são estatisticamente inferiores à média. Observa-se que as quantidades produzidas desta cultura são fortemente influenciadas pelo ciclo biológico, mas os preços apresentam poucas variações devido, provavelmente, ao fato de ser uma cultura que não abastece a necessidade do mercado interno, e por conseqüência o governo importa e determina o preço do produto.

\subsubsection{Análise utilizando-se média aritmética móvel centralizada}

As estimativas do componente estacional para a cultura de trigo podem ser observadas na tabela B.5 do apêndice B. Mostrando a existência de instabilidade para os preços e quantidades produzidas desse produto.

O componente estacional para as quantidades produzidas de trigo mostram sinais

positivos (superiores à média), no período de junho a setembro, isto é, no período de safra com resultados muito similares aos obtidos utilizando-se variáveis binárias (tabela B.2 do apêndice B). Nos meses de outubro a maio apresentam sinal negativo. $\mathrm{Na}$ realidade, nessa época a produção é praticamente nula, o que indica que vem a constituir, na maioria dos casos, uma cultura complementar na atividade agrícola dos Andes do Peru. 
As estimativas do componente estacional obtidas pela média aritmética móvel para os preços da cultura de trigo são superiores a média (sinal positivo) nos meses de agosto a janeiro, negativos (inferiores a média) nos meses de fevereiro a junho.

Os índices irregulares que estimam a variabilidade da série temporal, apresentamse muito baixos para os preços, indicando que o preço do trigo é mais estável. Para as quantidades produzidas o comportamento é diferente: alta variabilidade no período de safra e baixa variabilidade no período de entressafra.

As variações estacionais dos preços e quantidade da cultura de trigo, podem ser visualizadas nas figuras $12 \mathrm{e} 13$. 


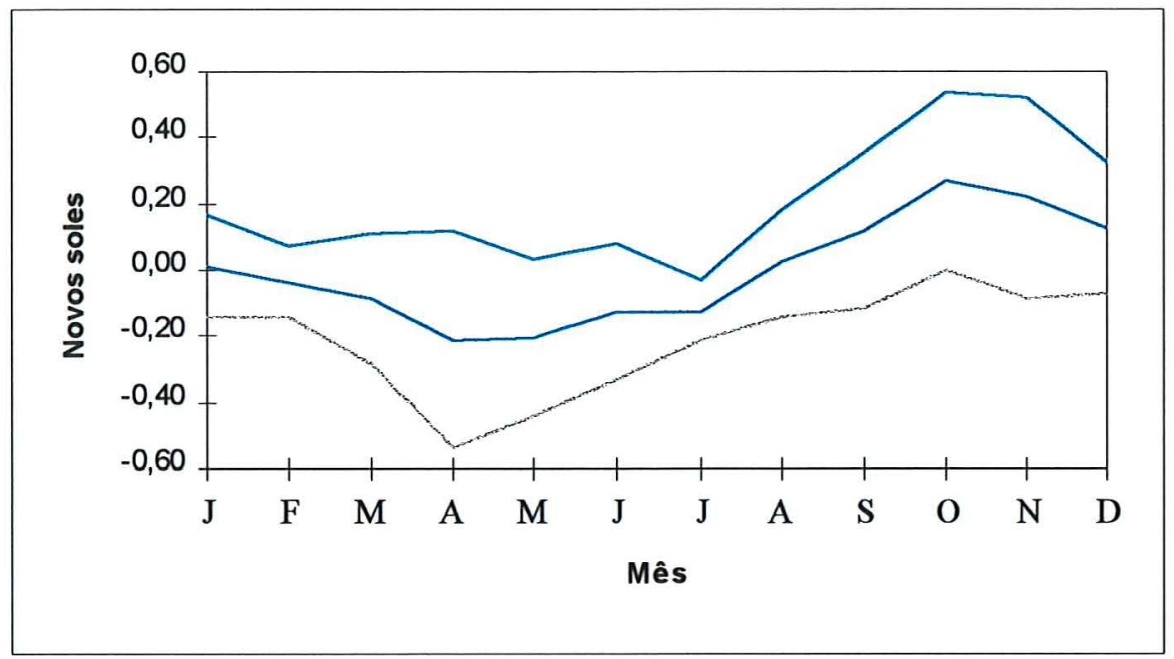

Figura 12 - Variação estacional do preço de trigo obtidas pelo método da média aritmética móvel centralizada, no Departamento de Cajamarca, período 1975 - 1994.

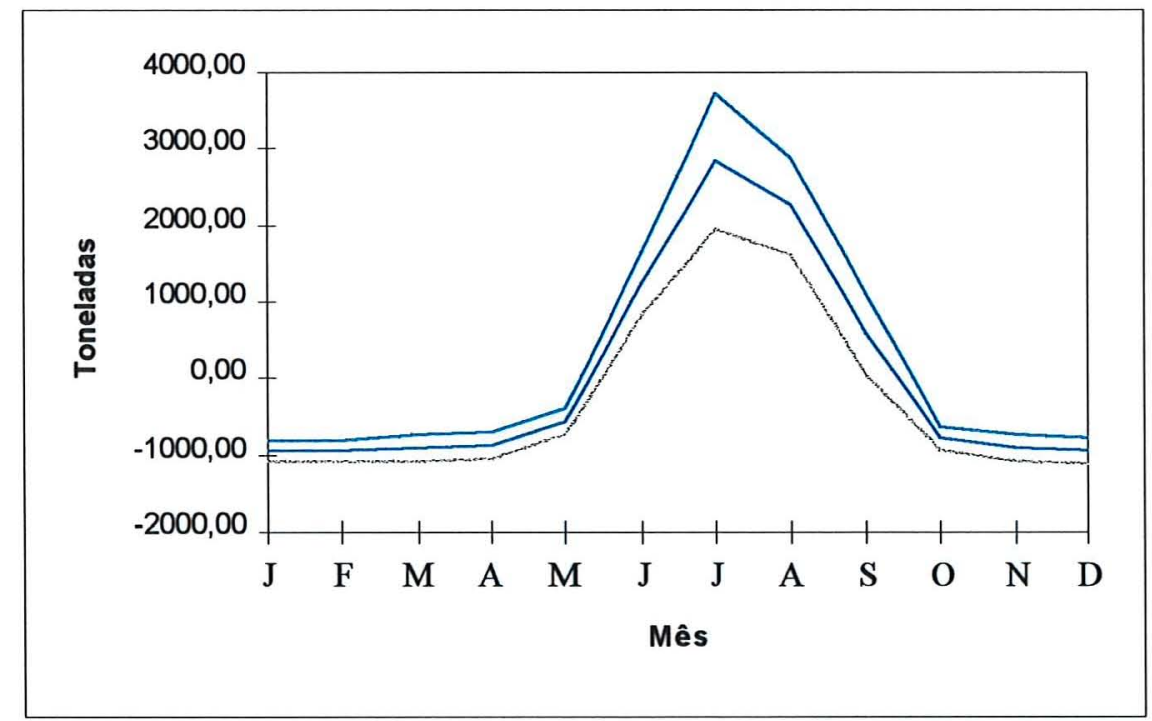

Figura 13 - Variação estacional da quantidade de trigo obtidas pelo método da média aritmética móvel centralizada, no Departamento de Cajamarca, período 1975 - 1994. 


\subsection{Análise das variações da cultura da cevada}

\subsubsection{Análise harmônica}

As estimativas dos parâmetros da série de preços e quantidades utilizando-se análise harmônica para a cultura da cevada encontra-se na tabela B1 do apêndice B.

\section{a) Preços}

A Análise harmônica aplicada aos preços reais mensais da cevada, durante o período de estudo fornece os seguintes resultados:

$$
\begin{aligned}
& \hat{\mathrm{P}}(\mathrm{t})=2,3685-0,0080 \mathrm{t}+0,1286 \cos \frac{2 \pi \mathrm{t}}{12}-0,0292 \operatorname{sen} \frac{2 \pi \mathrm{t}}{12}+0,0133 \cos \frac{2 \pi \mathrm{t}}{12}- \\
& 0,0486 \operatorname{sen} \frac{4 \pi \mathrm{t}}{12}-0,0160 \cos \frac{6 \pi \mathrm{t}}{12}-0,0193 \operatorname{sen} \frac{6 \pi \mathrm{t}}{12}+0,0166 \cos \frac{8 \pi \mathrm{t}}{12}-0,0058 \operatorname{sen} \frac{8 \pi \mathrm{t}}{12}+ \\
& (-1,222) \quad\left(-0,798^{* *}\right)\left(3,235^{* *}\right) \quad(-0,701) \quad(0,418) \\
& 0,0065 \cos \frac{10 \pi \mathrm{t}}{12}+0,0035 \operatorname{sen} \frac{10 \pi \mathrm{t}}{12}+0,0034 \cos \frac{12 \pi \mathrm{t}}{12} \\
& \begin{array}{c}
(0,163) \quad(0,089) \\
\mathrm{R}^{2}=0,64 \quad \mathrm{~F}=31,537 * *
\end{array}
\end{aligned}
$$

Escrevendo a equação (4.13) em termos de co-seno e ângulo fase, obtém-se a seguinte equação:

$$
\hat{\mathrm{P}}(\mathrm{t})=2,3685-0,0080 \mathrm{t}+0,1319 \cos \left(\frac{2 \pi \mathrm{t}}{12}-2,9183\right)
$$

\section{b) Quantidade}

A análise harmônica aplicada às quantidades de cevada, durante o período de estudo fornece os seguintes resultados: 


$$
\begin{aligned}
& \hat{Q}(t)=783,2452-0,7106 t-1055,4397 \cos \frac{2 \pi t}{12}-466,0566 \operatorname{sen} \frac{2 \pi t}{12}+421,9481 \cos \frac{4 \pi t}{12}+ \\
& \left(-2,353^{* *}\right)\left(-35,716^{* *}\right) \quad\left(-15,761^{* *}\right) \quad\left(14,279^{* *}\right) \\
& 544,4461 \operatorname{sen} \frac{4 \pi \mathrm{t}}{12}-7,5644 \cos \frac{6 \pi \mathrm{t}}{12}-298,1023 \operatorname{sen} \frac{6 \pi \mathrm{t}}{12}-97,1186 \cos \frac{8 \pi \mathrm{t}}{12}+22,1864 \operatorname{sen} \frac{8 \pi \mathrm{t}}{12}+ \\
& \left(18,422^{* *}\right) \quad(-0,256) \quad\left(-10,088^{* *}\right) \quad\left(-3,287^{* *}\right) \quad 12 \quad(0,751) \\
& 47,7359 \cos \frac{10 \pi \mathrm{t}}{12}+70,3975 \operatorname{sen} \frac{10 \pi \mathrm{t}}{12}-1,3697 \cos \frac{12 \pi \mathrm{t}}{12} \\
& (16,15) \quad(-0,066) \\
& \mathrm{R}^{2}=0,91 \quad \mathrm{~F}=189,171^{* *}
\end{aligned}
$$

Escrevendo a equação (4.15) em termos de co-seno e ângulo fase para o componente anual, obtém-se a seguinte equação:

$$
\begin{aligned}
\hat{Q}(t)= & 783,2452-0,7106 \mathrm{t}+1153,7598 \cos \left(\frac{2 \pi t}{12}-3,5574\right)+ \\
& 668,8118 \cos \left(\frac{4 \pi t}{12}-0,9115\right)
\end{aligned}
$$

Observa-se para esta cultura que os componentes harmônicos significativamente diferentes de zero também estão associados ao ciclo anual, como no caso das outras culturas. Esse comportamento se deve ao fato da cevada ser uma cultura anual e plantada na época de chuvas (ver tabela A9 do apêndice A). No caso das quantidades produzidas de cevada observa-se coeficientes significativos no par de variáveis: $\cos 4 \pi \mathrm{t} / 12+\operatorname{sen}$ $4 \pi \mathrm{t} / 12$ que corresponde aos ciclos de 6 meses. Pode-se, entretanto, verificar maior importância relativa para as quantidades de cevada produzidas no ciclo de 12 meses.

A análise da tendência para as séries de preços e quantidades produzidas é significativamente decrescente como no caso da cultura de trigo (figuras 14 e 15). Esse resultado indica que houve perda real por parte dos produtores, ao longo do período 
analisado, o que ocasionou a redução da área cultivada com essa cultura, e substituição para outras culturas com maior rentabilidade, principalmente batata.

A diminuição nos preços traduz-se numa queda de renda dos produtores. As perdas reais dos produtores da cultura da cevada é de $72 \%$ da média do período $75-80$ comparado com o período 89-94 (tabela A.4).

Os coeficientes de determinação observados foram de 64\% para as séries de preços e $91 \%$ para as séries de quantidades, considerando-se satisfatórios para a presente pesquisa.

Observa-se que, em todas as séries analisadas, o teste de "F" de Snedecor mostrou-se significativo. 


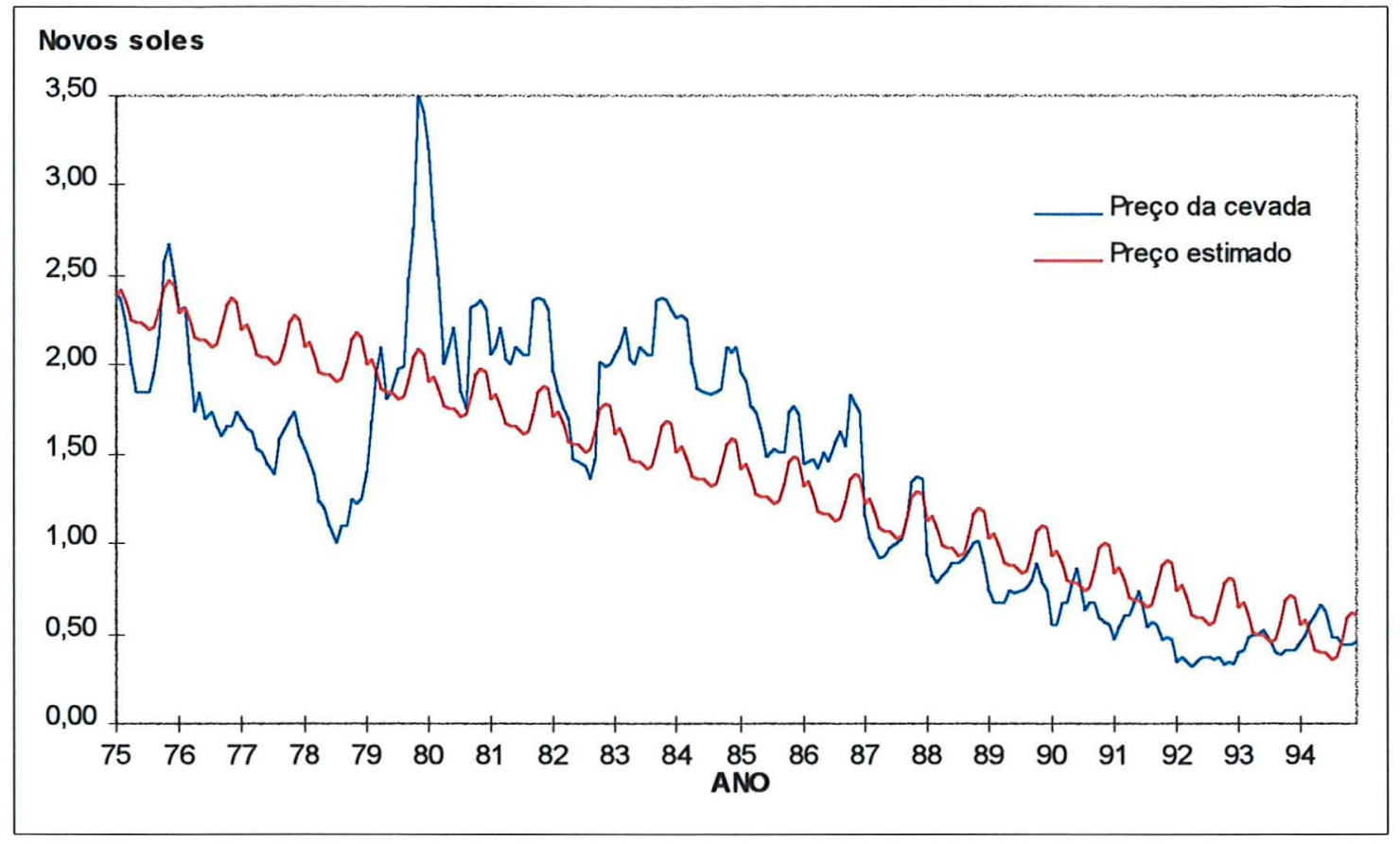

Figura 14 - Comparação entre preços deflacionados da cevada e preços estimados pelo modelo harmônico no período 1975 - 1994.

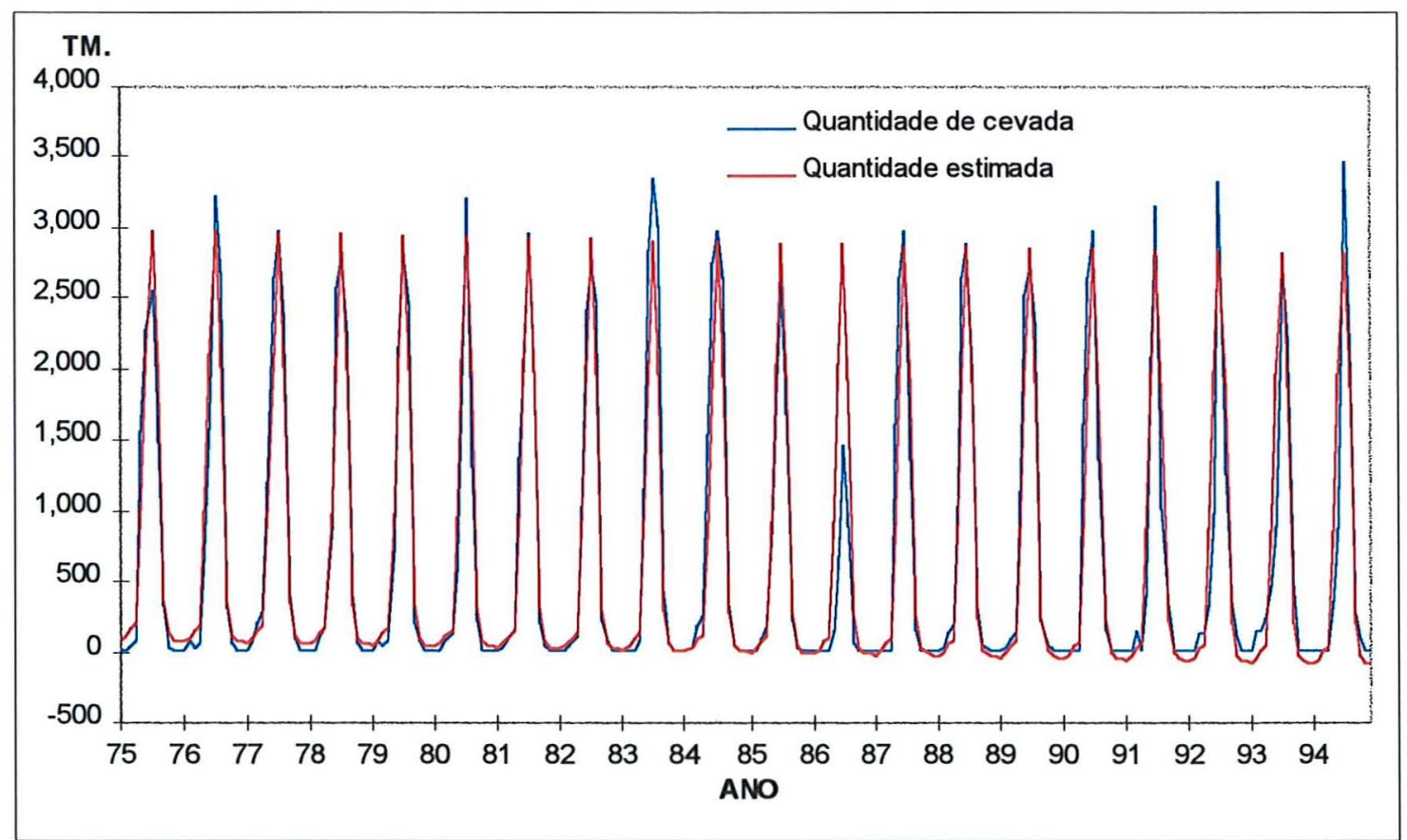

Figura 15 - Comparação entre quantidades produzidas da cevada e quantidade estimada pelo modelo harmônico no período 1975 - 1994. 


\subsubsection{Análise utilizando-se variáveis binárias}

Observa-se para a cultura da cevada que as médias mensais ou constantes sazonais (tabela B.2) apresentam um comportamento muito parecidas ao da cultura de trigo. Isso se deve ao fato de serem culturas muito similares no que se refere as práticas culturais, além de serem em alguns casos, culturas complementares da batata e milho, que são as preferidas do agricultor andino.

Os preços da cevada apresentam-se superiores à média (1,399 novos soles), nos meses de setembro a fevereiro (sinal positivo); e inferiores à média nos meses de março a agosto, embora, essas médias mensais não sejam estatisticamente significativas $(P>0,10)$ como se observa na tabela B.2 do apêndice.

As quantidades produzidas são superiores estatisticamente $(\mathrm{P}<0,05)$ à média $(697,617)$ de maio a agosto, e inferiores estatisticamente segundo a análise binária para os meses de setembro a abril. Semelhante à cultura de trigo, os preços não mostram grandes variações, devido às importações do produto no período de entressafra, embora os preços aumentem ligeiramente depois de finalizado o período de safra.

\subsubsection{Analise utilizando-se média aritmética móvel centralizada}

As estimativas do componente estacional calculadas pela média móvel da cultura de cevada podem ser visualizadas na tabela B.6 do apêndice B, indicando instabilidade nos preços e quantidades produzidas desta cultura.

Essas estimativas para as quantidades produzidas de cevada mostram sinais positivos (superiores à média), no período de maio até agosto. Essa cultura tem características muito similares a do trigo. Nos meses de setembro a abril apresentam sinal negativo quando a produção é praticamente nula. Na maioria dos casos é uma cultura complementar na atividade agrícola dos Andes do Peru, assim como o trigo.

As aestimativas do componente estacional dos preços da cultura de cevada mostram-se superiores a média (sinal positivo) nos meses de setembro a janeiro e negativos (inferiores a média), nos meses de fevereiro a agosto. Essas estimativas são similares às constantes sazonais $\left(\alpha_{\mathrm{j}}\right)$ obtidas utilizando-se variáveis binárias. 
Os índices irregulares no caso de preços são baixos indicando que o preço da cevada é mais estável. Para as quantidades produzidas o comportamento é diferente, alta variabilidade no período de safra e baixa variabilidade no período de entressafra como no caso da cultura de trigo.

As variações estacionais dos preços e quantidades da cevada e suas flutuações podem ser facilmente visualizadas nas figuras 16 e 17 . 


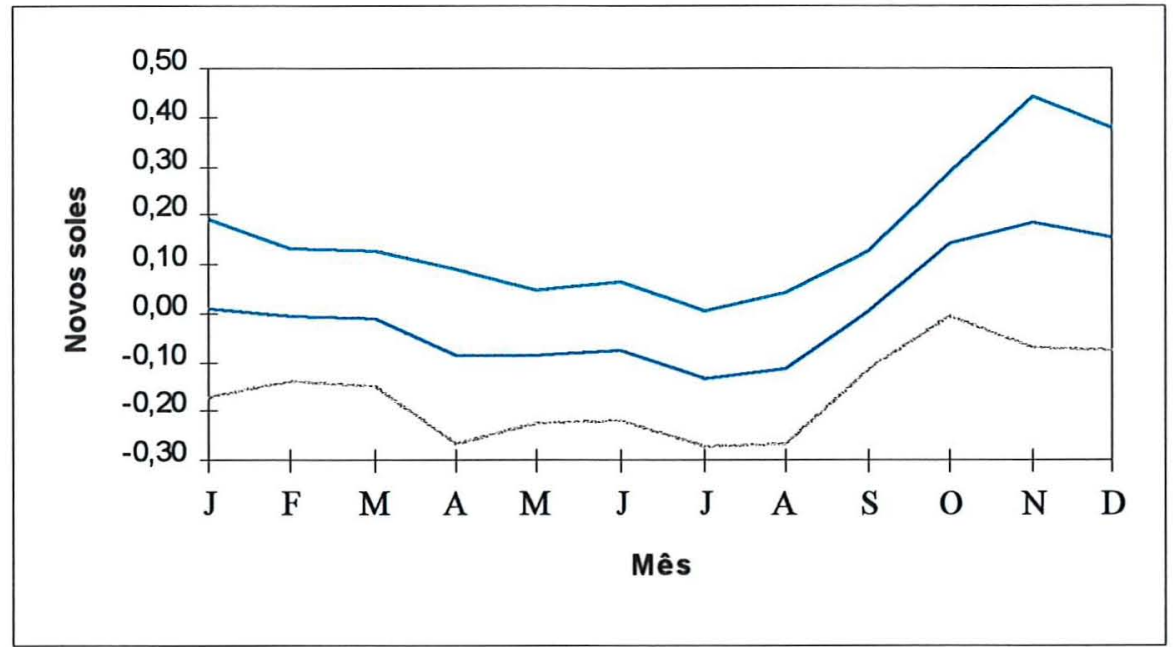

Figura 16 - Variação estacional do preço da cevada obtidas pelo método da média aritmética móvel centralizada, no Departamento de Cajamarca, período 1975 - 1994.

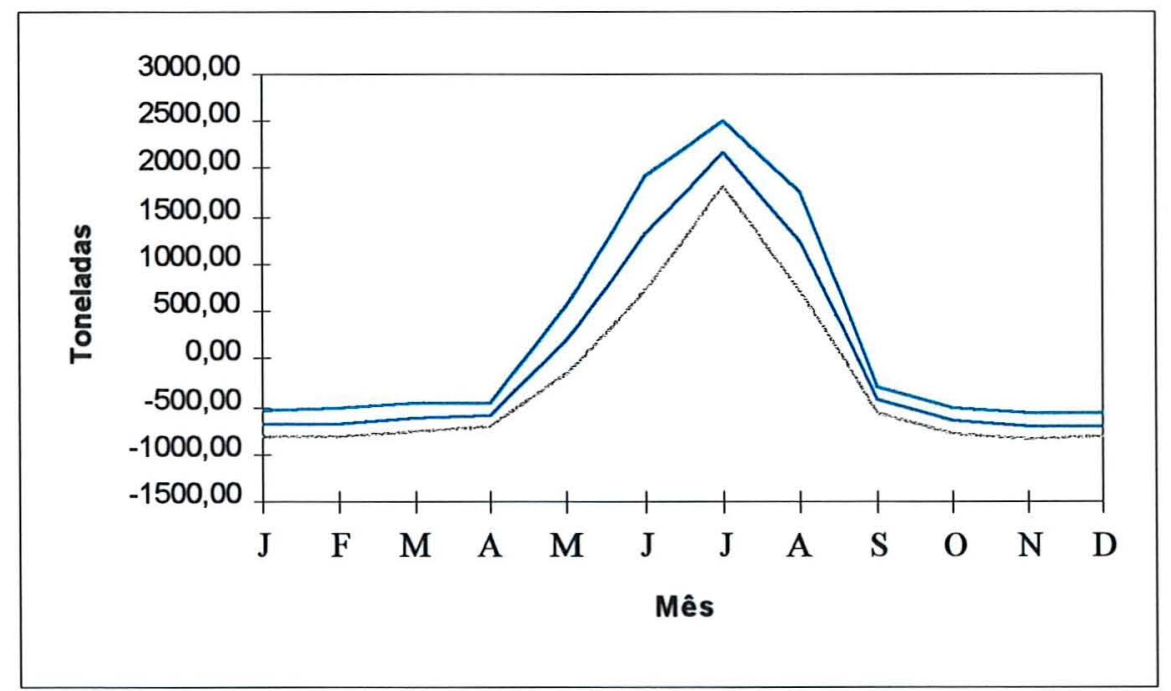

Figura 17 - Variação estacional da quantidade da cevada obtidas pelo método da média aritmética móvel centralizada, no Departamento de Cajamarca, período 1975 - 1994. 


\subsection{Estimativas da amplitude e fase nos modelos de análise harmônica}

Tabela 5 - Estimativas da amplitude e fase obtidos dos modelos de análise harmônica das séries de preços e quantidades de batata, milho, trigo e cevada.

\begin{tabular}{ccccc}
\hline Culturas & \multicolumn{2}{c}{ Amplitude } & \multicolumn{2}{c}{ Fase (12 meses) } \\
\cline { 2 - 5 } & $(\mathrm{P})$ & $(\mathrm{Q})$ & $(\mathrm{P})$ & $(\mathrm{Q})$ \\
\hline Batata & 0,2201 & 2771,91 & 3,9514 & 0,6137 \\
Milho & 0,1749 & 5267,20 & 0,2995 & 3,2277 \\
Trigo & 0,2079 & 1574,42 & 2,3936 & 3,8237 \\
Cevada & 0,1319 & 1153,76 & 2,9183 & 3,5574 \\
\hline
\end{tabular}

As amplitudes dos ciclos das séries de preços foram de $0,22,0,17,0,20$ e 0,13 para batata, milho, trigo e cevada, respectivamente (tabela 5). Essas amplitudes das séries de preços, dão idéia de variabilidade em torno da média da série. Observa-se que esta variabilidade é menor para a cultura de cevada e maior na cultura de batata.

No que se refere às séries de quantidades, observa-se grande variação nas culturas estudadas. A variabilidade em torno da média foi maior para o milho com relação as culturas de cevada e trigo. Essa forte variabilidade das culturas andinas se deve provavelmente às condições climáticas da região, o que acarreta riscos e desestímulo aos produtores.

\subsection{Fatores que influem na variação dos preços e quantidades}

A seguir são analisadas as possíveis causas de variações dos preços e quantidades das culturas andinas estudadas para o período que abrange desde 1975 até 1994.

As quantidades produzidas das culturas andinas estão fortemente influenciadas pela sazonalidade das precipitações pluviométricas na região, que ocorrem de outubro a março (tabela A.9 do apêndice A).

O plantio das culturas de trigo e cevada acompanham a sazonalidade das precipitações e as safras concentram-se em sua totalidade nos meses de junho a agosto 
com mais do $80 \%$ do total anual produzido. Essas culturas são plantadas para subsistência dos produtores e cultivadas em solos muito pobres e marginais, sem adubação e sem irrigação. Os preços dessas culturas não necessariamente aumentam na época de entressafra devido às importações do produto e, conseqüentemente, os preços mantêm-se estáveis durante o ano.

No caso da batata, e eventualmente o milho, a sazonalidade das precipitações também tem grande influência, mas essas culturas, por terem maior rentabilidade para os produtores, são plantadas nos melhores solos e, em alguns casos, em solos irrigados (na região andina corresponde a menos de $5 \%$ das terras de uso agrícola). Entretanto, o preço da batata é influenciado pelas épocas de safra e entressafra por ser um produto perecível.

O comportamento das variações sazonais das culturas andinas do Peru é diferente do encontrados por Hoffmann (1969) no estudo das variações sazonais de produtos hortícolas no Estado de São Paulo, que observou que as variações desses produtos eram afetadas principalmente pela temperatura, por serem irrigadas.

Observa-se em todas as culturas estudadas uma paulatina diminuição dos preços reais ao longo dos anos. Os incrementos que se observam em alguns intervalos não conseguiram reverter a tendência decrescente.

Esses incrementos são na realidade pontuais, ocorrendo nos períodos finais ou iniciais dos diferentes governos que dirigiram o país (Períodos 1975-80, 80-85, 85-90, 90-95). Eles buscavam recuperar o diferencial de preços perdido com políticas anteriores de congelamento (tabelamento) dos preços dos produtos e supervalorização da moeda nacional em relação ao dólar.

A supervalorização da moeda não somente aumentou as importações dos produtos mas também causou queda dos preços internos. Essa característica se repete no período 90-94 após o ajustamento econômico do governo atual.

As perdas reais do preço da batata são de $56 \%$ ao se comparar a média do período $98-94$ com a média do período $75-80$, $65 \%$ para o milho, $68 \%$ e $72 \%$ para trigo e cevada, respectivamente, nos mesmos períodos, como pode ser observado nas tabelas 
A.1 até A.4 do apêndice A. Esses resultados confirmam os observados por Dancourt $(1994)^{8}$.

Provavelmente outro fator muito importante que contribuiu probabelmente para a redução dos preços dos produtos andinos nos centros de produção é o custo do transporte, dado que os centros de produção desses produtos andinos encontram-se a longas distâncias dos centros de consumo. O problema agrava-se ainda mais pelas estradas deficientes devido às condições topográficas da região. Segundo Figueroa $(1992)^{9}$, quanto maior é a distância entre o centro produtor e o consumidor, menor é o preço no centro produtor.

Com relação à produção, observa-se níveis baixos devido à falta de investimentos, basicamente em tecnologia, estímulos às exportações e melhores preços das culturas. As quantidades produzidas ao longo dos anos não apresentam tendência decrescente significativa nas culturas de batata e milho. Entretanto, existe uma pequena diminuição no período 1991 a 1994, devido provavelmente à restrição do crédito agrícola barato, que era mantido com políticas populistas da década anterior, originando a diminuição do número de hectares plantados ${ }^{10}$. A diminuição da produção nos anos 81,86 e 87 deve-se às fortes secas ocorridas na região de estudo.

8 DANCOURT, O (1994). Observa que no ano de 1992, o preço real no centro de produção caiu em relação ao período 1985-1990 (governo de García) em 22\% para a batata, 20\% para o trigo, $9 \%$ para o arroz. Obra: Agricultura y política de estabilización en el Perú.

9 FIGUEROA, A (1992) A elevação dos preços dos combustíveis resulta não só no fato dos preços dos produtos serem menores na fazenda, mas também no fato de baixarem em menor proporção, quanto mais distante for o centro de produção do centro de consumo. Porém, os produtores situados perto das cidades apropriam-se de uma renda diferencial, isto é, recebem um preço maior no centro de produção do que os produtores situados a distâncias cada vez maiores. Obra: La agricultura peruana y el ajuste económico.

${ }^{10}$ A superficie de terras plantadas no Peru (milhões de hectares) para o milho nos anos 87-93: 454, 478, $448,323,343,276,360$, para o trigo; 102, 115, 118, 82, 102, 70, 81. Anuários estadísticos de América Latina y el Caribe, Edições 1987-1993. 


\subsection{Políticas econômicas agrícolas recomendadas para a produção e preços}

Considera-se como um aspecto importante a eliminação de obstáculos na comercialização, distorções de preços e prejuízos na agricultura, como a intervenção do governo com políticas de congelamento (tabelamento) de preços. Como é conhecido, os preços servem de estímulo aos produtores para que dediquem seus recursos à atividades que tenham maiores vantagens comparativas. As distorções que existem na agricultura fazem com que os produtores se sintam cada vez menos estimulados a aumentar a produção e, conseqüentemente, ocorre a descapitalização do setor agrícola como atualmente se observa no Peru.

Os produtores andinos devem diversificar suas atividades, buscando ter ganhos complementares que permitam, por um lado a adaptação melhor à sazonalidade dos ganhos provenientes da agricultura e, por outro, dispor de fundos que financiem as necessidades imediatas do consumo para poder armazenar parte da sua produção e vender em épocas de entressafra para obter melhores preços.

Para a atividade de armazenamento, dada a existência de padrões cíclicos dos produtos andinos, deve ser implementada a política de formação de estoques na época de safra, além do fornecimento de ajuda financeira aos produtores individuais, cooperativas ou comunidades camponesas.

O governo deve seguir fomentando a integração regional basicamente com os países do Grupo Andino, ${ }^{11}$ propondo zonas de livre comércio com a finalidade de aumentar suas exportações, principalmente das culturas de batata e milho para obter melhores preços para os produtores.

Também deve incentivar a instalação de pequenas agroindústrias com a finalidade de aumentar o valor agregado dos produtos e criar um mercado mais estável para os produtos. Nesta região, é necessário, basicamente, moinhos para grãos, e secadoras para tubérculos.

\footnotetext{
${ }^{11}$ Os países do grupo Andino são formados pela Bolívia, Colômbia, Equador, Peru e Venezuela, mas o Peru retirou-se temporariamente do Grupo em Outubro de 1992. Fonte: Estúdio Económico Mundial, Naciones Unidas, anos 1977-1993.
} 


\subsection{Previsões dos preços e quantidades dos principais produtos andinos}

Nas tabelas 6 a 13 são apresentados os valores observados dos preços e quantidades das séries originais, assim como as previsões conforme à análise harmônica para o período 1991 a 1995.

Esse período é muito importante na política econômica do Peru, já que foi um processo de estabilidade econômica, depois de um período de mais de 10 de anos de forte inflação.

De modo geral, as previsões utilizando-se a análise harmônica para preços podem ser consideradas boas. As estimativas das quantidades produzidas, assim como as previsões de curto prazo pelos modelos de regressão (harmônico ou binário) também foram boas, como pode ser observado nas tabelas 7, 9, 11 e 13. Isso se deve à característica determinística da série que facilita obter previsões devido ao padrão de repetição constante. Com isto, confirma-se a hipótese de que as quantidades produzidas das culturas andinas se repetem em forma quase constante todos os anos.

Obter modelos para analisar sazonalidade e prever preços e quantidades de produtos agrícolas na região andina do Peru é de grande importância para orientar produtores, comerciantes e entidades governamentais. Eles serão capazes de utilizar insumos na produção de forma mais planejada, tomar decisões de venda e compra no local e épocas apropriadas para maximizar o lucro, e orientar políticas governamentais na área agrícola. Além disso, espera-se que sirva de subsídio para futuros estudos sobre mercado futuro de "commodities" que, atualmente, não existe no Peru. 
Tabela 6 - Preços (p) e previsões reais de Kg. de batata obtidas utilizando-se análise harmônica, período 1991 - 1995.

\begin{tabular}{|c|c|c|c|c|c|c|c|c|c|}
\hline \multirow[t]{2}{*}{ ANO } & \multicolumn{2}{|c|}{1991} & \multicolumn{2}{|c|}{1992} & \multicolumn{2}{|c|}{1993} & \multicolumn{2}{|c|}{1994} & \multirow{2}{*}{$\frac{1995}{\text { Previsão }}$} \\
\hline & (P) & Previsão & (P) & Previsão & (P) & Previsão & (P) & Previsão $(\mathrm{P})$ & \\
\hline Jan. & 0,68 & 0,68 & 0,57 & 0,61 & 0,50 & 0,54 & 0,46 & 0,47 & 0,40 \\
\hline Fev. & 0,61 & 0,69 & 0,54 & 0,62 & 0,44 & 0,55 & 0,43 & 0,48 & 0,41 \\
\hline Mar. & 0,64 & 0,72 & 0,52 & 0,65 & 0,45 & 0,58 & 0,41 & 0,51 & 0,44 \\
\hline Abr. & 0,86 & 0,88 & 0,54 & 0,81 & 0,46 & 0,74 & 0,39 & 0,67 & 0,60 \\
\hline Maio & 0,58 & 0,95 & 0,55 & 0,88 & 0,54 & 0,81 & 0,43 & 0,75 & 0,68 \\
\hline Jun. & 0,55 & 0,95 & 0,58 & 0,88 & 0,55 & 0,82 & 0,50 & 0,75 & 0,68 \\
\hline Jul. & 0,51 & 1,04 & 0,57 & 0,97 & 0,56 & 0,90 & 0,49 & 0,83 & 0,76 \\
\hline Ago. & 0,46 & 1,05 & 0,55 & 0,98 & 0,62 & 0,92 & 0,65 & 0,85 & 0,78 \\
\hline Set. & 0,65 & 1,05 & 0,62 & 0,98 & 0,55 & 0,91 & 0,73 & 0,84 & 0,77 \\
\hline Out. & 0,99 & 1,00 & 0,76 & 0,93 & 0,55 & 0,86 & 0,55 & 0,79 & 0,72 \\
\hline Nov. & 0,77 & 0,75 & 0,59 & 0,68 & 0,51 & 0,61 & 0,45 & 0,54 & 0,47 \\
\hline Dez. & 0,73 & 0,62 & 0,47 & 0,55 & 0,50 & 0,48 & 0,45 & 0,42 & 0,35 \\
\hline
\end{tabular}

Tabela 7 - Quantidades (Q) e previsões das quantidades em TM. de batata utilizando-se análise harmônica, período 1991 - 1995.

\begin{tabular}{lrrrrrrrrr}
\hline ANO & \multicolumn{2}{c}{1991} & \multicolumn{2}{c}{1992} & \multicolumn{2}{c}{1993} & \multicolumn{2}{c}{1994} & \multicolumn{1}{c}{1995} \\
\cline { 2 - 10 } & \multicolumn{1}{c}{ (Q) } & Previsão & \multicolumn{1}{c}{ (Q) } & \multicolumn{1}{c}{ Previsão } & \multicolumn{1}{c}{ Q) } & \multicolumn{1}{c}{ Previsão } & \multicolumn{1}{c}{ (Q) } & Previsão (Q) & Previsão \\
\hline Jan. & 6.343 & $10.594,97$ & 8.070 & $10.604,50$ & 9.771 & $10.614,03$ & 10.345 & $10.623,5$ & $10.633,08$ \\
Fev. & 10.198 & $12.251,37$ & 6.596 & $12.260,90$ & 16.548 & $12.270,43$ & 10.234 & $12.279,9$ & $12.289,48$ \\
Mar. & 10.565 & $9.853,12$ & 9.471 & $9.862,65$ & 10.416 & $9.872,18$ & 8.797 & $9.881,7$ & $9.891,23$ \\
Abr. & 11.405 & $8.977,47$ & 10.972 & $8.987,00$ & 8.301 & $8.996,53$ & 5.678 & $9.006,0$ & $9.015,58$ \\
Maio & 10.389 & $7.701,37$ & 8.960 & $7.710,90$ & 7.837 & $7.720,43$ & 6.345 & $7.729,9$ & $7.739,48$ \\
Jun. & 9.478 & $6.488,62$ & 8.459 & $6.498,15$ & 7.406 & $6.507,68$ & 4.786 & $6.517,2$ & $6.526,73$ \\
Jul. & 7.294 & $6.238,42$ & 8.478 & $6.247,95$ & 6.395 & $6.257,48$ & 4.234 & $6.267,0$ & $6.276,53$ \\
Ago. & 7.479 & $5.957,87$ & 6.500 & $5.967,40$ & 7.675 & $5.976,93$ & 4.568 & $5.986,4$ & $5.995,98$ \\
Set. & 6.636 & $6.685,97$ & 5.639 & $6.695,50$ & 5.684 & $6.705,03$ & 5.435 & $6.714,5$ & $6.724,08$ \\
Out. & 10.037 & $8.965,72$ & 6.769 & $8.975,25$ & 6.143 & $8.984,78$ & 9.875 & $8.994,3$ & $9.003,83$ \\
Nov. & 6.386 & $10.191,82$ & 5.876 & $10.201,35$ & 12.305 & $10.210,88$ & 11.254 & $10.220,4$ & $10.229,93$ \\
Dez. & 9.250 & $11.018,82$ & 7.689 & $11.028,35$ & 13.308 & $11.037,88$ & 10.234 & $11.047,4$ & $11.056,93$ \\
\hline
\end{tabular}


Tabela 8 - Preços (p) e previsões de preços reais de $\mathrm{Kg}$. de milho utilizando-se análise harmônica, período 1991 - 1995.

\begin{tabular}{|c|c|c|c|c|c|c|c|c|c|}
\hline \multirow[t]{2}{*}{ ANO } & \multicolumn{2}{|c|}{1991} & \multicolumn{2}{|c|}{1992} & \multicolumn{2}{|c|}{1993} & \multicolumn{2}{|c|}{1994} & \multirow{2}{*}{$\frac{1995}{\text { Previsão }}$} \\
\hline & (P) & Previsão & (P) & Previsão & (P) & Previsão & (P) & Previsão (P) & \\
\hline Jan. & 1,42 & 1,43 & 0,89 & 1,32 & 0,85 & 1,22 & 0,64 & 1,11 & 1,01 \\
\hline Fev. & 1,32 & 1,37 & 0,84 & 1,27 & 0,73 & 1,16 & 0,66 & 1,06 & 0,95 \\
\hline Mar. & 1,23 & 1,32 & 0,83 & 1,22 & 0,66 & 1,11 & 0,63 & 1,01 & 0,90 \\
\hline Abr. & 1,05 & 1,21 & 0,72 & 1,10 & 0,60 & 1,00 & 0,64 & 0,89 & 0,79 \\
\hline Maio & 1,03 & 1,11 & 0,83 & 1,00 & 0,58 & 0,90 & 0,55 & 0,80 & 0,69 \\
\hline Jun. & 0,98 & 1,02 & 0,70 & 0,92 & 0,74 & 0,81 & 0,52 & 0,71 & 0,61 \\
\hline Jul. & 0,84 & 1,02 & 0,80 & 0,92 & 0,75 & 0,81 & 0,52 & 0,71 & 0,60 \\
\hline Ago. & 0,85 & 1,07 & 0,65 & 0,96 & 0,74 & 0,86 & 0,57 & 0,76 & 0,65 \\
\hline Set. & 0,84 & 1,17 & 0,62 & 1,06 & 0,95 & 0,96 & 0,59 & 0,86 & 0,75 \\
\hline Out. & 0,92 & 1,24 & 0,82 & 1,14 & 0,96 & 1,03 & 0,61 & 0,93 & 0,83 \\
\hline Nov. & 0,93 & 1,27 & 0,89 & 1,17 & 0,67 & 1,07 & 0,62 & 0,96 & 0,86 \\
\hline Dez. & 1,02 & 1,31 & 0,98 & 1,20 & 0,55 & 1,10 & 0,62 & 1,00 & 0,89 \\
\hline
\end{tabular}

Tabela 9 - Quantidades (Q) e previsões das quantidades em TM. de milho utilizando-se análise harmônica, período 1991 - 1995.

\begin{tabular}{|c|c|c|c|c|c|c|c|c|c|}
\hline \multirow[t]{2}{*}{$\mathrm{ANO}$} & \multicolumn{2}{|c|}{1991} & \multicolumn{2}{|c|}{1992} & \multicolumn{2}{|c|}{1993} & \multicolumn{2}{|c|}{1994} & \multirow{2}{*}{$\frac{1995}{\text { Previsão }}$} \\
\hline & $(\mathrm{Q})$ & Previsão & (Q) & Previsão & $(\mathrm{Q})$ & Previsão & (Q) & Previsão (Q) & \\
\hline Jan. & 5 & 0 & 2 & 0 & 34 & 0 & 15 & 0 & 0 \\
\hline Fev. & 84 & 136,43 & 3 & 111,42 & 363 & 86,41 & 57 & 61,4 & 36,39 \\
\hline Mar. & 127 & 379,38 & 348 & 354,37 & 360 & 329,36 & 478 & 304,3 & 279,34 \\
\hline Abr. & 1.476 & $2.636,63$ & 1.585 & $2.611,62$ & 1.814 & $2.586,61$ & 978 & $2.561,6$ & $2.536,59$ \\
\hline Maio & 5.187 & $7.086,63$ & 2.194 & $7.061,62$ & 8.796 & $7.036,61$ & 3.578 & $7.011,6$ & $6.986,59$ \\
\hline Jun. & 15.689 & $12.273,18$ & 10.510 & $12.248,17$ & 12.537 & $12.223,16$ & 10.568 & $12.198,1$ & $12.173,14$ \\
\hline Jul. & 13.290 & $11.371,73$ & 7.957 & $11.346,72$ & 8.833 & $11.321,71$ & 9.476 & $11.296,7$ & $11.271,69$ \\
\hline Ago. & 2.588 & $3.465,03$ & 960 & $3.440,02$ & 730 & $3.415,01$ & 1.345 & $3.390,0$ & $3.364,99$ \\
\hline Set. & 490 & 238,18 & 193 & 213,17 & 159 & 188,16 & 356 & 163,1 & 138,14 \\
\hline Out. & 26 & 11,53 & 49 & 0 & 5 & 0 & 87 & 0 & 0 \\
\hline Nov. & 278 & 0 & 25 & 0 & 2 & 0 & 137 & 0 & 0 \\
\hline Dez. & 80 & 0 & 4 & 0 & 2 & 0 & 23 & 0 & 0 \\
\hline
\end{tabular}


Tabela 10 - Preços $(\mathrm{P})$ e previsões de preços reais de Kg. de trigo utilizando-se análise harmônica, período 1991 - 1995.

\begin{tabular}{|c|c|c|c|c|c|c|c|c|c|c|}
\hline \multirow[t]{2}{*}{ ANO } & \multicolumn{2}{|c|}{1991} & \multicolumn{2}{|c|}{1992} & \multicolumn{2}{|c|}{1993} & \multicolumn{2}{|c|}{1994} & \multicolumn{2}{|c|}{1995} \\
\hline & (P) & Previsão & (P) & Previsão & (P) & Previsão & $(\mathrm{P})$ & Previsão & (P) & Previsão \\
\hline Jan. & 1,23 & 1,26 & 0,71 & 1,13 & 0,64 & 1,01 & 0,63 & 0,88 & & 0,76 \\
\hline Fev. & 1,28 & 1,21 & 0,79 & 1,09 & 0,69 & 0,96 & 0,56 & 0,84 & & 0,71 \\
\hline Mar. & 1,07 & 1,16 & 0,89 & 1,03 & 0,70 & 0,91 & 0,54 & 0,78 & & 0,66 \\
\hline Abr. & 0,71 & 1,03 & 0,96 & 0,90 & 0,69 & 0,78 & 0,56 & 0,65 & & 0,53 \\
\hline Maio & 0,73 & 1,02 & 0,92 & 0,90 & 0,62 & 0,77 & 0,58 & 0,65 & & 0,52 \\
\hline Jun. & 0,64 & 1,09 & 0,78 & 0,96 & 0,69 & 0,84 & 0,46 & 0,71 & & 0,58 \\
\hline Jul. & 0,78 & 1,10 & 0,61 & 0,97 & 0,71 & 0,85 & 0,68 & 0,72 & & 0,60 \\
\hline Ago. & 0,63 & 1,23 & 0,65 & 1,10 & 0,75 & 0,98 & 0,71 & 0,85 & & 0,73 \\
\hline Set. & 0,65 & 1,31 & 0,65 & 1,18 & 0,76 & 1,06 & 0,57 & 0,93 & & 0,81 \\
\hline Out. & 0,74 & 1,44 & 0,72 & 1,32 & 0,79 & 1,19 & 0,54 & 1,06 & & 0,94 \\
\hline Nov. & 0,73 & 1,38 & 0,76 & 1,26 & 0,84 & 1,13 & 0,50 & 1,01 & & 0,88 \\
\hline Dez. & 0,69 & 1,29 & 0,71 & 1,16 & 0,83 & 1,04 & 0,55 & 0,91 & & 0,79 \\
\hline
\end{tabular}

Tabela 11 - Quantidades (Q) e previsões das quantidades em TM. de trigo utilizando-se análise harmônica, período 1991 - 1995.

\begin{tabular}{lrrrrrrrrrr}
\hline ANO & \multicolumn{2}{c}{1991} & \multicolumn{2}{c}{1992} & \multicolumn{2}{c}{1993} & \multicolumn{2}{c}{1994} & \multicolumn{1}{c}{1995} \\
\cline { 2 - 11 } & (Q) & Previsão & (Q) & Previsão & (Q) & Previsão & $($ Q) & Previsão & (Q) & Previsão \\
\hline Jan. & 1 & 0 & 1 & 0 & 1 & 0 & 2 & 0 & 0 \\
Fev. & 1 & 0 & 3 & 0 & 2 & 0 & 2 & 0 & 0 \\
Mar. & 28 & 0 & 2 & 0 & 111 & 0 & 2 & 0 & 0 \\
Abr. & 153 & 20,65 & 46 & 12,19 & 159 & 3,74 & 151 & 0 & 0 \\
Maio & 419 & 330,30 & 751 & 321,84 & 248 & 313,39 & 415 & 304,93 & 296,48 \\
Jun. & 2.595 & $2.151,45$ & 1.630 & $2.142,99$ & 1.673 & $2.134,54$ & 2.548 & $2.126,08$ & $2.117,63$ \\
Jul. & 3.690 & $3.748,35$ & 6.049 & $3.739,89$ & 2.878 & $3.731,44$ & 4.238 & $3.722,98$ & $3.714,53$ \\
Ago. & 3.557 & $3.112,75$ & 2.391 & $3.104,29$ & 2.538 & $3.095,84$ & 2.618 & $3.087,38$ & $3.078,93$ \\
Set. & 1.053 & $1.375,80$ & 724 & $1.367,34$ & 1.368 & $1.358,89$ & 670 & $1.350,43$ & $1.341,98$ \\
Out. & 284 & 103,80 & 71 & 95,34 & 38 & 86,89 & 150 & 78,43 & 69,98 \\
Nov. & 75 & 0 & 80 & 0 & 20 & 0 & 2 & 0 & 0 \\
Dez. & 8 & 0 & 16 & 0 & 3 & 0 & 1 & 0 & 0 \\
\hline
\end{tabular}


Tabela 12 - Preços $(\mathrm{P})$ e previsões de preços reais de Kg. de cevada utilizando-se análise harmônica, período 1991 - 1995.

\begin{tabular}{lcrrrrrrrrr}
\hline ANO & \multicolumn{3}{c}{1991} & \multicolumn{2}{c}{1992} & \multicolumn{2}{c}{1993} & \multicolumn{2}{c}{1994} & \multicolumn{1}{c}{1995} \\
\cline { 2 - 10 } & (P) & Previsão & (P) & Previsão & (P) & Previsão & $(\mathrm{P})$ & Previsão & (P) & Previsão \\
\hline Jan. & 0,47 & 0,84 & 0,35 & 0,74 & 0,40 & 0,64 & 0,45 & 0,55 & 0,45 \\
Fev. & 0,54 & 0,87 & 0,37 & 0,78 & 0,42 & 0,68 & 0,49 & 0,58 & 0,49 \\
Mar. & 0,60 & 0,79 & 0,35 & 0,70 & 0,48 & 0,60 & 0,56 & 0,50 & 0,41 \\
Abr. & 0,61 & 0,71 & 0,32 & 0,61 & 0,49 & 0,51 & 0,61 & 0,42 & 0,32 \\
Maio & 0,68 & 0,69 & 0,34 & 0,59 & 0,50 & 0,50 & 0,66 & 0,40 & 0,30 \\
Jun. & 0,74 & 0,69 & 0,37 & 0,59 & 0,53 & 0,50 & 0,63 & 0,40 & 0,30 \\
Jul. & 0,54 & 0,64 & 0,37 & 0,55 & 0,46 & 0,45 & 0,48 & 0,35 & 0,26 \\
Ago. & 0,56 & 0,66 & 0,36 & 0,56 & 0,40 & 0,46 & 0,49 & 0,37 & 0,27 \\
Set. & 0,55 & 0,76 & 0,37 & 0,66 & 0,38 & 0,57 & 0,44 & 0,47 & 0,37 \\
Out. & 0,47 & 0,88 & 0,33 & 0,78 & 0,42 & 0,69 & 0,44 & 0,59 & 0,50 \\
Nov. & 0,48 & 0,92 & 0,34 & 0,82 & 0,42 & 0,72 & 0,45 & 0,63 & 0,53 \\
Dez. & 0,47 & 0,88 & 0,33 & 0,78 & 0,42 & 0,69 & 0,45 & 0,59 & 0,49 \\
\hline
\end{tabular}

Tabela 13 - Quantidades (Q) e previsões das quantidades em TM. de cevada utilizandose análise harmônica, período 1991 - 1995.

\begin{tabular}{lrrrrrrrrrr}
\hline ANO & \multicolumn{2}{c}{1991} & \multicolumn{2}{c}{1992} & \multicolumn{2}{c}{1993} & \multicolumn{2}{c}{1994} & \multicolumn{2}{c}{1995} \\
\cline { 2 - 11 } & (Q) & Previsão & (Q) & Previsão & (Q) & Previsão & (Q) & Previsão & (Q) & Previsão \\
\hline Jan. & 2 & 0 & 1 & 0 & 9 & 0 & 2 & 0 & 0 \\
Fev. & 15 & 0 & 1 & 0 & 143 & 0 & 1 & 0 & 0 \\
Mar. & 147 & 29,42 & 130 & 20,90 & 152 & 12,37 & 1 & 3,84 & 0 \\
Abr. & 6 & 59,62 & 126 & 51,10 & 236 & 42,57 & 1 & 34,04 & 25,51 \\
Maio & 400 & 872,87 & 327 & 864,35 & 462 & 855,82 & 367 & 847,29 & 838,76 \\
Jun. & 2.080 & $1.981,27$ & 976 & $1.972,75$ & 891 & $1.964,22$ & 867 & $1.955,69$ & $1.947,16$ \\
Jul. & 3.154 & $2.844,72$ & 3.324 & $2.836,20$ & 2.737 & $2.827,67$ & 3.467 & $2.819,14$ & $2.810,61$ \\
Ago. & 1.010 & $1.890,47$ & 1.253 & $1.881,95$ & 2.223 & $1.873,42$ & 2.045 & $1.864,89$ & $1.856,36$ \\
Set. & 320 & 220,27 & 344 & 211,75 & 463 & 203,22 & 268 & 194,69 & 186,16 \\
Out. & 18 & 0 & 108 & 0 & 5 & 0 & 97 & 0 & 0 \\
Nov. & 3 & 0 & 1 & 0 & 2 & 0 & 2 & 0 & 0 \\
Dez. & 2 & 0 & 1 & 0 & 1 & 0 & 2 & 0 & 0 \\
\hline
\end{tabular}




\section{CONCLUSÕES E SUGESTÕES}

Este estudo analisou as variações sazonais dos preços e quantidades das culturas de batata, milho, trigo e cevada na região andina do Peru, Departamento de Cajamarca.

Os resultados empíricos obtidos com o estudo evidenciam a existência de ciclos com período de 12 meses nas séries de preços e quantidades produzidas dessas culturas. Esse comportamento é um indicador de que, na época de safra dos produtos, que ocorre apenas uma vez por ano nesta região, as quantidades apresentam picos máximos e os preços tendem a apresentar quedas, que são ligeiramente mais acentuadas nas culturas mais perecíveis como é o caso da batata. O processo se reverte na entressafra, quando os preços tendem a subir e as quantidades tendem a diminuir.

As amplitudes das séries de preços e quantidades apresentam-se muito variadas. A série de preços de batata e a série de quantidades produzidas de milho apresentaram alta variância.

As médias mensais ou constantes sazonais obtidas utilizando-se variáveis binárias são muito similares às estimativas do componente estacional obtidas pela média móvel aritmética centralizada, embora a análise utilizando-se variáveis binárias forneça mais informações para se testar hipóteses.

A análise com função harmônica e utilizando-se variáveis binárias mostram-se muito eficientes para a determinação da sazonalidade determinística, como é o caso das quantidades produzidas das culturas, mas pouco eficientes para o caso dos preços que tem variabilidade estocástica. $\mathrm{O}$ método da média móvel é também eficiente para o ajustamento sazonal dos preços e das quantidades das culturas do presente estudo. 
Os preços dos produtos andinos estudados são decrescentes ao longo do tempo, o que acarreta aos produtores perdas reais ao longo do período analisado.

As quantidades produzidas das culturas no período de 1975 a 1994, em geral não mostraram tendências crescente ou decrescente significativa, indicando que os níveis de produção dessas culturas se mantêm ao longo dos anos. Isso ocorre, provavelmente, por não ter havido melhora no nível de tecnificação, de modo a permitir incrementos na produtividade das culturas. Outro fator é a não expansão da fronteira agrícola já que nessa região a maioria das terras agrícolas encontram-se cultivadas.

Provavelmente, o principal fator que determina a sazonalidade da produção é a sazonalidade das precipitações pluviométricas. Na região andina do Peru estas precipitações ocorrem nos meses de outubro a março correspondendo a mais de $80 \%$ da precipitação total anual.

As estimativas dos preços e quantidades para o curto prazo (1995), obtidas pelos modelos de regressão harmônica ou com variáveis binárias são consideradas boas. Espera-se que as previsões sirvam como meio de fornecimento de informações, principalmente aos produtores e autoridades com relação ao comportamento dos preços e da sazonalidade das quantidades produzidas a fim de fornecer informações para se fazer planejamentos com relação aos insumos utilizados na produção, e na tomada de decisões quanto ao local e época de venda dos produtos andinos.

Baseado nas variações sazonais dentro do ano, para as séries estudadas, sugere-se que sejam implementadas políticas de formação de estoques dos produtos na época de safra, que seriam comercializados na época de pico dos preços, que corresponde ao período de entressafra. Tal política poderia incrementar os níveis de bem-estar dos produtores que teriam uma renda mais estável no decorrer do ano. Também possibilitaria aos consumidores um melhor planejamento de compras, sem grandes oscilações de preços durante o ano. Esses produtos são de grande importância para os consumidores pois representam uma proporção substancial na cesta básica dessas famílias.

Outras políticas governamentais que sugerem-se para a região andina do Peru são as seguintes: 
1) No Peru e principalmente na região andina, a falta de alimentos e a desnutrição são problemas muito sérios. Assim sendo, o governo deve manter os preços dos alimentos básicos, consumidos principalmente pela população de baixa renda, em um patamar que seja acessível a esta população. $O$ aumento da produção de alimentos através do aproveitamento mais eficiente dos recursos naturais climatológicos e topográficos disponíveis, a diversidade de zonas ecológicas naturais e a diversidade de produtos pode, em grande parte, diminuir as perdas, aumentar a produtividade e, portanto, aliviar os problemas nutricionais.

2) O governo deve promover e facilitar o relacionamento entre as Universidades do país, institutos de pesquisa, comunidades camponesas e empresas produtivas agrárias para melhorar o nível tecnológico. Dessa forma se aumentaria a produção dos principais produtos alimentícios, assim como as fontes de trabalho, as quais são muito escassas na região andina, basicamente no período de entressafra.

3) Outra política que deve ser implementada é a assistência técnica para empresas coletivas nas zonas rurais, cooperativas e comunidades camponesas, com a finalidade de elevar o nível tecnológico de modo a aumentar a produção e a produtividade, melhorar seu acesso ao avanço tecnológico, à informação de mercado e à capacidade técnica de gestão. 


\section{REFERÊNCIAS BIBLIOGRÁFICAS}

ARAÚJO, J.; KHAN, A. Análise harmônica de preços e quantidades de laranja e banana no nordeste brasileiro. Economia Rural, v. 23, n. 4, p. 419-37, out./dez. 1987.

ARAÚJO, J.; PESSOA, P.; LEMOS, J. Análise harmônica da estacionalidade na comercialização de produtos agrícolas selecionados no nordeste do Brasil. Economia Rural, v. 23, n. 4, p. 467-578, out./dez. 1985.

CAVALCANTI, J. Análise harmônica aplicada as quantidades e aos preços de produtos agrícolas selecionados no Estado de São Paulo. Viçosa, 1978. 97 p. Dissertação (Mestrado) - Universidade Federal de Viçosa.

CAVASSA, A. Ajustandose a nuevas reglas de juego: cambios en las estrategias productivas e de financiamiento rural. In: DANCOURT, O.; MEYER, E.; MONGE, C., ed. Perú el problema agrario en debate. Lima: SEPIA, 1994. p. 271-96.

CROCOMO, C.; HOFFMANN, R. Variação estacional dos preços de produtos hortícolas no Estado de São Paulo no período 1964/1971. São Paulo: Universidade de São Paulo, 1972. 93 p. (Série de Pesquisas, 18).

DANCOURT, O.; MENDOZA, W. Agricultura e política de estabilización en el Perú. In: DANCOURT, O.; MEYER, E.; MONGE, C., ed. Perú el problema agrario en debate. Lima: SEPIA, 1994. p. 243-69.

DRAPER, N.; SMITH, H. Applied regression analysis. New York: John Wiley, 1966. $407 \mathrm{p}$.

FIGUEROA, A. La agricultura peruana en ajuste. Lima: GRADE, 1992. 28 p. 
FUNDAÇÃO GETÚlIO VARGAS. Centro de Estudios Agrícolas. Variações estacionárias de preços, ao nível dos agricultores, de alguns produtos selecionados anos de 1966 a 1969. Rio de Janeiro: Instituto Brasileiro de Economia, 1971. $211 \mathrm{p}$.

GALLARDO, J. Efectos del ajuste estructural sobre los determinantes de la producción em la economía campesina. In: DANCOURT, O.; MEYER, E.; MONGE, C., ed. Perú el problema agrario en debate. Lima: SEPIA, 1994. p. 317-35.

HOEL, P.G. Estatística elementar. 4. ed. New York: John Wiley, 1982. 312 p.

HOFFMANN, R. Variação estacional dos preços de produtos agropecuário no Estado de São Paulo. Piracicaba, 1969. 184 p. Tese (Doutorado) - Escola Superior de Agricultura "Luiz de Queiroz", Universidade de São Paulo.

HOFFMANN, R. Estatística para economistas. São Paulo: Pioneira, 1987. 379 p. (Obras Didáticas. Coleção Economia e Planeamento).

HOFFMANN, R. Análise harmônica. Piracicaba: ESALQ, 1995. 27p. (Série Didática, 99).

HOFFMANN, R.; VIERA, S. Análise de regressão: uma introdução à econometria. 2 . ed. São Paulo: HUCITEC, 1987. 379 p. (Obras Didáticas. Coleção Economia e Planejamento).

INSTITUTIO NACIONAL DE ESTADÍSTICA. Estadísticas del Perú. Lima, 1986. $87 \mathrm{p}$.

JUDGE, G. C. Introduction to the theory and practice of econometrics. New York: John Wiley, 1988. $1024 \mathrm{p}$.

KASSOUF, A.L. Previsão de preços na pecuária de corte do Estado de São Paulo. Piracicaba, 1988. 102 p. Dissertação (Mestrado) - Escola Superior de Agricultura "Luiz de Queiroz", Universidade de São Paulo.

LANGE, O. Introdução à econometria. 2. ed Rio de Janeiro: Fundo de Cultura, 1967. $374 \mathrm{p}$.

MONGE, C. Transformación de la sociedad rural en el Perú. In: DANCOURT, O.; MEYER, E.; MONGE, C., ed. Perú el problema agrario en debate. Lima: SEPIA, 1994. p. 33-67. 
MONTOYA, E. Geografía de Cajamarca. Lima: LABRUSA, 1990. v.1, 266 p.

MOREIRA, M.S.T.E. Estacionalidade e concentração no mercado atacadista de frutas do Estado de São Paulo. Piracicaba, 1991. 150p. Dissertação (Mestrado) - Escola Superior de Agricultura "Luiz de Queiroz", Universidade de São Paulo.

MORETTIN, P.; TOLOI, C.M.C. Previsão de séries temporais. 2. ed. São Paulo: Atual, 1985. $436 \mathrm{p}$.

OFICINA NACIONAL DE EVALUACIÓN DE RECURSOS NATURALES. Los recursos naturales de Perú. Lima, 1985. 230 p.

OKAWA, H. Análise harmônica das variações dos preços e das quantidades de sardinha fresca no mercado atacadista de São Paulo - 1981/1982. Piracicaba, 1985. 96 p. Dissertação (Mestrado) - Escola Superior de Agricultura "Luiz de Queiroz", Universidade de São Paulo.

ORGANIZACIÓN DE LAS NACIONES UNIDAS. Tendencias y políticas actuales en la economía mundial. New York, 1977/1993. (Estudio Económico Mundial, n 5). $280 \mathrm{p}$.

OTÁRALA, M. Econometria. Lima: Editora Universidad de Lima, 1993. 626 p.

PEREIRA, I.F. Variação estacional de preços agrícolas no Estado de São Paulo. Agricultura em São Paulo, v. 33 , n.7 , p. 257, jul. 1986.

RIVEIRO, A.C. Rentabilidade na estocagem de produtos agrícolas. Viçosa, 1977. 73 p. Dissertação (Mestrado) - Universidade Federal de Viçosa.

ROMERO, J.; MANCO, J. Estudio del régimen pluviométrico del valle de Cajamarca. Revista Ciencias Agropecuárias, n. 2, p. 1-19, 1983.

SALVATORE, D. Microeconomia. São Paulo: Mc Graw Hill, 1984. 476 p.

SANDRONI, P. Dicionário de economia. 3. ed. São Paulo: Best Seller, 1994. 357 p.

SAS INSTITUTE. SAS/ETS USER'S Guide, version 6. 2. ed. Cary, , 1991 p. 785 825.

SERVICIO NACIONAL DE METEOROLOGÍA E HIDROLOGÍA. Información meteorológica del Perú. Lima,1988. 67 p.

SPIEGEL, M. R. Estatística. São Paulo: Mc Graw Hill, 1970. 320 p. 
TAPIA, M. Conservación y uso de recursos fitogenéticos andinos para un desarrollo agrícola sostenido. In: DANCOURT, O.; MEYER, E.; MONGE, C., ed. Perú el problema agrario en debate. Lima: SEPIA, 1994. p. 535-50.

THIEBAUT, J.T.L. O emprego da análise harmônica no estudo das precipitações mensais do município de Viçosa (MG). Viçosa, 1976. 92p. Dissertação (Mestrado) - Escola Superior de Agricultura "Luiz de Queiroz", Universidade de São Paulo. 
APÊNDICE A

Informação Básica 
Tabela A.1 - Preços em novos soles $/ \mathrm{kg}$ da cultura de BATATA, deflacionados dezembro 1994.

\begin{tabular}{cccccccccccccc}
\hline ANO & $J A N$ & $F E V$ & $M A R$ & $A B R$ & MAI & JUN & JUL & AGO & SET & OUT & NOV & DEZ & MÉDIA \\
\hline 1975 & 1,00 & 1,10 & 1,30 & 1,60 & 1,70 & 1,69 & 2,56 & 2,34 & 1,80 & 1,74 & 1,25 & 1,15 & 1,60 \\
1976 & 1,10 & 1,17 & 1,17 & 1,34 & 1,37 & 1,36 & 1,38 & 1,35 & 1,40 & 1,34 & 1,24 & 1,14 & 1,28 \\
1977 & 1,04 & 1,05 & 1,27 & 1,50 & 1,60 & 1,78 & 1,75 & 1,75 & 1,86 & 1,85 & 1,30 & 1,20 & 1,50 \\
1978 & 1,05 & 0,95 & 0,84 & 1,17 & 2,25 & 1,26 & 1,32 & 1,37 & 1,42 & 1,42 & 1,22 & 1,10 & 1,28 \\
1979 & 2,57 & 2,84 & 2,95 & 3,47 & 3,60 & 3,89 & 3,80 & 3,59 & 3,69 & 3,78 & 2,58 & 2,36 & 3,26 \\
1980 & 1,68 & 1,57 & 2,05 & 2,46 & 2,48 & 2,53 & 2,63 & 2,68 & 2,95 & 2,68 & 2,28 & 1,67 & 2,31 \\
1981 & 1,24 & 1,38 & 1,41 & 1,43 & 1,38 & 1,38 & 1,52 & 1,73 & 1,85 & 1,57 & 1,24 & 1,02 & 1,43 \\
1982 & 0,96 & 0,76 & 0,89 & 0,86 & 0,68 & 0,65 & 0,78 & 0,96 & 1,12 & 1,16 & 1,17 & 1,07 & 0,92 \\
1983 & 1,37 & 1,57 & 1,57 & 1,96 & 2,45 & 2,50 & 2,45 & 2,34 & 2,10 & 1,89 & 1,47 & 1,35 & 1,92 \\
1984 & 1,24 & 1,28 & 1,31 & 1,36 & 1,28 & 1,27 & 1,25 & 1,35 & 1,32 & 1,25 & 1,23 & 1,07 & 1,27 \\
1985 & 0,96 & 0,89 & 0,78 & 1,14 & 1,19 & 1,28 & 1,34 & 1,45 & 1,36 & 1,28 & 1,00 & 0,96 & 1,14 \\
1986 & 1,35 & 1,47 & 1,34 & 1,45 & 1,52 & 1,72 & 1,85 & 1,94 & 1,83 & 1,64 & 1,45 & 1,42 & 1,58 \\
1987 & 1,32 & 1,25 & 0,96 & 0,94 & 0,85 & 0,94 & 1,34 & 1,47 & 1,40 & 1,45 & 1,34 & 1,23 & 1,21 \\
1988 & 0,95 & 0,84 & 0,56 & 0,46 & 0,49 & 0,53 & 0,54 & 0,62 & 0,63 & 0,58 & 0,53 & 0,50 & 0,60 \\
1989 & 1,23 & 1,27 & 1,29 & 1,33 & 1,26 & 1,27 & 1,25 & 1,35 & 1,37 & 1,25 & 1,27 & 1,16 & 1,28 \\
1990 & 1,17 & 1,23 & 1,57 & 1,74 & 1,76 & 1,76 & 1,78 & 1,42 & 1,23 & 1,10 & 0,94 & 0,86 & 1,38 \\
1991 & 0,68 & 0,61 & 0,64 & 0,86 & 0,58 & 0,55 & 0,51 & 0,46 & 0,65 & 0,99 & 0,77 & 0,73 & 0,67 \\
1992 & 0,57 & 0,54 & 0,52 & 0,54 & 0,55 & 0,58 & 0,57 & 0,55 & 0,62 & 0,76 & 0,59 & 0,47 & 0,57 \\
1993 & 0,50 & 0,44 & 0,45 & 0,46 & 0,54 & 0,55 & 0,56 & 0,62 & 0,55 & 0,55 & 0,51 & 0,50 & 0,52 \\
1994 & 0,46 & 0,43 & 0,41 & 0,39 & 0,43 & 0,50 & 0,49 & 0,65 & 0,73 & 0,55 & 0,45 & 0,45 & 0,50 \\
\hline MÉDIA & 1,12 & 1,13 & 1,16 & 1,32 & 1,40 & 1,40 & 1,48 & 1,50 & 1,49 & 1,44 & 1,19 & 1,07 & 1,31 \\
\hline
\end{tabular}

FONTE: MINISTÉRIO DE AGRICULTURA - Oficina de Estadística Agraria - Perú.

1 nuevo sol Dezembro de $1994=2.20$ Dólares.

Tabela A.2 - Preços em novos soles/kg da cultura de MILHO, deflacionados dezembro 1994.

\begin{tabular}{cccccccccccccc}
\hline ANO & $J A N$ & $F E V$ & MAR & $A B R$ & MAI & $J U N$ & $J U L$ & $A G O$ & SET & OUT & NOV & DEZ & MÉDIA \\
\hline 1975 & 3,25 & 3,03 & 2,83 & 2,64 & 2,57 & 2,39 & 2,25 & 2,34 & 2,38 & 2,46 & 2,45 & 2,42 & 2,58 \\
1976 & 2,46 & 2,44 & 2,46 & 2,04 & 1,45 & 1,42 & 1,38 & 1,40 & 1,65 & 1,76 & 1,85 & 1,89 & 1,85 \\
1977 & 1,84 & 1,78 & 1,73 & 1,75 & 1,65 & 1,54 & 1,56 & 1,75 & 1,97 & 2,10 & 2,23 & 2,21 & 1,84 \\
1978 & 2,20 & 2,34 & 2,45 & 2,37 & 2,38 & 2,20 & 2,35 & 2,48 & 2,68 & 2,79 & 2,86 & 2,95 & 2,50 \\
1979 & 2,94 & 3,16 & 3,27 & 3,32 & 3,02 & 2,90 & 3,01 & 3,36 & 3,48 & 3,43 & 3,36 & 3,34 & 3,22 \\
1980 & 3,40 & 3,25 & 3,07 & 2,97 & 2,85 & 2,64 & 2,67 & 2,72 & 2,75 & 2,84 & 2,87 & 2,93 & 2,91 \\
1981 & 2,96 & 2,99 & 3,06 & 2,85 & 2,64 & 2,37 & 2,14 & 2,03 & 2,04 & 2,10 & 2,16 & 2,22 & 2,46 \\
1982 & 2,18 & 2,04 & 2,06 & 2,03 & 2,01 & 2,00 & 2,10 & 2,10 & 2,14 & 2,23 & 2,26 & 2,25 & 2,12 \\
1983 & 2,27 & 2,33 & 2,29 & 2,03 & 1,91 & 1,86 & 1,73 & 1,84 & 1,85 & 1,93 & 1,95 & 1,96 & 2,00 \\
1984 & 2,12 & 2,16 & 2,24 & 2,26 & 2,29 & 2,36 & 2,46 & 2,63 & 2,78 & 2,97 & 3,10 & 3,23 & 2,55 \\
1985 & 3,12 & 2,84 & 2,63 & 2,42 & 2,36 & 2,24 & 2,21 & 2,33 & 2,51 & 2,63 & 2,73 & 2,85 & 2,57 \\
1986 & 2,81 & 2,64 & 2,59 & 2,45 & 2,50 & 2,41 & 2,34 & 2,26 & 2,38 & 2,43 & 2,48 & 2,49 & 2,48 \\
1987 & 2,38 & 2,27 & 2,03 & 1,96 & 1,80 & 1,75 & 1,67 & 1,84 & 1,96 & 2,01 & 2,08 & 2,12 & 1,99 \\
1988 & 2,19 & 2,04 & 1,93 & 1,71 & 1,52 & 1,41 & 1,34 & 1,17 & 1,14 & 1,02 & 1,04 & 1,11 & 1,47 \\
1989 & 1,12 & 1,18 & 1,11 & 1,08 & 1,10 & 1,03 & 0,95 & 0,91 & 0,93 & 1,03 & 1,04 & 1,13 & 1,05 \\
1990 & 1,04 & 0,94 & 0,85 & 0,79 & 0,67 & 0,55 & 0,88 & 0,96 & 1,26 & 1,35 & 1,46 & 1,45 & 1,02 \\
1991 & 1,42 & 1,32 & 1,23 & 1,05 & 1,03 & 0,98 & 0,84 & 0,85 & 0,84 & 0,92 & 0,93 & 1,02 & 1,04 \\
1992 & 0,89 & 0,84 & 0,83 & 0,72 & 0,83 & 0,70 & 0,80 & 0,65 & 0,62 & 0,82 & 0,89 & 0,98 & 0,80 \\
1993 & 0,85 & 0,73 & 0,66 & 0,60 & 0,58 & 0,74 & 0,75 & 0,74 & 0,95 & 0,96 & 0,67 & 0,55 & 0,73 \\
1994 & 0,64 & 0,66 & 0,63 & 0,64 & 0,55 & 0,52 & 0,52 & 0,57 & 0,59 & 0,61 & 0,62 & 0,62 & 0,60 \\
\hline MÉDIA & 2,10 & 2,05 & 2,00 & 1,88 & 1,79 & 1,70 & 1,70 & 1,75 & 1,85 & 1,92 & 1,95 & 1,99 & 1,89 \\
\hline
\end{tabular}

FONTE: MINISTÉRIO DE AGRICULTURA - Oficina de Estadística Agraria - Perú. 
Tabela A.3 - Preços em novos soles/kg da cultura de TRIGO, deflacionados dezembro 1994.

\begin{tabular}{rrrrrrrrrrrrrrr}
\hline ANO & $J A N$ & $F E V$ & $M A R$ & $A B R$ & MAI & JUN & JUL & AGO & SET & OUT & NOV & DEZ & MÉDIA \\
\hline 1975 & 2,30 & 2,50 & 2,58 & 2,46 & 2,52 & 2,53 & 2,63 & 2,73 & 3,46 & 3,45 & 3,42 & 2,89 & 2,79 \\
1976 & 2,64 & 2,43 & 2,36 & 1,75 & 1,85 & 1,96 & 2,10 & 2,65 & 2,70 & 2,75 & 2,68 & 2,40 & 2,36 \\
1977 & 2,36 & 2,47 & 2,52 & 2,50 & 2,49 & 2,54 & 2,47 & 2,50 & 2,45 & 2,58 & 2,60 & 2,43 & 2,49 \\
1978 & 2,30 & 2,26 & 2,28 & 2,16 & 2,24 & 2,35 & 2,40 & 2,46 & 2,43 & 2,65 & 2,64 & 2,65 & 2,40 \\
1979 & 2,84 & 2,95 & 3,50 & 3,70 & 3,65 & 3,74 & 3,74 & 4,47 & 4,52 & 4,97 & 4,96 & 4,10 & 3,93 \\
1980 & 3,80 & 3,76 & 3,47 & 2,68 & 2,70 & 2,75 & 2,95 & 2,95 & 2,86 & 3,28 & 3,20 & 2,89 & 3,11 \\
1981 & 2,53 & 2,18 & 1,85 & 1,63 & 1,85 & 2,00 & 2,12 & 2,25 & 2,35 & 2,80 & 2,75 & 2,40 & 2,23 \\
1982 & 2,34 & 2,27 & 2,10 & 1,75 & 1,80 & 1,78 & 1,95 & 2,07 & 2,46 & 2,52 & 2,34 & 2,36 & 2,15 \\
1983 & 2,10 & 1,96 & 1,60 & 1,69 & 1,75 & 1,89 & 2,10 & 2,36 & 2,60 & 2,63 & 2,45 & 2,10 & 2,10 \\
1984 & 2,00 & 2,35 & 2,55 & 2,74 & 2,43 & 2,36 & 2,45 & 2,73 & 2,94 & 3,20 & 2,32 & 3,34 & 2,62 \\
1985 & 3,12 & 2,85 & 2,74 & 2,56 & 2,36 & 2,93 & 2,50 & 2,78 & 2,83 & 2,80 & 2,86 & 2,97 & 2,78 \\
1986 & 2,85 & 2,63 & 2,47 & 2,60 & 2,89 & 2,98 & 2,67 & 2,48 & 2,39 & 2,68 & 2,79 & 2,83 & 2,69 \\
1987 & 2,74 & 2,53 & 2,42 & 2,27 & 2,01 & 1,78 & 1,76 & 1,81 & 1,83 & 1,87 & 1,84 & 1,80 & 2,06 \\
1988 & 1,73 & 1,60 & 1,50 & 1,24 & 1,21 & 1,22 & 1,22 & 1,29 & 1,32 & 1,31 & 1,29 & 1,25 & 1,35 \\
1989 & 1,23 & 1,27 & 1,26 & 1,33 & 1,26 & 1,27 & 1,25 & 1,35 & 1,37 & 1,47 & 1,46 & 1,43 & 1,33 \\
1990 & 1,37 & 1,25 & 1,07 & 0,86 & 0,92 & 1,35 & 1,16 & 1,23 & 1,27 & 1,35 & 1,48 & 1,47 & 1,23 \\
1991 & 1,23 & 1,28 & 1,07 & 0,71 & 0,73 & 0,64 & 0,78 & 0,63 & 0,65 & 0,74 & 0,73 & 0,69 & 0,82 \\
1992 & 0,71 & 0,79 & 0,89 & 0,96 & 0,92 & 0,78 & 0,61 & 0,65 & 0,65 & 0,72 & 0,76 & 0,71 & 0,76 \\
1993 & 0,64 & 0,69 & 0,70 & 0,69 & 0,62 & 0,69 & 0,71 & 0,75 & 0,76 & 0,79 & 0,84 & 0,83 & 0,73 \\
1994 & 0,63 & 0,56 & 0,54 & 0,56 & 0,58 & 0,46 & 0,68 & 0,71 & 0,57 & 0,54 & 0,50 & 0,55 & 0,57 \\
\hline MÉDIA & 2,07 & 1,93 & 1,88 & 1,75 & 1,75 & 1,81 & 1,82 & 1,95 & 2,02 & 2,15 & 2,09 & 2,00 & 2,02 \\
\hline
\end{tabular}

FONTE: MINISTÉRIO DE AGRICULTURA - Oficina de Estadística Agraria - Perú.

1 nuevo sol Dezembro de $1994=2.20$ Dólares.

Tabela A.4 - Preços em novos soles/kg da cultura de CEVADA, deflacionados dezembro 1994.

\begin{tabular}{rrrrrrrrrrrrrrr}
\hline ANO & $J A N$ & $F E V$ & MAR & ABR & MAI & JUN & JUL & AGO & SET & OUT & NOV & DEZ & MÉDIA \\
\hline 1975 & 2,40 & 2,35 & 2,20 & 2,00 & 1,84 & 1,85 & 1,85 & 1,95 & 2,15 & 2,58 & 2,67 & 2,50 & 2,20 \\
1976 & 2,30 & 2,32 & 2,00 & 1,74 & 1,84 & 1,70 & 1,73 & 1,65 & 1,60 & 1,65 & 1,65 & 1,73 & 1,78 \\
1977 & 1,69 & 1,64 & 1,63 & 1,53 & 1,52 & 1,45 & 1,39 & 1,59 & 1,64 & 1,69 & 1,73 & 1,60 & 1,57 \\
1987 & 1,53 & 1,46 & 1,39 & 1,24 & 1,20 & 1,10 & 1,00 & 1,10 & 1,10 & 1,25 & 1,22 & 1,25 & 1,18 \\
1979 & 1,40 & 1,68 & 1,95 & 2,10 & 1,80 & 1,85 & 1,97 & 1,99 & 2,48 & 2,76 & 3,50 & 3,40 & 2,57 \\
1980 & 3,20 & 2,80 & 2,50 & 2,00 & 2,10 & 2,20 & 1,85 & 1,75 & 2,32 & 2,33 & 2,35 & 2,30 & 2,29 \\
1981 & 2,05 & 2,10 & 2,21 & 2,03 & 2,00 & 2,10 & 2,05 & 2,05 & 2,35 & 2,37 & 2,35 & 2,30 & 2,16 \\
1982 & 1,96 & 1,84 & 1,75 & 1,70 & 1,48 & 1,46 & 1,43 & 1,37 & 1,47 & 2,01 & 1,98 & 2,00 & 1,70 \\
1983 & 2,05 & 2,10 & 2,21 & 2,03 & 2,00 & 2,10 & 2,05 & 2,05 & 2,35 & 2,37 & 2,35 & 2,30 & 2,16 \\
1984 & 2,26 & 2,28 & 2,25 & 2,00 & 1,86 & 1,85 & 1,83 & 1,84 & 1,86 & 2,10 & 2,07 & 2,10 & 2,03 \\
1985 & 1,95 & 1,90 & 1,76 & 1,73 & 1,64 & 1,49 & 1,53 & 1,52 & 1,52 & 1,74 & 1,76 & 1,72 & 1,69 \\
1986 & 1,45 & 1,46 & 1,47 & 1,42 & 1,52 & 1,46 & 1,57 & 1,62 & 1,55 & 1,83 & 1,78 & 1,73 & 1,57 \\
1987 & 1,16 & 1,04 & 0,98 & 0,93 & 0,94 & 0,98 & 1,01 & 1,03 & 1,15 & 1,35 & 1,38 & 1,36 & 1,11 \\
1988 & 0,94 & 0,82 & 0,79 & 0,83 & 0,86 & 0,89 & 0,90 & 0,92 & 0,96 & 1,00 & 1,02 & 0,89 & 0,90 \\
1989 & 0,74 & 0,68 & 0,67 & 0,67 & 0,74 & 0,73 & 0,74 & 0,76 & 0,80 & 0,89 & 0,79 & 0,75 & 0,75 \\
1990 & 0,55 & 0,55 & 0,67 & 0,68 & 0,79 & 0,87 & 0,64 & 0,67 & 0,67 & 0,59 & 0,57 & 0,55 & 0,65 \\
1991 & 0,47 & 0,54 & 0,60 & 0,61 & 0,68 & 0,74 & 0,54 & 0,56 & 0,55 & 0,47 & 0,48 & 0,47 & 0,56 \\
1992 & 0,35 & 0,37 & 0,35 & 0,32 & 0,34 & 0,37 & 0,37 & 0,36 & 0,37 & 0,33 & 0,34 & 0,33 & 0,35 \\
1993 & 0,40 & 0,42 & 0,48 & 0,49 & 0,50 & 0,53 & 0,46 & 0,40 & 0,38 & 0,42 & 0,42 & 0,42 & 0,44 \\
1994 & 0,45 & 0,49 & 0,56 & 0,61 & 0,66 & 0,63 & 0,48 & 0,49 & 0,44 & 0,44 & 0,45 & 0,45 & 0,51 \\
\hline MEDDIA & 1,47 & 1,44 & 1,42 & 1,33 & 1,32 & 1,32 & 1,27 & 1,28 & 1,39 & 1,51 & 1,54 & 1,51 & 1,41 \\
\hline
\end{tabular}

FONTE: MINISTERIO DE AGRICULTURA - Oficina de Estadística Agraria - Perú. 
Tabela A.5 - Quantidade produzida da cultura de BATATA (TM).

\begin{tabular}{|c|c|c|c|c|c|c|c|c|c|c|c|c|c|}
\hline & $4 N$ & $E V$ & $A R$ & $3 R$ & $\angle A I$ & JUN & JUL & $A G O$ & DEI & $00 T$ & & & \\
\hline 1975 & & 654 & 531 & 456 & 352 & 897 & 4.297 & 5.219 & 7831 & & 9.023 & 10.232 & \\
\hline & & & & & & & & & & & & & \\
\hline & 452 & & & & 934 & & .678 & 5.478 & 853 & 423 & 1.342 & .452 & \\
\hline 1978 & 023 & & & 7.345 & 37 & 5.673 & 43 & 5.6 & .684 & 931 & & 52 & \\
\hline 1979 & 445 & 234 & 77 & 9.573 & & 4.85 & & & 6.5 & & & & \\
\hline & 422 & 237 & 456 & 7.032 & 6.569 & 6.458 & 5.471 & 6.065 & 5.678 & 8.732 & 9.37 & .342 & \\
\hline 1 & & 982 & & 9.345 & 6.458 & 5.358 & 5.674 & 5.046 & 6.023 & 8.034 & 9.821 & 10.211 & \\
\hline & 078 & 382 & .892 & .987 & 9.965 & 7.391 & $6.83 \mathrm{~S}$ & 5.731 & 7.382 & 12.092 & 14.902 & 16.822 & \\
\hline 1 & & 234 & 312 & 567 & 6.312 & 6.036 & 3.896 & .341 & 6.731 & 234 & 3.498 & 9.678 & \\
\hline & & 092 & 9 & 8.942 & 6.4 & 5.370 & 6.678 & 7.298 & 8.934 & 9.312 & 10.476 & 0.292 & \\
\hline 1985 & 982 & 209 & 7.829 & 6.921 & 5.932 & 4.592 & 5.092 & 5.831 & 6.012 & 8.934 & 9.832 & 10.342 & \\
\hline & 028 & .092 & 882 & 9.823 & & 6.783 & 7.892 & 38 & 6.5 & 873 & 10.382 & 0.341 & 113.529 \\
\hline & & 456 & 234 & .728 & .012 & 6.342 & 6.789 & 5.342 & 5.589 & 120 & 10.123 & 1.287 & 478 \\
\hline & 909 & .093 & 982 & .922 & 9.342 & 8.934 & 6.983 & 6.390 & 7.831 & 234 & 12.093 & 12.303 & \\
\hline 1 & 13.879 & 14.987 & 10.982 & 10.233 & 8.983 & 7.862 & 6.892 & 5.983 & 7.833 & 10.982 & 10.192 & 12.098 & .906 \\
\hline & 104 & 9.456 & 5.939 & 6.305 & 6.297 & 5.077 & 7.274 & 6.140 & 5.979 & 6.446 & 12.236 & 10.290 & 7.543 \\
\hline & 343 & 10.198 & 10.565 & 11.405 & 10.389 & 9.478 & 7.294 & 7.479 & 6.636 & 10.037 & 6.386 & 9.250 & 105 \\
\hline & $8.0^{\circ}$ & 6.596 & 9.4 & 10.9 & 8.9 & 8.459 & 8.478 & 6.500 & 5.639 & 6.769 & 5.876 & 7.689 & \\
\hline 1993 & 9.771 & 16.548 & 10.416 & 8.301 & 7.837 & 7.406 & 6.395 & 7.675 & 5.684 & 6.143 & 12.305 & 13.308 & 111.789 \\
\hline 1994 & .345 & .234 & 8.797 & 5.678 & 6.345 & 4.786 & 4.234 & 4.568 & 5.435 & 9.875 & 11.254 & 10.234 & 91.785 \\
\hline & & .189 & 791 & .916 & 7.63 & 6.427 & 617 & 5.896 & 662 & & & & \\
\hline
\end{tabular}

FONTE: MINISTÉRIO DE AGRICULTURA - Oficina de Estadística e Agraria - Perú.

Tabela A.6 - Quantidade produzida da cultura de MILHO (TM).

\begin{tabular}{rrrrrrrrrrrrrrr}
\hline \multicolumn{1}{c}{ ANO } & $J A N$ & $F E V$ & $M A R$ & $A B R$ & \multicolumn{1}{c}{ MAI } & \multicolumn{1}{c}{$J U N$} & \multicolumn{1}{c}{ JUL } & \multicolumn{1}{c}{ AGO } & SET & OUT & NOV & DEZ & TOTAL \\
\hline 1975 & 9 & 66 & 342 & 4.327 & 7.463 & 9.032 & 10.231 & 678 & 176 & 268 & 123 & 12 & 32.727 \\
1976 & 17 & 157 & 354 & 1.872 & 5.489 & 8.349 & 14.328 & 3.872 & 254 & 256 & 88 & 82 & 35.118 \\
1977 & 32 & 358 & 357 & 3.023 & 12.438 & 15.438 & 9.843 & 1.894 & 234 & 14 & 9 & 3 & 43.643 \\
1978 & 39 & 892 & 934 & 5.342 & 9.834 & 13.478 & 6.783 & 2.347 & 587 & 256 & 87 & 6 & 40.585 \\
1979 & 33 & 558 & 699 & 4.650 & 10.132 & 15.123 & 8.934 & 4.023 & 234 & 123 & 82 & 12 & 44.603 \\
1980 & 21 & 119 & 734 & 3.023 & 7.042 & 9.903 & 7.986 & 1.327 & 442 & 146 & 94 & 33 & 30.870 \\
1981 & 48 & 332 & 732 & 5.076 & 9.682 & 14.328 & 10.342 & 3.872 & 342 & 91 & 78 & 42 & 44.965 \\
1982 & 13 & 442 & 547 & 4.231 & 8.934 & 14.932 & 9.432 & 6.348 & 587 & 432 & 345 & 256 & 46.499 \\
1983 & 9 & 134 & 534 & 2.869 & 6.784 & 9.345 & 17.583 & 6.342 & 478 & 21 & 145 & 34 & 44.278 \\
1984 & 11 & 213 & 663 & 3.462 & 5.548 & 8.998 & 15.325 & 7.432 & 478 & 162 & 53 & 21 & 42.366 \\
1985 & 13 & 94 & 354 & 1.774 & 5.234 & 8.543 & 14.231 & 3.679 & 332 & 143 & 82 & 12 & 34.491 \\
1986 & 8 & 454 & 648 & 1.324 & 8.435 & 11.852 & 16.543 & 5.493 & 476 & 258 & 25 & 8 & 45.524 \\
1987 & 19 & 213 & 538 & 1.832 & 8.329 & 19.054 & 9.843 & 4.292 & 458 & 142 & 102 & 49 & 44.871 \\
1988 & 21 & 684 & 953 & 3.823 & 8.439 & 13.832 & 14.382 & 6.231 & 538 & 347 & 312 & 120 & 49.682 \\
1989 & 4 & 427 & 538 & 2.894 & 9.453 & 16.432 & 13.893 & 4.092 & 601 & 289 & 632 & 83 & 49.338 \\
1990 & 3 & 330 & 599 & 609 & 1.993 & 10.772 & 11.451 & 5.007 & 600 & 367 & 108 & 8 & 31.847 \\
1991 & 5 & 84 & 127 & 1.476 & 5.187 & 15.689 & 13.290 & 2.588 & 490 & 26 & 278 & 80 & 39.320 \\
1992 & 2 & 3 & 348 & 1.585 & 2.194 & 10.510 & 7.957 & 960 & 193 & 49 & 25 & 4 & 23.830 \\
1993 & 34 & 363 & 360 & 1.814 & 8.796 & 12.537 & 8.833 & 730 & 159 & 5 & 2 & 2 & 33.635 \\
1994 & 15 & 57 & 478 & 978 & 3.578 & 10.568 & 9.476 & 1.345 & 356 & 87 & 137 & 23 & 27.098 \\
\hline MÉDIA & 18 & 299 & 542 & 2.799 & 7.249 & 12.436 & 11.534 & 3.628 & 401 & 174 & 140 & 45 & 39.265 \\
\hline
\end{tabular}

FONTE: MINISTÉRIO DE AGRICULTURA - Oficina de Estadística e Agraria - Perú. 
Tabela A.7 - Quantidade produzida da cultura de TRIGO (TM).

\begin{tabular}{crrrrrrrrrrrrrr}
\hline ANO & $J A N$ & $F E V$ & $M A R$ & $A B R$ & $M A I$ & $J U N$ & $J U L$ & $A G O$ & \multicolumn{1}{l}{ SET } & OUT & NOV & DEZ & TOTAL \\
\hline 1975 & 1 & 1 & 75 & 80 & 678 & 2.678 & 3.329 & 3.562 & 2.212 & 254 & 9 & 7 & 12.886 \\
1976 & 1 & 6 & 32 & 88 & 423 & 2.438 & 3.821 & 3.211 & 1.892 & 202 & 39 & 4 & 12.157 \\
1977 & 1 & 2 & 39 & 98 & 623 & 2.568 & 4.234 & 3.998 & 2.012 & 168 & 62 & 2 & 13.807 \\
1978 & 2 & 3 & 89 & 32 & 214 & 2.821 & 3.672 & 2.489 & 2.321 & 147 & 39 & 2 & 11.831 \\
1979 & 2 & 2 & 57 & 53 & 321 & 1.982 & 3.723 & 2.931 & 1.758 & 243 & 53 & 1 & 11.126 \\
1980 & 2 & 3 & 14 & 96 & 342 & 2.773 & 3.423 & 2.721 & 432 & 231 & 14 & 2 & 10.053 \\
1981 & 1 & 2 & 30 & 86 & 359 & 2.027 & 4.344 & 3.044 & 995 & 150 & 32 & 8 & 11.080 \\
1982 & 1 & 4 & 17 & 27 & 276 & 2.367 & 4.963 & 3.732 & 1.346 & 186 & 74 & 1 & 12.994 \\
1983 & 2 & 3 & 17 & 126 & 566 & 2.501 & 3.821 & 3.327 & 2.468 & 176 & 25 & 8 & 13.040 \\
1984 & 3 & 4 & 26 & 73 & 492 & 2.376 & 3.992 & 3.429 & 2.268 & 169 & 31 & 3 & 12.866 \\
1985 & 2 & 2 & 4 & 12 & 87 & 2.123 & 3.452 & 4.135 & 1126 & 84 & 24 & 17 & 11.068 \\
1986 & 1 & 2 & 12 & 25 & 78 & 942 & 1.242 & 1.128 & 975 & 4 & 14 & 2 & 4.425 \\
1987 & 1 & 1 & 3 & 35 & 634 & 2.145 & 3.951 & 3.257 & 1.025 & 56 & 37 & 8 & 11.153 \\
1988 & 1 & 4 & 32 & 162 & 398 & 2.431 & 2.438 & 3.323 & 2.032 & 263 & 63 & 11 & 11.158 \\
1989 & 1 & 3 & 13 & 9 & 376 & 2.186 & 4.782 & 3.589 & 1.645 & 127 & 12 & 2 & 12.745 \\
1990 & 2 & 2 & 1 & 1 & 5 & 1.324 & 4.024 & 4.374 & 1.293 & 172 & 5 & 14 & 11.217 \\
1991 & 1 & 1 & 28 & 153 & 419 & 2.595 & 3.690 & 3.557 & 1.053 & 284 & 75 & 8 & 11.864 \\
1992 & 1 & 3 & 2 & 46 & 751 & 1.630 & 6.049 & 2.391 & 724 & 71 & 80 & 16 & 11.764 \\
1993 & 1 & 2 & 111 & 159 & 248 & 1.673 & 2.878 & 2.538 & 1.368 & 38 & 20 & 3 & 9.039 \\
1994 & 2 & 2 & 2 & 151 & 415 & 2.548 & 4.238 & 2.618 & 670 & 150 & 2 & 1 & 10.799 \\
\hline MEDIA & 1 & 3 & 30 & 76 & 385 & 2.206 & 3.803 & 3.168 & 1.481 & 159 & 35 & 6 & 11.354 \\
\hline
\end{tabular}

FONTE: MINISTÉRIO DE AGRICULTURA - Oficina de Estadística e Agraria - Perú.

Tabela A.8 - Quantidade produzida da cultura de CEVADA (TM).

\begin{tabular}{crrrrrrrrrrrrrr}
\hline ANO & $J A N$ & $F E V$ & $M A R$ & $A B R$ & \multicolumn{1}{c}{ MAI } & JUN & JUL & $A G O$ & SET & OUT & NOV & DEZ & TOTAL \\
\hline 1975 & 2 & 2 & 37 & 87 & 1.548 & 2.278 & 2.567 & 1.478 & 325 & 23 & 2 & 1 & 8.350 \\
1976 & 1 & 87 & 35 & 56 & 648 & 1.579 & 3.232 & 2.678 & 302 & 68 & 5 & 3 & 8.694 \\
1977 & 1 & 85 & 204 & 265 & 1.213 & 2.646 & 2.974 & 2.387 & 389 & 98 & 6 & 2 & 10.270 \\
1978 & 3 & 10 & 124 & 165 & 875 & 2.573 & 2.786 & 2.267 & 389 & 56 & 6 & 2 & 9.256 \\
1979 & 1 & 75 & 42 & 76 & 712 & 2.146 & 2.845 & 2.473 & 195 & 83 & 4 & 3 & 8.655 \\
1980 & 1 & 1 & 87 & 132 & 579 & 1.743 & 3.211 & 1.318 & 217 & 12 & 4 & 1 & 7.306 \\
1981 & 1 & 28 & 111 & 156 & 1.387 & 1.987 & 2.967 & 1.985 & 202 & 53 & 4 & 2 & 8.883 \\
1982 & 2 & 16 & 86 & 124 & 1.022 & 2.426 & 2.739 & 2.486 & 223 & 73 & 13 & 1 & 9.211 \\
1983 & 2 & 2 & 14 & 84 & 1.147 & 2.834 & 3.346 & 3.016 & 436 & 62 & 12 & 4 & 10.959 \\
1984 & 1 & 34 & 189 & 253 & 1.532 & 2.748 & 2.984 & 2.647 & 331 & 53 & 9 & 2 & 10.783 \\
1985 & 1 & 11 & 103 & 174 & 835 & 1.835 & 2.632 & 1.671 & 212 & 34 & 7 & 3 & 7.518 \\
1986 & 1 & 1 & 5 & 8 & 156 & 675 & 1.462 & 894 & 65 & 5 & 1 & 2 & 3.275 \\
1987 & 1 & 2 & 3 & 17 & 1.601 & 2.645 & 2.976 & 1.363 & 149 & 6 & 2 & 1 & 8.766 \\
1988 & 2 & 32 & 131 & 186 & 1.022 & 2.639 & 2.893 & 2.032 & 312 & 46 & 8 & 2 & 9.305 \\
1989 & 2 & 21 & 93 & 132 & 1.132 & 2.521 & 2.731 & 2.329 & 223 & 41 & 11 & 2 & 9.238 \\
1990 & 1 & 2 & 3 & 17 & 1.601 & 2.645 & 2.976 & 1.363 & 149 & 6 & 2 & 1 & 8.766 \\
1991 & 2 & 15 & 147 & 6 & 400 & 2.080 & 3.154 & 1.010 & 320 & 18 & 3 & 2 & 7.157 \\
1992 & 1 & 1 & 130 & 126 & 327 & 976 & 3.324 & 1.253 & 344 & 108 & 1 & 1 & 6.592 \\
1993 & 9 & 143 & 152 & 236 & 462 & 891 & 2.737 & 2.223 & 463 & 5 & 2 & 1 & 7.324 \\
1994 & 2 & 1 & 1 & 1 & 367 & 867 & 3.467 & 2.045 & 268 & 97 & 2 & 2 & 7.120 \\
\hline MEEDIA & 2 & 28 & 85 & 115 & 928 & 2.037 & 2.900 & 1.946 & 276 & 47 & 5 & 2 & 8.371 \\
\hline
\end{tabular}

FONTE: MINISTERIO DE AGRICULTURA - Oficina de Estadística e Agraria - Perú. 
Tabela A.9 - Precipitações medias mensais históricas para o vale de Cajamarca no período 1973 - 1988.

\begin{tabular}{crrrrrrrrrrrrr}
\hline \multicolumn{1}{c}{ JAN } & FEV & MAR & ABR & MAI & JUN & JUL & AGO & SET & OUT & NOV & DEZ & ANO \\
\hline PP & 78,1 & 101,7 & 93,9 & 62,7 & 30,3 & 11,1 & 5,7 & 10,0 & 30,3 & 68,7 & 61,7 & 66,7 & 621 \\
D.S & 34,6 & 52,8 & 44,5 & 25,7 & 20,4 & 9,0 & 5,3 & 7,8 & 19,6 & 32,3 & 22,9 & 21,9 & 142 \\
C.V. & 44,3 & 52,0 & 47,3 & 40,9 & 67,5 & 81,1 & 93,3 & 72,7 & 68,4 & 47,0 & 37,1 & 47,8 & 23 \\
PPMá & 130,4 & 223,6 & 19,4 & 105,7 & 69,5 & 29,3 & 23,4 & 23,6 & 87,2 & 130,4 & 111,0 & 118,4 & 906 \\
PPMí & 12,7 & 34,4 & 36,2 & 27,4 & 4,6 & 0,4 & 0,0 & 0,1 & 1,3 & 24,4 & 23,9 & 0,9 & 3,57 \\
\hline
\end{tabular}

FONTE: Estúdio del Régimen pluviométrico del valle de Cajamarca, 1993.

PP = Precipitação média histórica no Departamento de Cajamarca Período 19731988.

DS = Desvio padrão

C.V. = Coeficiente de variação

PPMá = Precipitação máxima registrada no mês

PPMí = Precipitação mínima registrada no mês 


\section{APÊNDICE B}

Estimativas dos modelos estatísticos. 
Tabela B.1 - Estimativas dos parâmetros utilizando-se análise harmônica para as séries de preços $(\mathrm{P})$ e quantidades $(\mathrm{Q})$ de batata, milho, trigo e cevada, período 1975-1994.

\begin{tabular}{|c|c|c|c|c|c|c|c|c|}
\hline \multirow[t]{2}{*}{ Variáveis } & \multicolumn{2}{|c|}{ Batata } & \multicolumn{2}{|c|}{ Milho } & \multicolumn{2}{|c|}{ Trigo } & \multicolumn{2}{|c|}{ Cevada } \\
\hline & (P) & (Q) & (P) & (Q) & (P) & (Q) & (P) & (Q) \\
\hline Constante & 1,9988 & 8586,2124 & 2,9353 & 3523,1865 & 3,819 & 1026,8557 & 2,3685 & 783,2452 \\
\hline \multirow[t]{2}{*}{ Tendência } & $-0,0057$ & 0,7939 & $-0,0087$ & $-2,0842$ & $-0,0104$ & $-0,7045$ & $-0,0080$ & $-0,7106$ \\
\hline & $(-10,737)^{* *}$ & $(0,445)$ & $(-17,182)^{* *}$ & $(-1,340)$ & $(-19,014)^{* *}$ & $(-1,757)^{*}$ & $(-19,798)^{* *}$ & $(-2,353)^{* *}$ \\
\hline \multirow[t]{2}{*}{$\operatorname{Cos} 2 \pi t / 12$} & $-0,1518$ & 2266,0269 & 0,1671 & $-5247,6824$ & 0,1524 & $-1222,1074$ & 0,1286 & $-1055,4397$ \\
\hline & $(-2,914)^{* *}$ & $(12,973)^{* *}$ & $(3,378)^{* *}$ & $(-34,481)^{* *}$ & $(2,837)^{* *}$ & $(-31,139)^{* *}$ & $(3,235)^{* *}$ & $(-35,716)^{* *}$ \\
\hline \multirow[t]{2}{*}{$\operatorname{Sen} 2 \pi t / 12$} & $-0,1594$ & 1596,4406 & 0,0516 & $-453,0937$ & $-0,1414$ & -9992.5877 & $-0,0292$ & $-466,0566$ \\
\hline & $(-3,057)^{* *}$ & $(9,134)^{* *}$ & $(1,042)$ & $(-2,975)^{* *}$ & $(-2,629)^{* *}$ & $(-25,274)^{* *}$ & $(-0,734)$ & $(-15.761)^{* *}$ \\
\hline \multirow[t]{2}{*}{$\operatorname{Cos} 4 \pi t / 12$} & $-0,0424$ & 41,7769 & $-0,0224$ & 2928,4883 & $-0,0168$ & 194,3504 & 0,0133 & 421,9481 \\
\hline & $(-0,813)$ & $(0,239)$ & $(-0,452)$ & $(19,2430 * *$ & $(-0,314)$ & $(4,952)^{* *}$ & $(0,334)$ & $(14,279)^{* *}$ \\
\hline \multirow[t]{2}{*}{$\operatorname{Sen} 4 \pi t / 12$} & $-0,0268$ & $-113,1962$ & $-0,0069$ & 734,8210 & $-0,0288$ & 911,0126 & $-0,0486$ & 544,4461 \\
\hline & $(-0,514)$ & $(-0,648)$ & $(-0,139)$ & $(4,828)^{* *}$ & $(-0,537)$ & $(23,209)^{* *}$ & $(-1,222)$ & $(18,422)^{* *}$ \\
\hline \multirow[t]{2}{*}{$\operatorname{Cos} 6 \pi t / 12$} & $-0,0076$ & $-292,7189$ & $-0,0001$ & $-1070,8408$ & $-0,0221$ & 147,6295 & $-0,0160$ & $-7,5644$ \\
\hline & $(-0,146)$ & $(-1,676)^{*}$ & $(-0,001)$ & $(-7,036)^{* *}$ & $(-0,441)$ & $(3,762)^{* *}$ & $(-0,401)$ & $(-0,256)$ \\
\hline \multirow[t]{2}{*}{$\operatorname{Sen} 6 \pi t / 12$} & 0,0234 & $-216,0478$ & 0,0060 & $-760,2259$ & $-0,0186$ & $-342,6295$ & $-0,0193$ & $-298,1023$ \\
\hline & $(0,450)$ & $(-1,237)$ & $(0,121)$ & $(-4,995)^{* *}$ & $(-0,346)$ & $(-8,730)^{* *}$ & $(-0,485)$ & $(-10,088)^{* *}$ \\
\hline \multirow[t]{2}{*}{$\operatorname{Cos} 8 \pi t / 12$} & $-0,0222$ & $-232,9564$ & 0,0021 & 85,7800 & 0,0111 & -22.9163 & 0,0166 & $-97,1186$ \\
\hline & $(-0,426)$ & $(-1,134)$ & $(0,042)$ & $(0,564)$ & $(0,207)$ & $(-0,584)$ & $(0,418)$ & $(-3,287)^{* *}$ \\
\hline \multirow[t]{2}{*}{ Sen $8 \pi t / 12$} & 0,0182 & $-190,9172$ & 0,0054 & 462,0256 & $-0,0094$ & 64,2656 & $-0,0060$ & 22,1864 \\
\hline & $(0,349)$ & $(-1,093)$ & $(0,110)$ & $(3,036)^{* *}$ & $(-0,175)$ & $(1,637)$ & $(-0,146)$ & $(0,751)$ \\
\hline \multirow[t]{2}{*}{$\operatorname{Cos} 10 \pi t / 12$} & 0,0121 & 289,4103 & 0,0018 & 129,1508 & 0,0032 & $-23,6085$ & 0,0065 & 47,7359 \\
\hline & $(0,233)$ & $(1,657)$ & $(0,036)$ & $(0,849)$ & $(0,059)$ & $(-0,602)$ & $(0,163)$ & $(1,615)$ \\
\hline \multirow[t]{2}{*}{$\operatorname{Sen} 10 \pi t / 12$} & 0,0007 & $-226,5318$ & 0,0046 & $-242,7847$ & 0,0179 & $-52,4305$ & 0,0035 & 70,3975 \\
\hline & $(0,013)$ & $(-1,297)^{*}$ & $(0,093)$ & $(-1,595)$ & $(0,334)$ & $(-1,336)$ & $(0,089)$ & $(2,382)^{* *}$ \\
\hline \multirow[t]{2}{*}{$\operatorname{Cos} 12 \pi t / 12$} & 0,0039 & 199,1197 & $-0,0036$ & $-40,9746$ & 0,0101 & $-5,4311$ & 0,0034 & $-1,3697$ \\
\hline & $(0,107)$ & $(1,612)$ & $(-0,103)$ & $(-0,381)$ & $(0,267)$ & $(-0,196)$ & $(0,121)$ & $(-0,066)$ \\
\hline Média & 1,310 & 8681,875 & 1,889 & 3272,042 & 2,024 & 941,958 & 1,399 & 697,617 \\
\hline $\mathrm{R}^{2}$ & 0,37 & 0,54 & 0,58 & 0,88 & 0,62 & 0,91 & 0,64 & 0,91 \\
\hline $\mathrm{F}$ & $11,105^{* *}$ & $22,228^{* *}$ & $25,756^{* *}$ & $140,097^{* *}$ & $31,085^{* *}$ & $189,171^{* *}$ & $33,537^{* *}$ & $182,859^{* *}$ \\
\hline GLR & 227 & 227 & 227 & 227 & 227 & 227 & 227 & 227 \\
\hline DW & $0,163^{+}$ & $0,905^{+}$ & $0,039^{+}$ & $1,439^{+}$ & $0,124^{+}$ & $1,572^{+}$ & $0,095^{+}$ & $1,336^{+}$ \\
\hline
\end{tabular}

Onde: $\mathrm{R}^{2}$ é o coeficiente de determinação ajustado; F é a estatística de Snedecor do modelo; GLR é o número de graus de libertade dos resíduos; DW é a estatística de Durbin Watson; (**) significativa estatisticamente diferente de zero ao nível de $5 \%$ de probabilidade, $\left({ }^{*}\right)$ significativamente diferente e zero entre os níveis de $5 \%$ e $10 \%$ de probabilidade (+) não significativo, probabilidade maior de $5 \%$, e os valores entre parêntesis são as estatísticas de $t$ de Student. 
Tabela B.2 - Estimativas dos parâmetros utilizando-se variáveis binárias para as séries de preços $(\mathrm{P})$ e quantidades $(\mathrm{Q})$ de batata, milho, trigo e cevada, período 1975-1994.

\begin{tabular}{|c|c|c|c|c|c|c|c|c|}
\hline \multirow[t]{2}{*}{ Variáveis } & \multicolumn{2}{|c|}{ Batata } & \multicolumn{2}{|c|}{ Milho } & \multicolumn{2}{|c|}{ Trigo } & \multicolumn{2}{|c|}{ Cevada } \\
\hline & (P) & (Q) & (P) & (Q) & (P) & (Q) & (P) & (Q) \\
\hline Constante & 1,998790 & 8586,2124 & 2,9353 & 3523,1865 & 3,2820 & 1026,8587 & 2,3685 & 783,2452 \\
\hline \multirow[t]{2}{*}{ Tendência } & $-0,0057$ & 0,7939 & $-0,0087$ & $-2,0842$ & $-0,0104$ & $-0,7945$ & $-0,0080$ & $-0,7106$ \\
\hline & $(-10,737)^{* *}$ & $(0,445)$ & $(-17,182)^{* *}$ & $(-1,340)$ & $(-19,014)^{* *}$ & $(-1,757)^{*}$ & $(-19,798)^{* *}$ & $(-2,353)^{* *}$ \\
\hline \multirow[t]{2}{*}{$\operatorname{Jan}(\mathrm{Zl})$} & $-0,2194$ & 1855,5413 & 0,1674 & $-3265,7047$ & $-0,0083$ & $-944,3833$ & 0,0215 & $-699,6750$ \\
\hline & $(-1,795)^{*}$ & $(4,529)^{* *}$ & $(1,443)$ & $(-9.148)^{* *}$ & $(-0,066)$ & $(-10,258)^{* *}$ & $(0,230)$ & $(-10,094)^{* *}$ \\
\hline \multirow[t]{2}{*}{ Feb (Z2) } & $-0,2036$ & 3511,1475 & 0,1211 & $-2982,4205$ & $-0,0419$ & $-942,5288$ & 0,0065 & $-672,3644$ \\
\hline & $(-1,666)^{*}$ & $(8,570)^{* *}$ & $(1,043)$ & $(-8,355)^{* *}$ & $(-0,332)$ & $(-10,239)^{* *}$ & $(0,070)$ & $(-9,701)^{* *}$ \\
\hline \multirow[t]{2}{*}{$\operatorname{Mar}(\mathrm{Z} 3)$} & $-0,1659$ & 1112,1036 & 0,0782 & $-2737,3863$ & $-0,0870$ & $-914,2242$ & $-0,0064$ & $-615,2538$ \\
\hline & $(-1,358)$ & $(2,715)^{* *}$ & $(0,674)$ & $(-7,669)^{* *}$ & $(-0,690)$ & $(-9,932)^{* *}$ & $(-0,069)$ & $(-8,877)^{* *}$ \\
\hline \multirow[t]{2}{*}{ Abr (Z4) } & $-0,0012$ & 235,6597 & $-0,0266$ & $-478,0521$ & $-0,2080$ & $-868,1197$ & $-0,0864$ & $-584,3432$ \\
\hline & $(-0,010)$ & $(0,575)$ & $(-0,229)$ & $(-1,339)$ & $(-1,651)$ & $(-9,432)^{* *}$ & $(-0,927)$ & $(-8,432)^{* *}$ \\
\hline \multirow[t]{2}{*}{ May (Z5) } & 0,0795 & $-1041,2342$ & $-0,1164$ & 3974,0320 & $-0,2006$ & $-557,7651$ & $-0,0958$ & 229,6174 \\
\hline & $(0,651)$ & $(-2,532)^{* *}$ & $(-1,004)$ & $(11.135)^{* *}$ & $(-1,592)$ & $(-6,060)^{* *}$ & $(-1,028)$ & $(3,313)^{* *}$ \\
\hline \multirow[t]{2}{*}{ Jun (Z6) } & 0,0867 & $-2254,7781$ & $-0,1927$ & 9162,6662 & $-0,1291$ & 1264,0894 & $-0,0858$ & 1338,7280 \\
\hline & $(0,710)$ & $(-5,505)^{* *}$ & $(-1,662)^{*}$ & $(25,673)^{* *}$ & $(-1,025)$ & $(13,735)^{* *}$ & $(-0,920)$ & $(19,318)^{* *}$ \\
\hline \multirow[t]{2}{*}{ Jul (Z7) } & 0,1764 & $-2505,7719$ & $-0,1870$ & 8263,3004 & $-0,1061$ & 2861,6939 & $-0,1258$ & 2202,8886 \\
\hline & $(0,1444)$ & $(-6,118)^{* *}$ & $(-1,613)$ & $(23,153)^{* *}$ & $(-0,843)$ & $(31,093)^{* *}$ & $(-1,349)$ & $(31,788)^{* *}$ \\
\hline \multirow[t]{2}{*}{ Ago (Z8) } & 0,1982 & $-2787,1158$ & $-0,12794$ & 358,6846 & 0,0342 & 2226,7985 & $-0,1037$ & 1249,3492 \\
\hline & $(1,622)$ & $(-6,804)^{* *}$ & $(-1,115)$ & $(1,005)$ & $(0,272)$ & $(24,194)^{* *}$ & $(-1,113)$ & $(18,028)^{* *}$ \\
\hline \multirow[t]{2}{*}{ Set (Z9) } & 0,1984 & $-2059,8097$ & $-0,0222$ & $-2866,0812$ & 0,1229 & 490,5530 & 0,0063 & $-420,1401$ \\
\hline & $(1,623)$ & $(-5,029)^{* *}$ & $(-0,191)$ & $(-8,030)^{* *}$ & $(0,974)$ & $(5,330)^{* *}$ & $(0,068)$ & $(-6.062)^{* *}$ \\
\hline \multirow[t]{2}{*}{ Oct (Z10) } & 0,1516 & 219,1464 & 0,0610 & $-3090,6470$ & 0,2676 & $-780,7424$ & 0,1374 & $-647,7795$ \\
\hline & $(1,240)$ & $(0,535)$ & $(0,526)$ & $(-8,659)^{* *}$ & $(2,124)^{* *}$ & $(-8,482)^{* *}$ & $(1,473)$ & $(-9,347)^{* *}$ \\
\hline \multirow[t]{2}{*}{ Nov (Z11) } & $-0,0927$ & 1444,4525 & 0,1017 & $-3122,3128$ & 0,2186 & $-903,2879$ & 0,1799 & $-689,2189$ \\
\hline & $(-0,758)$ & $(3,526)^{* *}$ & $(0,877)$ & $(-8,747)^{* *}$ & $(1,734)^{*}$ & $(-9,813)^{* *}$ & $(1,929)^{*}$ & $(-9,944)^{* *}$ \\
\hline $\operatorname{Dez}^{\mathrm{E}}$ & $-0,2104$ & 2270,6587 & 0,1449 & $-3216,0786$ & 0,1380 & $-932,0833$ & 0,1524 & $-691,8083$ \\
\hline Média & 1,310 & 8681,875 & 1,889 & 3272,042 & 2,024 & 941,958 & 1,399 & 697,617 \\
\hline $\mathrm{R}^{2}$ & 0,37 & 0,54 & 0,58 & 0,88 & 0,62 & 0,91 & 0,64 & 0,91 \\
\hline $\mathrm{F}$ & $11,105^{* *}$ & $22,228^{* *}$ & $25,756^{* *}$ & $140,097^{* *}$ & $31,085^{* *}$ & $189,171^{* *}$ & $33,537 * *$ & $182,859^{* *}$ \\
\hline GLR & 227 & 227 & 227 & 227 & 227 & 227 & 227 & 227 \\
\hline DW & $0,163^{+}$ & $0,905^{+}$ & $0,039^{+}$ & $1,439^{+}$ & $0,124^{+}$ & $1,572^{+}$ & $0,095^{+}$ & $1,336^{+}$ \\
\hline
\end{tabular}

Onde: $\mathrm{R}^{2}$ é o coeficiente de determinação ajustado; $\mathrm{F}$ é a estatística de Snedecor do modelo; GLR é o número dos graus de libertade dos residuos; DW é a estatística de Durbin Watson; $\left.{ }^{* *}\right)$ significativa estatisticamente diferente de zero ao nivel de $5 \%$ de probabilidade, $\left({ }^{*}\right)$ significativamente diferente e zero entre os niveis de $5 \%$ e $10 \%$ de probabilidade (+) não significativo, probabilidade maior $5 \%$, e os valores entre parêntesis são as estatísticas de $t$ de Student. ${ }^{\mathrm{E}}$ ) Valores estimados mês de dezembro conforme o modelo (3.21) da metodologia. 
Tabela B.3 - Estimativas do componente estacional $\left(\hat{e}_{\mathrm{j}}\right)$ e indices de irregularidade $\left(\mathrm{S}_{\mathrm{j}}\right)$ dos preços e quantidades da cultura de batata obtidas pelo método da média aritmética móvel, no Departamento de Cajamarca, período 1975-1994.

\begin{tabular}{lrrrr}
\hline \multirow{2}{*}{ Mês } & \multicolumn{2}{c}{ Preços } & \multicolumn{2}{c}{ Quantidades } \\
\cline { 2 - 5 } & $\begin{array}{c}\text { Estimativas do } \\
\text { componente } \\
\text { estacional }\left(\hat{\mathrm{e}}_{\mathrm{i}}\right)\end{array}$ & $\begin{array}{c}\text { Índice de } \\
\text { irregularidade } \\
\left(\mathrm{S}_{\mathrm{j}}\right)\end{array}$ & $\begin{array}{c}\text { Estimativas do } \\
\text { componente } \\
\text { estacional }\left(\hat{\mathrm{e}}_{\mathrm{j}}\right)\end{array}$ & $\begin{array}{c}\text { Índice de } \\
\text { irregularidade }\left(\mathrm{S}_{\mathrm{j}}\right)\end{array}$ \\
\hline Janeiro & $-0,199$ & 0,312 & $1.923,783$ & $1.944,217$ \\
Fevereiro & $-0,185$ & 0,299 & $3.573,481$ & $2.476,859$ \\
Março & $-0,154$ & 0,217 & $1.110,967$ & $2.588,155$ \\
Abril & 0,001 & 0,225 & 256,318 & $1.609,556$ \\
Maio & 0,081 & 0,325 & $-980,348$ & $1.260,384$ \\
Junho & 0,087 & 0,264 & $-2.242,765$ & $1.208,897$ \\
Julho & 0,183 & 0,278 & $-2.460,296$ & $1.306,447$ \\
Agosto & 0,193 & 0,222 & $-2.784,068$ & $1.165,579$ \\
Setembro & 0,186 & 0,224 & $-2.065,822$ & $1.024,404$ \\
Outubro & 0,145 & 0,250 & 99,064 & $1.390,091$ \\
Novembro & $-0,107$ & 0,234 & $1.324,915$ & $1.921,967$ \\
Dezembro & $-0,230$ & 0,250 & $2.244,770$ & $1.861,509$ \\
\hline
\end{tabular}

Tabela B.4 - Estimativas do componente estacional $\left(\hat{(}_{\mathrm{j}}\right)$ e índices de irregularidade $\left(\mathrm{S}_{\mathrm{j}}\right)$ dos preços e quantidades da cultura de milho obtidas pelo método da média aritmética móvel, no Departamento de Cajamarca, período 1975-1994.

\begin{tabular}{lrrrr}
\hline \multirow{2}{*}{ Mês } & \multicolumn{2}{c}{ Preços } & \multicolumn{2}{c}{ Quantidades } \\
\cline { 2 - 5 } & $\begin{array}{c}\text { Estimativas do } \\
\text { componente } \\
\text { estacional }\left(\hat{\mathrm{e}}_{\mathrm{i}}\right)\end{array}$ & $\begin{array}{c}\text { Índice de } \\
\text { irregularidade } \\
\left(\mathrm{S}_{\mathrm{i}}\right)\end{array}$ & $\begin{array}{c}\text { Estimativas do } \\
\text { componente } \\
\text { estacional }\left(\hat{\mathrm{e}}_{\mathrm{i}}\right)\end{array}$ & $\begin{array}{c}\text { Índice de } \\
\text { irregularidade } \\
\left(\mathrm{S}_{\mathrm{j}}\right)\end{array}$ \\
\hline Janeiro & 0,150 & 0,111 & $-3.274,584$ & 624,634 \\
Fevereiro & 0,112 & 0,093 & $-2.978,273$ & 533,200 \\
Março & 0,076 & 0,144 & $-2.739,988$ & 578,679 \\
Abril & $-0,026$ & 0,117 & $-574,461$ & $1.193,565$ \\
Maio & $-0,118$ & 0,135 & $3.945,490$ & $2.407,914$ \\
Junho & $-0,190$ & 0,135 & $9.322,376$ & $2.750,652$ \\
Julho & $-0,191$ & 0,133 & $8.325,376$ & $3.019,229$ \\
Agosto & $-0,131$ & 0,120 & 430,455 & $1.754,815$ \\
Setembro & $-0,017$ & 0,137 & $-2.914,137$ & 532,789 \\
Outubro & 0,069 & 0,121 & $-3.139,154$ & 578,277 \\
Novembro & 0,111 & 0,125 & $-3.162,624$ & 536,962 \\
Dezembro & 0,156 & 0,143 & $-3.240,479$ & 488,208 \\
\hline
\end{tabular}


Tabela B.5 - Estimativas do componente estacional $\left(\hat{\mathrm{e}}_{\mathrm{j}}\right)$ e Índices de irregularidade $\left(\mathrm{S}_{\mathrm{j}}\right)$ dos preços e quantidades da cultura de trigo obtidas pelo método da média aritmética móvel, no Departamento de Cajamarca, período 1975-1994.

\begin{tabular}{lrrrr}
\hline \multirow{2}{*}{ Mês } & \multicolumn{2}{c}{ Preços } & \multicolumn{2}{c}{ Quantidades } \\
\cline { 2 - 5 } & $\begin{array}{c}\text { Estimativas do } \\
\text { componente } \\
\text { estacional }\left(\hat{\mathrm{e}}_{\mathrm{j}}\right)\end{array}$ & $\begin{array}{c}\text { Indice de } \\
\text { irregularidade } \\
\left(\mathrm{S}_{\mathrm{j}}\right)\end{array}$ & $\begin{array}{c}\text { Estimativas do } \\
\text { componente } \\
\text { estacional }\left(\hat{\mathrm{e}}_{\mathrm{j}}\right)\end{array}$ & $\begin{array}{c}\text { Indice de } \\
\text { irregularidade } \\
\left(\mathrm{S}_{\mathrm{j}}\right)\end{array}$ \\
\hline Janeiro & 0,014 & 0,157 & $-946,092$ & 143,718 \\
Fevereiro & $-0,035$ & 0,109 & $-948,874$ & 143,005 \\
Março & $-0,088$ & 0,197 & $-919,614$ & 175,615 \\
Abril & $-0,208$ & 0,325 & $-865,277$ & 173,810 \\
Maio & $-0,201$ & 0,236 & $-570,362$ & 183,084 \\
Junho & $-0,125$ & 0,203 & $1.241,416$ & 407,957 \\
Julho & $-0,120$ & 0,094 & $2.831,114$ & 882,977 \\
Agosto & 0,022 & 0,166 & $2.447,327$ & 625,647 \\
Setembro & 0,120 & 0,238 & 574,124 & 533,820 \\
Outubro & 0,272 & 0,267 & $-789,792$ & 146,332 \\
Novembro & 0,220 & 0,304 & $-912,063$ & 164,180 \\
Dezembro & 0,130 & 0,199 & $-941,906$ & 157,190 \\
\hline
\end{tabular}

Tabela B.6 - Estimativas do componente estacional $\left(\hat{\mathrm{e}}_{\mathrm{j}}\right)$ e Índices de irregularidade $\left(\mathrm{S}_{\mathrm{j}}\right)$ dos preços e quantidades da cultura da cevada obtidas pelo método da média aritmética móvel, no Departamento de Cajamarca, período 19751994.

\begin{tabular}{lrrrr}
\hline \multirow{2}{*}{ Mês } & \multicolumn{2}{c}{ Preços } & \multicolumn{2}{c}{ Quantidades } \\
\cline { 2 - 5 } & $\begin{array}{c}\text { Estimativas do } \\
\text { componente } \\
\text { estacional }\left(\hat{\mathrm{e}}_{\mathrm{j}}\right)\end{array}$ & $\begin{array}{c}\text { Índice de } \\
\text { irregularidade } \\
\left(\mathrm{S}_{\mathrm{j}}\right)\end{array}$ & $\begin{array}{c}\text { Estimativas do } \\
\text { componente } \\
\text { estacional }\left(\hat{\mathrm{e}}_{\mathrm{i}}\right)\end{array}$ & $\begin{array}{c}\text { Índice de } \\
\text { irregularidade } \\
\left(\mathrm{S}_{\mathrm{j}}\right)\end{array}$ \\
\hline Janeiro & 0,013 & 0,182 & $-681,471$ & 136,152 \\
Fevereiro & $-0,003$ & 0,137 & $-657,419$ & 144,308 \\
Março & $-0,011$ & 0,139 & $-602,379$ & 140,384 \\
Abril & $-0,086$ & 0,179 & $-572,971$ & 131,505 \\
Maio & $-0,087$ & 0,138 & 205,862 & 354,671 \\
Junho & $-0,075$ & 0,142 & $1.334,178$ & 601,784 \\
Julho & $-0,133$ & 0,137 & $2.175,094$ & 341,757 \\
Agosto & $-0,110$ & 0,153 & $1.245,463$ & 527,914 \\
Setembro & 0,006 & 0,119 & $-419,112$ & 134,786 \\
Outubro & 0,143 & 0,147 & $-650,322$ & 134,432 \\
Novembro & 0,185 & 0,256 & $-689,314$ & 142,538 \\
Dezembro & 0,152 & 0,226 & $-687,607$ & 129,890 \\
\hline
\end{tabular}

